\title{
MEASUREMENT OF X-RAY SCATTERING FORM FACTORS OVER A WIDE MOMENTUM TRANSFER RANGE
}

\author{
by
}

Ziaul Hasan

M.Sc. (Jahangirnagar University)

A thesis submitted to the Faculty of Graduate Studies and Research in partial fulfillment of the requirements for the degree of

Master of Science

Ottawa Carleton Institute for Physics

Department of Physics

Carleton University

December, 2003

(C) 2003, Z. Hasan 


\author{
National Library \\ of Canada \\ Acquisitions and \\ Bibliographic Services \\ 395 Wellington Street \\ Ottawa ON K1A ON4 \\ Canada
}

Bibliothèque nationale

du Canada

Acquisisitons et services bibliographiques

395 , rue Wellington Ottawa ON K1A 0N4 Canada
Your file Votre référence ISBN: 0-612-93982-0 Our file Notre référence ISBN: 0-612-93982-0
The author has granted a nonexclusive licence allowing the National Library of Canada to reproduce, loan, distribute or sell copies of this thesis in microform, paper or electronic formats.

The author retains ownership of the copyright in this thesis. Neither the thesis nor substantial extracts from it may be printed or otherwise reproduced without the author's permission.
L'auteur a accordé une licence non exclusive permettant à la Bibliothèque nationale du Canada de reproduire, prêter, distribuer ou vendre des copies de cette thèse sous la forme de microfiche/film, de reproduction sur papier ou sur format électronique.

L'auteur conserve la propriété du droit d'auteur qui protège cette thèse. $\mathrm{Ni}$ la thèse ni des extraits substantiels de celle-ci ne doivent être imprimés ou aturement reproduits sans son autorisation.
In compliance with the Canadian Privacy Act some supporting forms may have been removed from this dissertation.

While these forms may be included in the document page count, their removal does not represent any loss of content from the dissertation.
Conformément à la loi canadienne sur la protection de la vie privée, quelques formulaires secondaires ont été enlevés de ce manuscrit.

Bien que ces formulaires aient inclus dans la pagination, il n'y aura aucun contenu manquant. 
PAGINATION ERROR.

ERREOR DE PAGINATION. TEXT COMPLETE. LE TEXTE EST COMPLET. 


\begin{abstract}
In some particular diagnostic $\mathrm{x}$-ray exams such as neuroradiology and breast imaging, scattered radiation can give more information than conventional transmission imaging. To optimize a scatter imaging system, it is required to know the coherent scattering form factors of biological materials. An energy dispersive form factor measurement technique has been developed. It uses a geometry that consists of an x-ray tube, target and high purity germanium detector. The tube and detector are kept fixed and the target is moved transversely to get the desired scatter angles. Geometry was optimized by analyzing the variation of scatter angle with the dimensions of extended target and geometric parameters. To develop the technique, coherent form factors in the momentum transfer parameter range $0.15 \mathrm{~nm}^{-1}$ to $11.87 \mathrm{~nm}^{-1}$ of lexan, PMMA, polystyrene, polyethylene, nylon and water were measured. The scatter angles as obtained by geometry optimization and the respective $\mathrm{x}$-ray spectra used were $1.32^{\circ}, 86 \mathrm{kV} ; 3.13^{\circ}, 106 \mathrm{kV}$; and $15.41^{\circ}, 121$ $\mathrm{kV}$. Weighted averaging was done at the two overlapping regions of the three form factor datasets to get one continuous dataset. Comparison of our data with published data obtained by the angle dispersive technique using a powder diffractometer showed that the energy dispersive technique can be used as a substitute for the angle dispersive technique.
\end{abstract}




\section{Acknowledgements}

I extend my sincere gratitude and appreciation to many people who made this Masters thesis possible. Special thanks are due to my supervisor Professor Paul C. Johns, Dept. of Physics, Carleton University, who reorganized and rethought the thesis scripts and suggested me the problem and for his constant supervision, affectionate guidance and inspiration throughout the progress of the work without which the work would have been impossible. Special thanks to Greg Cron and Albert Cross, MRI lab, Carleton University, for their assistance in supplying liquid nitrogen for detector. Thanks to Graham Beard, Science Technology Centre, Carleton University, for his help in making the aperture assembly. Thanks to Philippe Gravelle for his assistance in drilling small aperture holes. Finally, my special thanks to Mohammad Nisar, Graduate student, Carleton University, who helped me in solving many problems for the thesis. 


\section{Table of Contents}

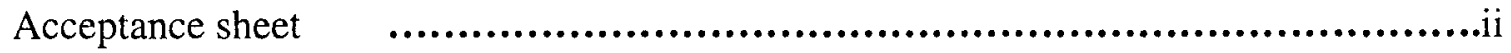

Abstract $\quad$...........................................................................ii

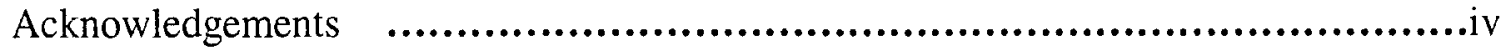

Table of Contents $\quad$..................................................................v

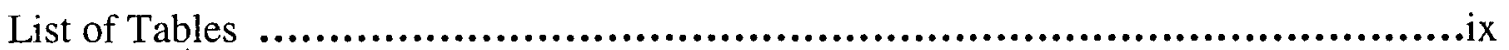

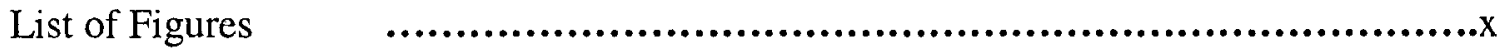

List of Symbols $\quad$...............................................................xii

\section{Chapter 1 Introduction}

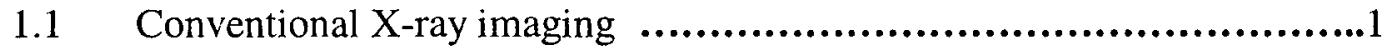

$1.2 \quad$ Scatter imaging $\quad$..................................................4

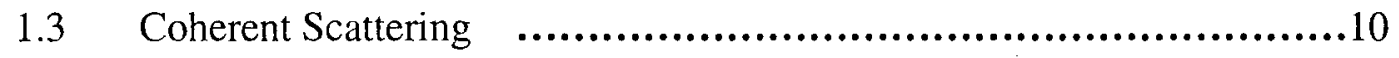

1.3.1 Coherent Scatter Form Factor $\quad$.........................10

1.3.2 Form Factor measurement $\quad$..................................11

1.3.3 Previous investigations $\quad$.................................12

$1.4 \quad$ Objective of the thesis $\quad$........................................... 15

1.5 Outline $\quad$..........................................................15

\section{Chapter 2 Theory}

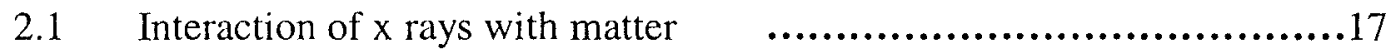

2.1.1 Photoelectric effect $\quad$...........................................17 
2.1.2 Coherent scattering $\quad$...............................................18

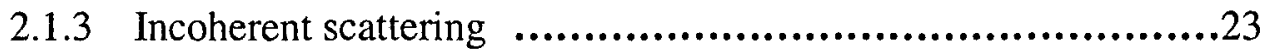

2.2 Total scattering cross section ….........................................25

\section{Chapter 3 Mathematical formulation for cross section and geometry} optimization

3.1 Measurement of differential scattering cross section $\quad$...............26

3.2 Necessary angles and respective x-ranges $\quad$.............................29

3.3 Study of variation of scatter angle with the extended target geometry .....30

3.4 Calculation for weighting the average angle and standard deviation ......32

3.4.1 Proof that exponential factor is simply a constant $\quad$................33

3.4.2 List of steps in the numerical calculation to determine average

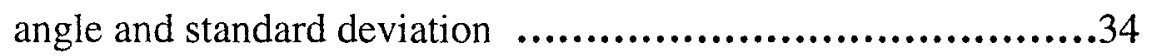

3.4.3 Results and Discussions $\quad$........................................35

3.4.3.1 Effect of length on average angle and standard deviation.35

3.4.3.2 Effect of aperture radii on average angle and standard

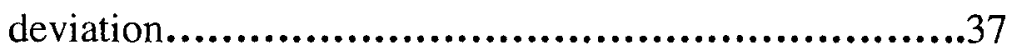

3.5 Selection of the target Dimensions and Aperture radii $\quad$...............38

\section{Chapter 4 Apparatus and Materials}

4.1 Top view of the experimental setup $\quad$.......................................41

4.2 Description of apparatus $\quad$.............................................41

4.3 Operation Method $\quad$........................................................50 


\section{Chapter 5 Methods and results}

5.1 Acquiring the transmitted and scatter spectra $\quad \ldots . . \ldots \ldots \ldots \ldots \ldots \ldots \ldots . . . .52$

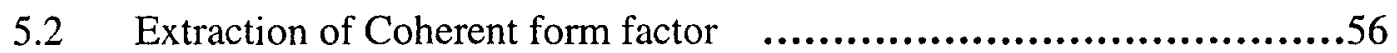

5.2.1 Calculating the electron densities $\quad$...............................57

5.2.2 Calculating parameters from the experimental setup ................57

5.2.3 Calculating the polarization factor $\quad$................................57

5.2.4 Calculating scatter to transmission ratio $\quad$.......................58

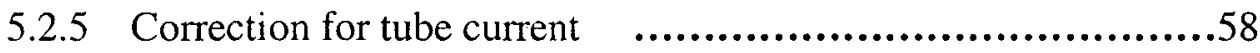

5.2.6 Correction for exposure time .....................................59

5.2.7 Calculating Klein-Nishina coefficient …...................59

5.2.8 Incoherent form factor $\quad$.......................................59

5.2.9 Subtraction of incoherent form factor $\quad$.....................61

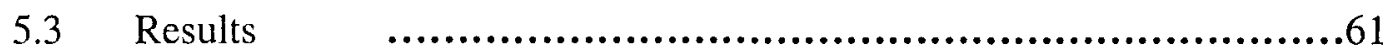

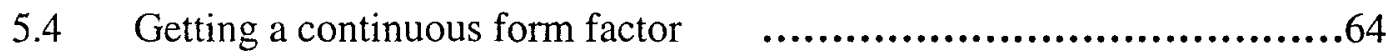

5.4.1 Calculating the weighted average $\quad$..............................65

5.4.2 Calculating the error of each bin $\quad$...............................65

5.4.3 Coherent form factor of two target materials ........................66

\section{Chapter 6 Comparison and Conclusions}

6.1 Comparison with the data of the previous investigators $\quad$...............68

6.1.1 Comparison of coherent form factors of plastic samples $\quad$......68

6.1.2 Comparison of water sample ......................................73

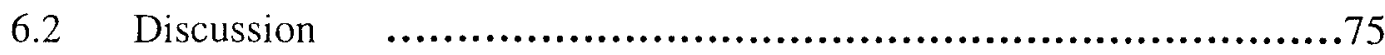


6.3 Conclusion and Future work

6.3.1 Exact alignment $\quad$..........................................77

6.3.2 Exact scatter angle calculation $\quad$..........................77

6.3.3 Calculation of multiple scatter events $\quad \ldots \ldots \ldots \ldots \ldots \ldots \ldots \ldots \ldots \ldots . \ldots . \ldots . \ldots . \ldots 18$

6.3.4 Variable aperture $\quad$...........................................78

References $\quad$..........................................................................79

Appendix $\quad$ Computer routines for form factor calculation $\quad$......................82 


\section{List of Tables}

Table

$1 \quad$ Necessary spectra, energy range, scatter angle and $\mathrm{x}$ range

2 Dimensions of target used to analyze the variation of scatter angle with length

3 Dimensions of target used to analyze the variation of scatter angle with aperture radii

$4 \quad$ Summary of $\mathrm{x}$ ray spectra, energy ranges, scatter angles and $\mathrm{x}$ ranges

5 The diameters of holes in the lead sheets 46

$6 \quad$ Name and chemical formula for target materials

$7 \quad$ Values of $\mathrm{G}$ 56

$8 \quad$ X-ray tube current $\quad 58$

9 Typical values of errors $\quad 65$

10 Weighting region 66

11 Comparison of average relative absolute difference of different form 72 factors for lexan, nylon, polyethylene, polystyrene and PMMA

12 Comparison of average relative absolute difference of different form factors for water sample

13 Time to perform form factor experiment 


\section{List of Figures}

Figure

Caption

Page

1 Geometry for conventional x-ray imaging system 2

2 Differential scattering cross section of $35 \mathrm{keV} x$ ray in $\mathrm{H}_{2} \mathrm{O}$

3 Geometry of diffraction computed tomography 8

$4 \quad$ Contour plot of $\mathrm{x}$ as a function of energy and scatter angle. 11

$5 \quad$ The three interaction mechanisms in oxygen at different energies $\quad 17$

6 Diagram of path difference between incident and scattered wave 20

$7 \quad$ Construction of the normal to the reflecting plane 22

8 Diagram to determine scatter cross section 26

9 Diagram to determine average angle and standard deviation 31

$10 \quad$ Variation of average angle and $\sigma$ with length of the target 36

$11 \quad$ Variation of average angle and $\sigma$ with the aperture radius 37

12 Schematic of experimental setup, top view 41

13 Heel effect in x-ray tube 43

14 Schematic of connection of $x$-ray voltage generator, voltage divider and 44 x-ray tube

15 Collimator assembly $\quad 45$

$\begin{array}{lll}16 & \text { Target holder } & 48\end{array}$

$17 \quad$ Support for target holder $\quad 48$ 
19 Transmitted $\mathrm{x}$-ray spectrum of tungsten target at $86 \mathrm{kV}$ potential

20 Transmitted $x$-ray spectrum of tungsten target at $121 \mathrm{kV}$ potential 53

21 Scatter spectrum of polyethylene at $86 \mathrm{kV}, 1.32^{\circ}$

22 Scatter spectrum of polyethylene at $121 \mathrm{kV}, 15.41^{\circ}$

23 Incoherent form factor for polyethylene, nylon, PMMA 60

24 Incoherent form factor for water, polystyrene and lexan $\quad 60$

$25 \quad$ Form factors of lexan at different angles and potentials 61

$26 \quad$ Form factors of nylon at different angles and potentials 62

$27 \quad$ Form factors of polyethylene at different angles and potentials 62

$28 \quad$ Form factors of polystyrene at different angles and potentials 63

$29 \quad$ Form factors of PMMA at different angles and potentials 63

$30 \quad$ Form factors of water at different angles and potentials $\quad 64$

$31 \quad$ Form factors for lexan with weighting at the overlapping region $\quad 67$

32 Form factor for polystyrene with weighting at the overlapping region $\quad 67$

$33 \quad$ Form factor for lexan. $\quad 69$

$34 \quad$ Form factor for nylon. $\quad 69$

$\begin{array}{lll}35 & \text { Form factor for polyethylene. } & 70\end{array}$

$\begin{array}{lll}36 & \text { Form factor for polystyrene. } & 70\end{array}$

$37 \quad$ Form factor for PMMA. $\quad 71$

$\begin{array}{lll}38 & \text { Form factor for water. } & 74\end{array}$ 


\section{List of Symbols}

Symbol Meaning

$A_{t}$

$A_{d}^{s}$

$\mathrm{A}_{\mathrm{d}}^{\mathrm{T}}$

$\alpha$

$\mathrm{C}$

$\mathrm{c}$

d

$\frac{\mathrm{d} \sigma}{\mathrm{d} \theta}$

$\frac{\mathrm{d}_{\mathrm{a}} \sigma_{\mathrm{R}}}{\mathrm{d} \Omega}$

$\frac{\mathrm{d}_{\mathrm{e}} \sigma_{\mathrm{o}}}{\mathrm{d} \Omega}$

$\frac{\mathrm{d}_{\mathrm{e}} \sigma_{\mathrm{INC}}}{\mathrm{d} \Omega}$

$\mathrm{E}$

$\mathrm{e}$

$F_{\text {atom }}(x)$

$F_{\text {IAM }}$

$F_{K N}$
Cross section of the target

Active area for detection for the detector for the scattered radiation

Active area for detection for the detector for the transmitted radiation

Ratio between incident energy of photon and electron rest mass energy

Contrast

Speed of light

Length of the target

Differential scattering cross section per unit angle

Differential scattering cross section for Rayleigh per atom

Classical scattering coefficient or Thomson coefficient per electron

Differential Compton cross section per electron

Energy of $x$-ray photon

Charge of electron

Coherent scatter form factor for an atom

IAM form factor

Klein-Nishina coefficient 


\begin{tabular}{|c|c|}
\hline $\mathrm{H}$ & Target offset \\
\hline hv & $\mathrm{X}$-ray photon energy \\
\hline IAM & Independent Atom Model \\
\hline$\hat{\mathrm{k}}_{\mathrm{i}}$ & Unit vector for incident $\mathrm{x}$-ray beam \\
\hline$\hat{\mathrm{k}}_{\mathrm{s}}$ & Unit vector for scattered $\mathrm{x}$-ray beam \\
\hline $\mathrm{L}_{\mathrm{st}}$ & Source to target distance \\
\hline $\mathrm{L}_{\mathrm{dd}}$ & Target to detector distance \\
\hline$\lambda$ & Wavelength of $x$ ray \\
\hline$\mu_{0}$ & Permeability of free space \\
\hline$\mu_{\mathrm{t}}(\mathrm{h} v)$ & Attenuation coefficient of target at energy hv \\
\hline $\mathrm{m}_{\mathrm{o}}$ & Mass of electron \\
\hline$m_{0} c^{2}$ & Electron rest energy \\
\hline $\mathrm{N}_{\mathrm{b}}$ & Number of photons scattered by the background \\
\hline$N^{s}$ & Number of scattered photons \\
\hline $\mathrm{N}^{\mathrm{T}}$ & Number of transmitted photons \\
\hline$\Omega$ & Solid angle \\
\hline $\mathrm{p}$ & Polarization factor \\
\hline PMMA & Polymethlmethacrylate \\
\hline$\varphi$ & Work function \\
\hline$r_{0}$ & Classical electron radius \\
\hline$\rho_{\mathrm{e}}$ & Electron density per unit volume \\
\hline$S^{T}$ & Photon emission rate from $x$-ray tube for transmi \\
\hline
\end{tabular}


Photon emission rate from $\mathrm{x}$-ray tube scattered signal

$S_{0}$ Amplitude of incident $x$-ray beam

$S(x)$

Incoherent scatter function

$\mathrm{S}_{\text {atom }}(\mathrm{x})$

Incoherent form factor for an atom

SNR

Signal-to-noise ratio

$\mathrm{T}$

Electron kinetic energy in photoelectric effect

$\theta$

Scatter angle

$\Delta \mathrm{V}$

Volume element

$\mathrm{X}$

Momemtum transfer parameter, $=\lambda^{-1} \sin \left(\frac{\theta}{2}\right)$

Z

Atomic number 


\section{Chapter 1}

\section{Introduction}

This chapter gives an overview of some imaging modalities used in diagnostic $\mathrm{x}$-ray imaging, including conventional $\mathrm{x}$-ray imaging and scatter imaging which can be used to obtain diagnostic information. It also describes the necessity of knowing the coherent scattering form factor for scatter imaging.

\subsection{Conventional X-ray Imaging}

Diagnostic radiology is based on the formation of projection images using $\mathrm{x}$-ray photons. Figure 1 is a schematic of an $\mathrm{x}$-ray imaging system. A tungsten anode $\mathrm{x}$-ray tube emits a polychromatic beam having energies between $15-150 \mathrm{keV}$. The beam is then collimated by a primary diaphragm before it falls onto the patient. As the beam passes through the patient's body, it is attenuated by air, soft tissue, bone, blood and other liquids. The transmitted beam is then allowed to fall on an image receptor such as radiographic film. Figure 1 also shows the intensity distribution of the beam with position after being attenuated by various part of the body. Since different parts of the body attenuate differently, such as air attenuates $\mathrm{x}$ rays less than bone and so on, the intensity profiles produce the images on the $\mathrm{x}$-ray film. The commonly used image receptors are screenfilm combinations, $x$-ray image intensifiers and photo-stimulable phosphors. 


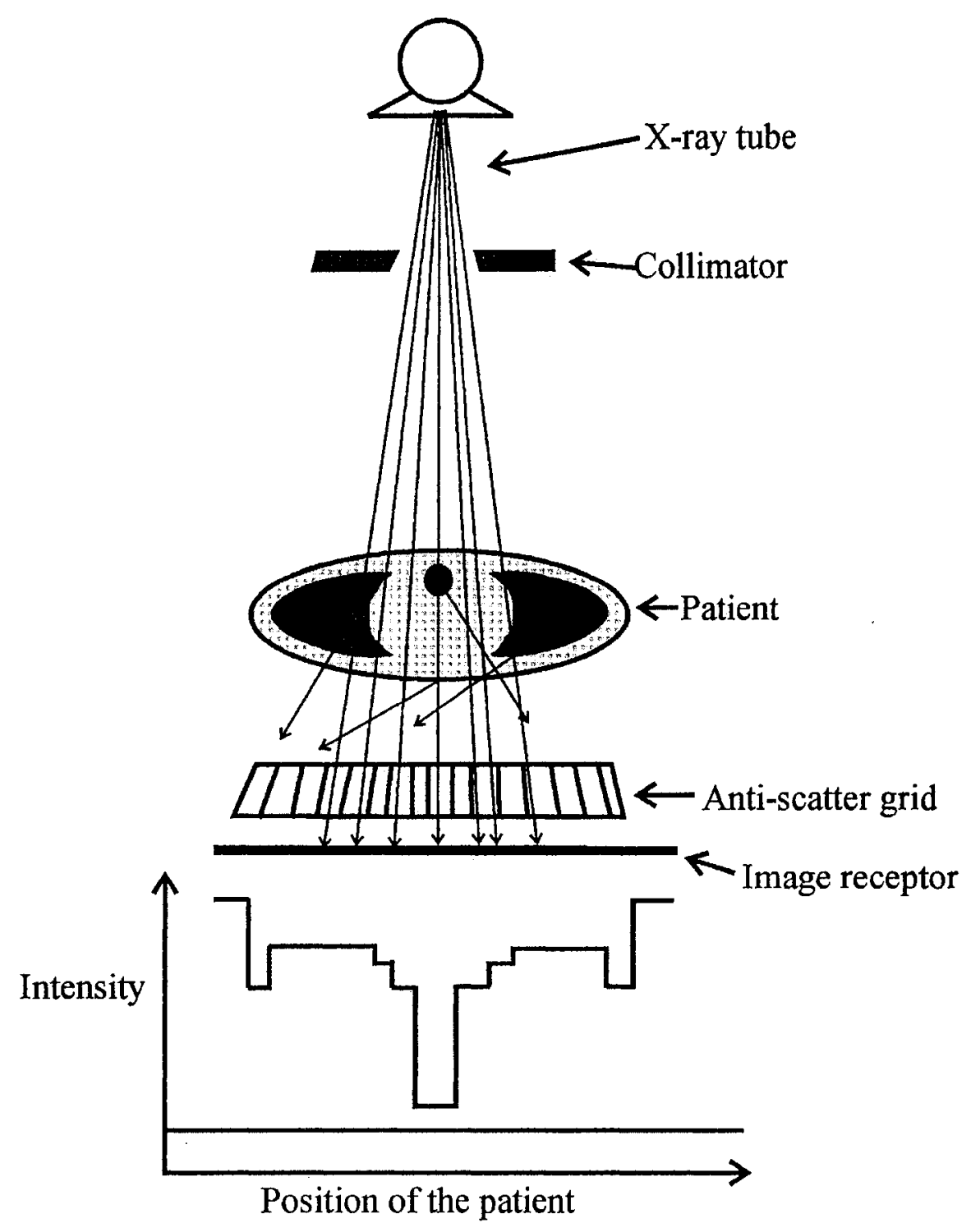

Figure 1. Geometry for conventional x-ray imaging system.

In the diagnostic energy range $(50-150 \mathrm{keV})$ there occur three processes when $\mathrm{x}$-ray photons interact with matter, namely: photoelectric effect, incoherent scattering and coherent scattering. In water at $30 \mathrm{keV}, 13 \%$ of the interactions are coherent, $50.7 \%$ are incoherent and $36.3 \%$ are photoelectric effect [1]. The scattered photons that are produced during imaging usually reduce the contrast and signal-to-noise ratio (SNR). It 
was found that up to $90 \%$ of the photons reaching the image receptor [2] are coherently and incoherently scattered.

Motz and Danos [3] introduced the relationship between information content in conventional imaging and patient exposure. In their model they imaged a target object against a background material using the $\mathrm{x}$-ray attenuation properties of the materials. They considered $N_{t}$ and $N_{b}$ to be the number of $x$-ray photons from the target and background material and they defined $\mathrm{C}$ and SNR as

$$
\begin{aligned}
& C=2 \frac{\left|N_{t}-N_{b}\right|}{\left|N_{t}+N_{b}\right|}, \\
& S N R=\frac{\left|N_{t}-N_{b}\right|}{\sqrt{N_{t}+N_{b}}} .
\end{aligned}
$$

A number of methods have been devised to increase contrast in $\mathrm{x}$ ray images by reducing scatter. The size of the beam that falls on the patient is constrained to make the illuminated area small so that fewer scatter events occur. Another method is to decrease the peak potential $(\mathrm{kVp})$ of the $\mathrm{x}$-ray tube and at the same time to increase the tube current for compensation. Sometimes especially when it is possible, the patient is compressed. Compression is done so as to lessen tissue overlap for better visualization of anatomy and potential abnormalities. Consequently it reduces x-ray scatter. The air gap between patient and detector can be increased to reduce scattered radiation because of inverse square law. 
The most effective method to reduce scattered radiation is to use an anti-scatter grid. An anti-scatter grid has directional properties. It consists typically of extremely thin lead strips interspaced by either carbon fibre or paper (low energy), plastic or aluminum (high energy) [4]. Because the scattered photons will not meet the grid at normal incidence, they will be largely absorbed by the lead strips, whereas most of the primary photons will pass through the grid. Some of the primary and most of the secondary radiation is absorbed by both the lead strips and the interspace medium, and therefore the exposure required is increased.

\subsection{Scatter Imaging}

Although scattered photons have been considered as a nuisance in conventional imaging a number of investigators used them as an imaging tool and thus the idea of scatter imaging arose. Certainly in this kind of imaging system scattered rays are used rather than primary. Usually an energy integrating detector detects the scattered photons that come out of the patient body. The detector makes a solid angle $\mathrm{d} \Omega$ with the point of interest inside the patient body and detects the photons that are scattered at angle $\theta$. The probability of scattering is characterized by the differential scattering cross section $\mathrm{d} \sigma / \mathrm{d} \Omega$ $\left(\mathrm{cm}^{2} \mathrm{sr}^{-1}\right.$ electron $\left.{ }^{-1}\right)$ of that particular point of interest. A number of investigators (Ref. Johns and Yaffe [5], Leclair and Johns [6], Harding and Kosanetzky [7], Westmore et al [8], Luggar and Gilboy [9] and others) demonstrated the possibility of x-ray scatter imaging and its potential uses in medicine and biology. 
One of the pioneer groups in understanding x-ray scattering, Johns and Yaffe [5], showed that radiation which reaches the image receptor after one scattering has a large coherentscattered component. They determined that in radiography of the abdomen, coherent first scatter is $10 \%$ of total scatter and $26 \%$ of the primary fluence without a grid. After the grid the coherent part increases to $22 \%$ of total scatter and is $7.5 \%$ of primary. They also showed coherently scattered photons deviate significantly and can degrade image contrast. Figure 2 shows the two x-ray ( $35 \mathrm{keV}$ ) scattering processes in $\mathrm{H}_{2} \mathrm{O}$ in terms of differential scattering cross section vs angle. The coherent scattering cross section is highly peaked at a small $\theta$ and the coherent part dominates over the incoherent one for $\theta<18^{\circ}$. For lower photon energy $E$ this angle is larger and vice versa.

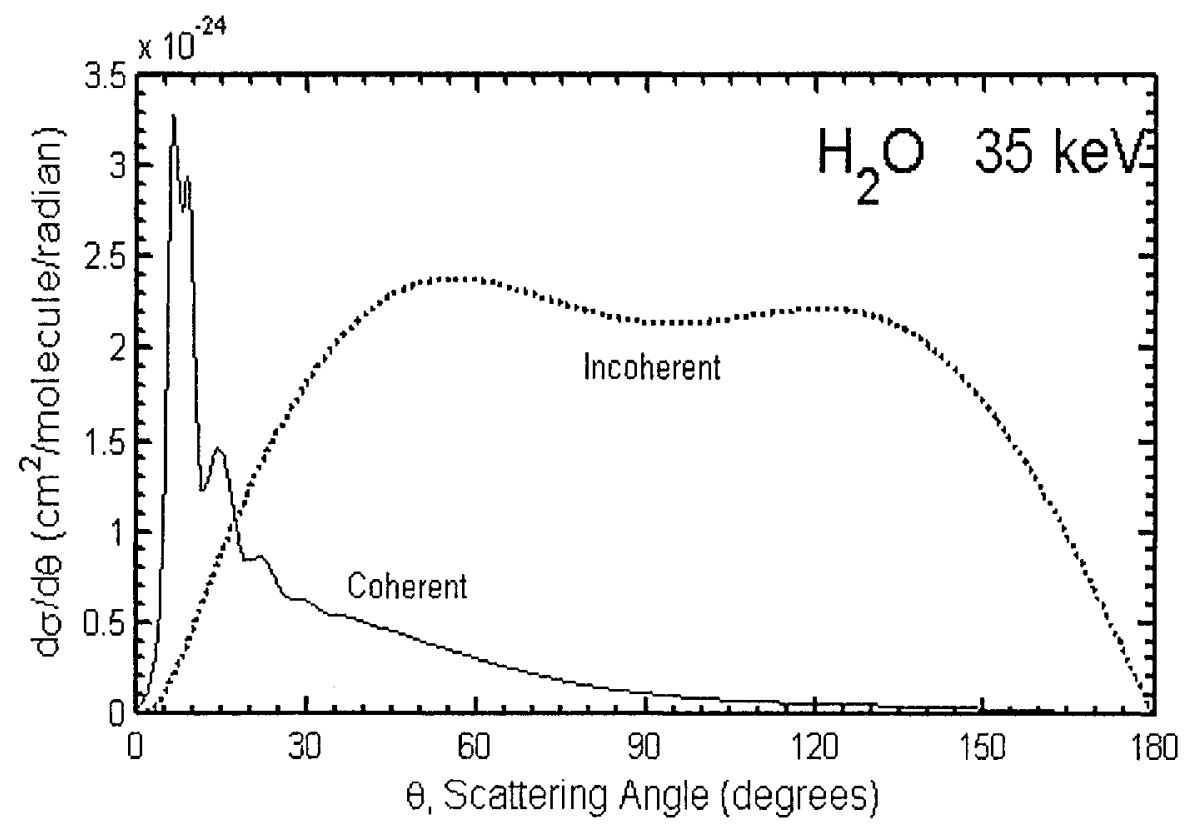

Figure 2. Differential scattering cross section of $35 \mathrm{keV} x$ rays in $\mathrm{H}_{2} \mathrm{O}$ [coherent[10], incoherent[11]]. 
Leclair and Johns [6] modeled forward and back-scattering x-ray imaging systems. The model considers the imaging of a target object against a background material of the same dimensions when both are situated within a water phantom. They analyzed the signal-tonoise-ratio and contrast of both systems. They used liver, fat, bone, muscle, blood and brain matter in their study since coherent scattering form factors (Rcf. scc. 1.3.1 and 2.1.2) were available (Ref. [12],[13]). They developed analytical relationships between $C$ and SNR and evaluated them numerically versus the target object thickness $(0.01-40 \mathrm{~mm})$ and photon energy (10-200 keV). They found that in imaging white brain matter versus blood in a $15 \mathrm{~cm}$ thick water phantom, the maximum SNR, over all energies, for images based on the detection of all forward scatter within the angular range $2^{\circ}-12^{\circ}$ is greater than that of primary images for target object thicknesses $\leq 23 \mathrm{~mm}$.

Leclair and Johns [14] reassessed their model for polyenergetic beams since their previous study considered monoenergetic x-ray beams. In clinical practice polyenergetic beams are used. They modeled four different photon beams: a monoenergetic beam, a dual peak beam, a clinical x-ray beam and a rectangular beam. They matched the centroids and standard deviations of the dual peak and rectangular spectra to those of the clinical $x$-ray spectra. In imaging liver versus fat they found that the predicted SNR obtained with a $100 \mathrm{kV}$ beam is $87.5 \%$ of the SNR acquired with the optimum monoenergetic beam and $84.4 \%$ for dual peak beam and $86.3 \%$ for rectangular beam. They showed that the monoenergetic beam is not necessary for $\mathrm{x}$-ray scatter imaging. 
The proposed model was then validated [15] by designing an apparatus to measure the SNR and contrast for plastic targets. They used a conventional rotating anode $\mathrm{x}$-ray tube. To compare quantitatively the results between primary and forward-scatter imaging systems an ionization chamber was used to determine the number of incident photons. They took various plastic materials such as PMMA (polymethyl methacrylate), polycarbonate, polystyrene, polyethylene, nylon as target or background material. A high purity Germanium detector was used as photon counter. Good agreement between experiment and predictions was obtained for many imaging tasks.

Leclair and Johns [16] showed that in order to maximize the signal-to-noise ratio obtained with scattered $\mathrm{x}$ rays, photons have to be detected with specific $\mathrm{x}$ values (Ref. sec. 1.3.1 and 2.1.2). They used $2 \mathrm{~cm}$ thick PMMA and nylon as target sitting inside a 15 $\mathrm{cm}$ diameter spherical water phantom. An $80 \mathrm{kV}$ beam was used. Experiment shows that for $\overline{\mathrm{x}}$ between 0.5 and $0.7 \mathrm{~nm}^{-1}$ experimental and predicted values are consistent. When the range of $\bar{x}$ is extended from 0.5 to $1.1 \mathrm{~nm}^{-1}$ experimentally $S N R / \sqrt{\mathrm{K}_{c}^{\text {air }}}\left(\mathrm{K}_{\mathrm{c}}^{\mathrm{air}}\right.$ is the air collision kerma) decreases by $38 \%$ and the predicted value of the model decreases too.

Harding and Kosanetzky [7] introduced an x-ray diffraction computed tomography technique, which is analogous to conventional CT. Figure 3 shows their $\mathrm{x}$-ray diffraction tomography geometry. This imaging system utilizes the $\mathrm{x}$-ray diffraction properties of an object. In this technique instead of integrating the linear attenuation coefficient $\mu(\mathrm{x}, \mathrm{y})$ for a line, the integrated $d \sigma / d \Omega$ is measured and used to reconstruct the tomogram. The technique has been investigated using a first generation (single pencil beam) CT scanner 
to measure small angle $\left(\leq 10^{\circ}\right)$ coherent scatter and at the same time measuring the transmitted radiation. They showed in some particular cases the scatter images give more information than conventional radiological images.

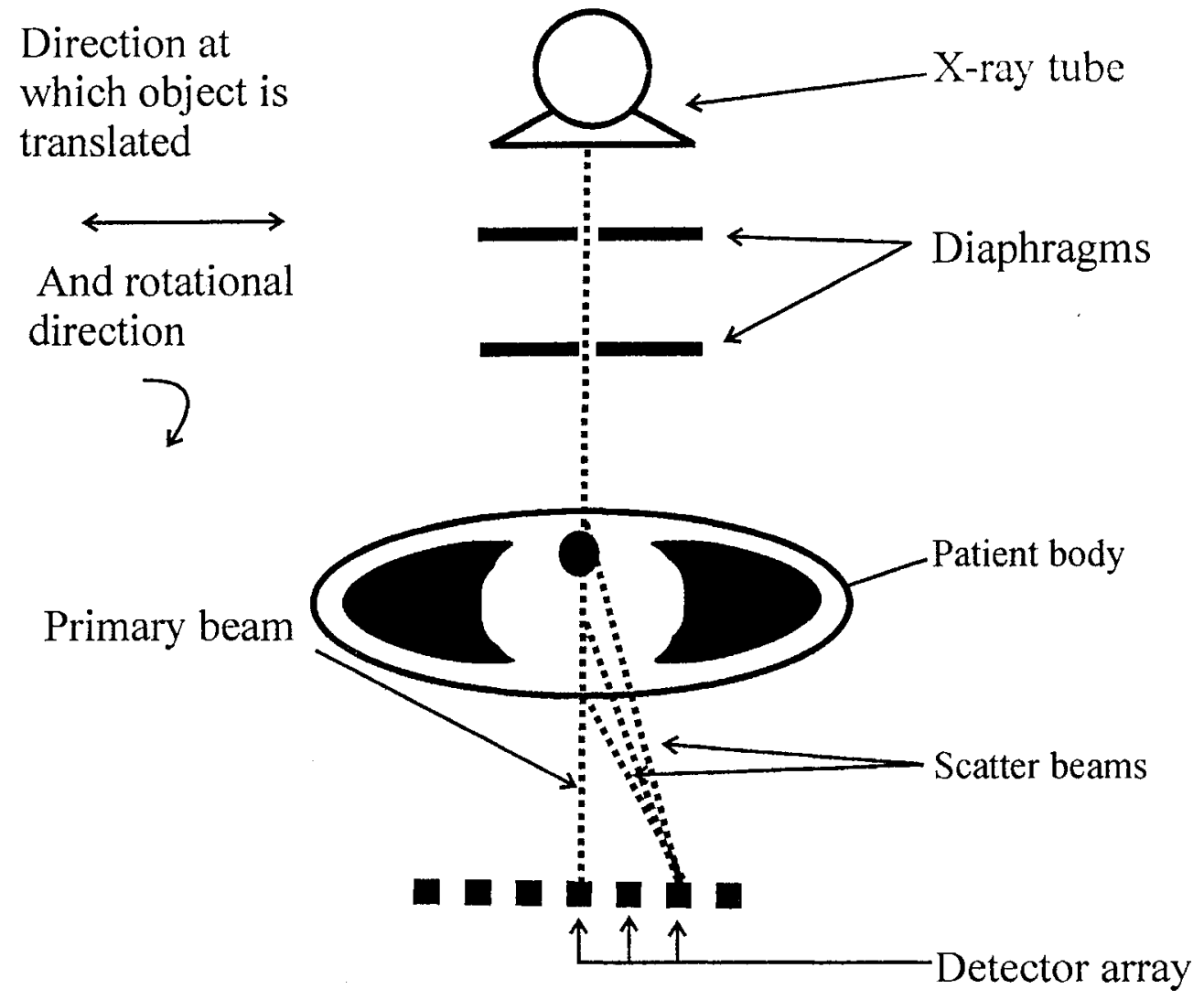

Figure 3. Geometry of diffraction computed tomography.

Westmore et al [8] proposed a computed tomographic imaging system based on measurements of the low angle $\left(0-10^{\circ}\right) \mathrm{x}$-ray diffraction properties of an object. At this angular and diagnostic energy range (15-150 keV) coherent scatter is dominant and they acquired coherently scattered photon using a first generation CT geometry. The patterns are used to reconstruct a series of images, which represent the coherent-scatter cross section at a series of scatter angles. They used a phantom consisting of a water-filled 
PMMA cylinder containing rods of polythylene, PMMA, polycarbonate, and nylon. Coherent-scatter cross sections of these materials were generated for each pixel from this sequence of images and compared with cross sections measured separately. The excellent agreement of the results shows that coherent-scatter cross-section can be accurately imaged in a tomographic slice through an object.

Bachelar and Cunningham [17] used coherent-scatter computed tomography (CSCT) to measure bone-mineral density (BMD). In their experiment they used a diagnostic $\mathrm{x}$-ray source and image intensifier to acquire scatter patterns under first generation CT geometry. They corrected the effect of temporal lag by using an approximate convolution method. Self-attenuation caused by the specimen that makes cupping artifact in the CSCT was corrected using measurement of the transmitted primary beam. They used a series of PMMA sheets of increasing thickness and a series of acrylic rods containing varying amounts of hydroxyapatite that simulate the physiological range of bone-mineral density found in trabecular bone. They got excellent agreement between known and measured density.

Luggar and Gilboy [9] showed the potential application of scatter imaging over the conventional imaging system for substance identification. In contaminant identification within bulk matrices they demonstrated that inclusions of plastics (e.g. nylon, polycarbonate, polyethylene, polypropylene and polytetrafluoroethylene) which are indistinguishable in the transmission images become apparent (contrast up to 28\%) in the scatter images simply taking the measurement at a particular scatter angle, which is 
determined by the $\mathrm{x}$-ray diffraction of the material of interest. A silver anode $\mathrm{x}$-ray tube was used and High Purity Germanium detector (HPGe) or $\mathrm{Si}(\mathrm{Li})$ detector were used. Their technique can be used in any system that currently uses conventional transmission radiography.

\subsection{Coherent Scattering}

\subsubsection{Coherent Scatter Form Factor}

Coherent scattering is a cooperative phenomenon, which occurs when the incident photon interacts with all the electrons in an atom or molecule. The parameter that characterizes this scattering event is the coherent scattering cross section. This is the interaction probability of a photon with an electron or a group of electrons of an atom or a molecule. More generally this scattering event can be described by coherent scatter form factor.

Form factor depends on two parameters. The first one is momentum transfer parameter, $\mathrm{x}$ and the second one is atomic number, $\mathrm{Z}$. Since for a particular material $\mathrm{Z}$ is fixed, it depends upon $\mathrm{x}$. If a photon having energy $\mathrm{E}$ undergoes scattering with angle $\theta$, the change in momentum can be given by, $\Delta \mathrm{p}=2 \mathrm{hx}$. Hence $\mathrm{x}$ characterizes the transfer of momentum and therefore called momentum transfer parameter. The $\mathrm{x}$ depends on energy of the incident photon and the angle at which it scatters and can be shown as,

$$
\mathrm{x}=\frac{1}{\lambda} \sin \left(\frac{\theta}{2}\right)=\frac{\mathrm{E}}{\mathrm{hc}} \sin \left(\frac{\theta}{2}\right) \quad\left(\text { length }^{-1}\right)
$$


where $\lambda$ is the wavelength of the incident or scattered photon since no energy is lost in this process. The contour plot of equation (3) is shown Figure 4.

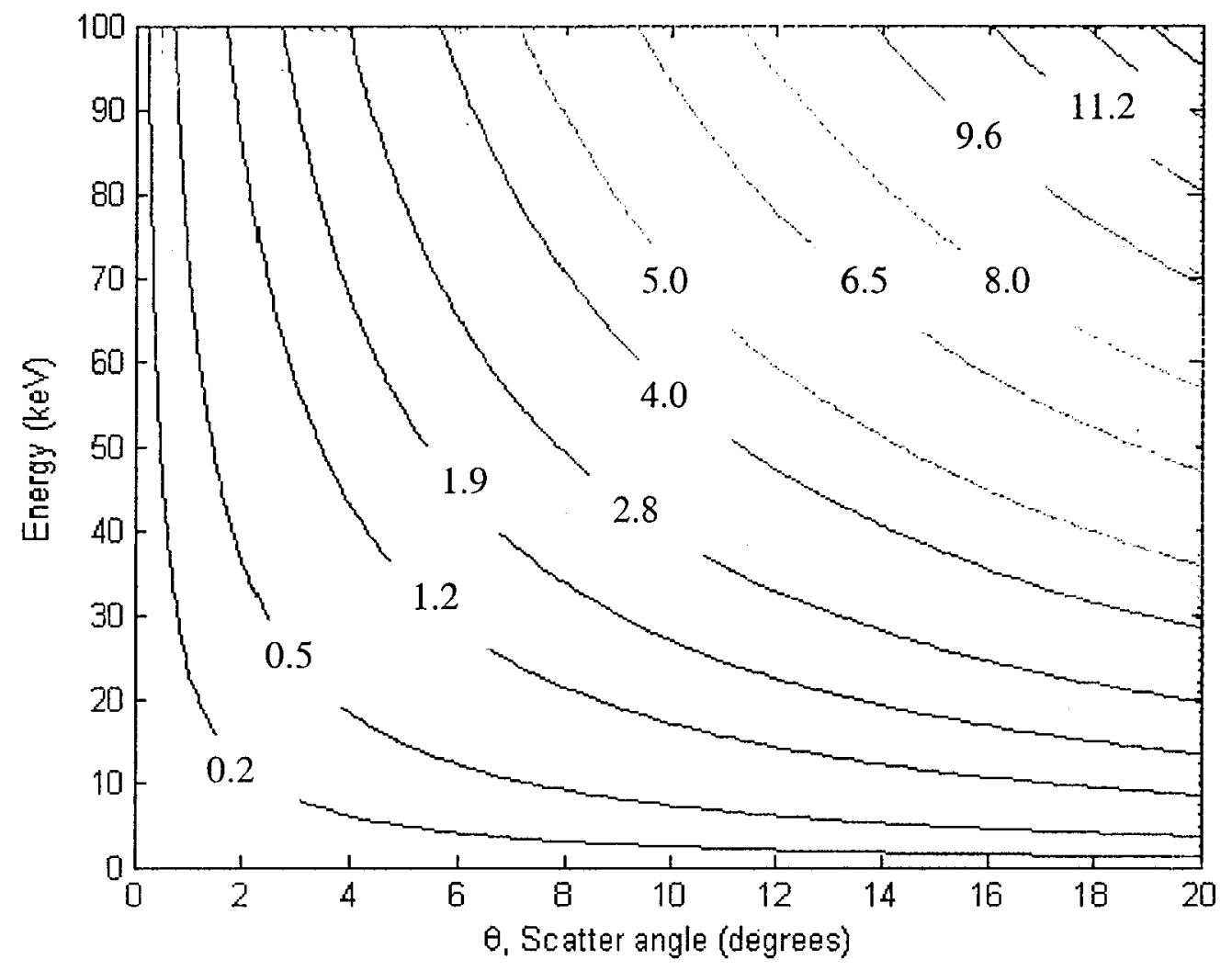

Figure 4. Contour plot of $x$ as a function of energy and scatter angle. The units of $\mathrm{x}$ are $\mathrm{nm}^{-1}$.

\subsubsection{Form Factor Measurement}

To optimize a scatter imaging system it is required to tabulate the form factor data of the various tissues to be imaged. For example the diffraction patterns of fat, muscle, and bone are sufficiently dissimilar to allow these three tissue types to be clearly separated on the basis of their diffraction patterns alone. Therefore the tissue characterization and detection can be assessed when comprehensive measurements of form factors for body tissues are available. 


\subsubsection{Previous Investigations}

Narten [10] measured the diffraction pattern of triple distilled water using powder diffractometer where monochromatic $x$-radiation $(\mathrm{MoK} \alpha=17.48 \mathrm{keV})$ was used. His lab used a bent and ground crystal monochromator mounted in the diffracted beam. The diffraction patterns were observed with various beam divergences ranging from $0.5^{\circ}-4^{\circ}$. The times for a fixed number of counts, ranging from 100,000 to 600,000 , were measured at $0.25^{\circ}$ to $1^{\circ}$ intervals in the half-scattering angle $\theta$. The corresponding $\mathrm{x}$ ranges were $0.39<\mathrm{x}<12.73 \mathrm{~nm}^{-1}$. These water data were observed at eight temperatures between $4^{\circ} \mathrm{C}$ and $200^{\circ} \mathrm{C}$. The sample pressure was $1 \mathrm{~atm}$ at temperatures below $100^{\circ} \mathrm{C}$ and equal to the vapour pressure above this temperature.

Kosanetzky et al [12] observed the diffraction patterns of some phantom materials (e.g., water, PMMA, polystyrene, and polycarbonate) and some biological materials (e.g., blood, tendon, muscle, bone, fat, liver, brain white brain matter and gray brain matter). A standard automated powder diffractometer was used for this measurement. The solid materials were examined by cutting thin slices of about $3 \mathrm{~mm}$ thickness and $25 \mathrm{~mm}$ diameter, whereas to examine the biological samples a special sample holder was constructed $(12 \mathrm{~mm} \times 18 \mathrm{~mm} \times 3 \mathrm{~mm}$ cavity). A compensating divergence slit was used to keep the irradiated area constant. To avoid the sample drying Kapton foil was used as cover. They registered the scattered intensity from $5^{\circ}$ to $100^{\circ}$ in steps of $0.05^{\circ}$ and with an integration time of 5 s/reading. Compton and multiple scattering correction was done by Monte Carlo simulation. Scattered intensities were also corrected for sample holder and Kapton foil since they show their own diffraction patterns. The differential cross section 
per unit volume was extracted by normalizing the scattered intensity to the IAM (Independent Atom Model) region. The phantom materials showed different diffraction patterns. The diffraction patterns of water, blood, liver, and muscle did not differ very much, since water is the dominant component of all tissues.

Evans et al [18] analyzed the scattering photon distributions of water, liver oil, Perspex (PMMA) and 19 breast tissue samples and whole blood in the angular range of scattering $2^{\circ}-12^{\circ}$. The water, olive oil, blood and breast tissue samples were placed in $6 \mathrm{~mm}$ diameter plastic tubes, and the Perspex samples consisted of rods of diameter 5, 10 and $15 \mathrm{~mm}$. The samples were mounted with a wooden clamp and exposed using a highly collimated and heavily filtered x-ray beam. A multi-wire proportional counter (MWPC) was used to detect the scattered photons. The x-ray tube peak potential was $60 \mathrm{kVp}$, the mean energy obtained from it was $46 \mathrm{keV}$ and the FWHM was $18 \mathrm{keV}$. The energy spread of the $\mathrm{x}$-ray beam was reduced using a $0.5 \mathrm{~mm} \mathrm{Cu}$ filter. In their experiment the adipose tissues produced peaks in the scattered photon intensity at a similar angles to those produced by Perspex and olive oil $\left(\sim 4^{\circ}\right)$. Fibrograndular tissues produced peaks at similar scattering angles to that of water $\left(\sim 6^{\circ}\right)$.

Peplow and Verghese [19] measured the coherent scattering form factor of 16 samples (which included plastics, commonly used phantoms and some biological samples). They used synchrotron $x$-ray beams of two energies. The low energy measurements were made at $8 \mathrm{keV}$ at an interval of $0.25^{\circ}$ from $1^{\circ}$ to $60^{\circ}$ and the high energy measurements were made at $20 \mathrm{keV}$ at same intervals from $1^{\circ}$ to $110^{\circ}$. The $\mathrm{x}$ range that they covered was 
0.056 to $13 \mathrm{~nm}^{-1}$. Data collection times varied from $20 \mathrm{~min}$ to $2 \mathrm{~h}$. The raw data were then corrected for Compton scattering, air scattering, and multiple scattering by simulated data.

Wismayer [20] in our lab measured the coherent scatter form factor of some amorphous materials such as nylon, lexan, distilled water, beef muscle, iodized salt using an x-ray diffractometer. He measured the form factor over the range $0.102<\mathrm{x}<5.39 \mathrm{~nm}^{-1}$. He extracted the coherent scatter form factor by normalizing the high $\theta$ data to the IAM form factors. He compared his initial two sets of data obtained from two different diffractometers to test their reliability and compared his form factors with the previous investigators.

A diffractometer has a monochromator, which allows only a particular wavelength of $\mathrm{x}$ ray to diffract at a particular scatter angle. This kind of geometry (Wismayer [20]) has a few demerits. As it uses crystal monochromator, when $x$ ray passes through it the count rate is reduced. To compensate the count rate it needs higher exposure time. Another demerit of this geometry is the fringe radiation. At low angle region, i.e. $2-20^{\circ}$, the beam from the $\mathrm{x}$-ray tube goes directly to the detector without interacting with the target. The easy way to stop it is by using a defining slit in front of the $\mathrm{x}$-ray tube. This again needs longer exposure time as compensation. On the other hand, in the energy dispersive technique all the wavelengths of $\mathrm{x}$-ray beam produced by an $\mathrm{x}$-ray tube after being scattered by a particular scatter angle by the target are detected by the detector. 
Therefore, this technique take less time to measure form factor in comparison to the angle dispersive technique.

\subsection{Objective of the Thesis}

The objective of this thesis is to develop a method to measure the differential scattering cross section of some plastic samples and water. The coherent scatter form factor will be calculated from the measured data. In Figure 4 if we would take the practical limit $16 \leq \mathrm{E}$ $\leq 140 \mathrm{keV}$ and $0.5^{\circ} \leq \theta \leq 179^{\circ}$ for scatter imaging in diagnostic radiology, there is still a need to tabulate $F$ values for tissues and phantom materials from $\mathrm{x} \sim 0.1 \mathrm{~nm}^{-1}$ to the IAM region, $x \geq 10 \mathrm{~nm}^{-1}$. This experiment will cover the $\mathrm{x}$ range of $0.15 \mathrm{~nm}^{-1}$ to $11.87 \mathrm{~nm}^{-1}$ using the energy dispersive technique.

\subsection{Outline}

Chapter 2 develops the theory behind this experiment, which includes photoelectric effect, incoherent scattering, coherent scattering and development of the form factor.

Chapter 3 shows the equations that have been developed to determine the differential scattering cross section for the geometry that I used. It also describes the study of the effect of extended target in term of standard deviation and results from geometry analysis are also given.

Chapter 4 describes the experimental apparatus including $x$-ray tube, heavy and light shielding, HPGe detector, fast spectroscopy amplifier, fast ADC.

Chapter 5 shows the calculation to determine form factor and correction for incoherent form factor, and the form factors obtained for five plastic samples and a water sample. 
Chapter 6 gives comparisons of these form factors with the data obtained by previous investigators, conclusion and future work.

I wrote computer programs for coherent form factor measurement in $\mathrm{C}++$ and in Matlab. Examples of these are given in the Appendix. The routine for geometry optimization was zhavevar.cpp. The routines to calculate coherent form factor were: zhfexny.m (for the case of nylon), zhavelx.m (for the case of lexan), zhcompar.m. The subroutines were: zhsttr.m, zhtotins.m, zhklnis.m, zhfoerr.m, zhweiave.m. 


\section{Chapter 2}

\section{Theory}

\subsection{Interaction of $\mathrm{x}$ rays with matter}

In the diagnostic energy range there are three basic ways that an $\mathrm{x}$-ray photon can interact with matter. These are: the photoelectric effect, coherent scattering and incoherent or Compton scattering. Figure 5 shows the interaction cross sections in oxygen at various energies.

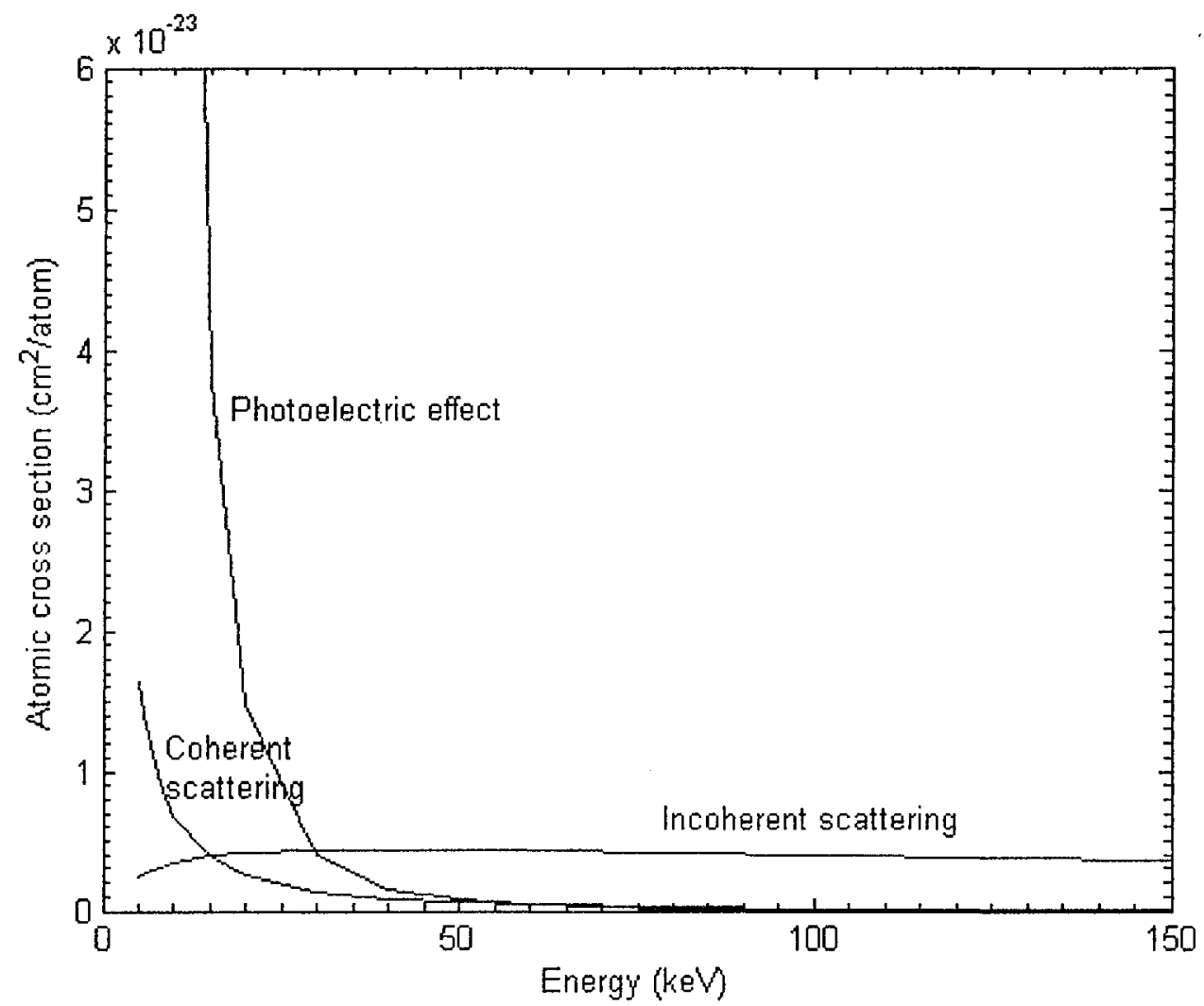

Figure 5. The three interaction mechanisms in oxygen at different energies [Ref [1], Table A-4d].

\subsubsection{Photoelectric effect}

The photoelectric effect is that in which incident photons cause the emission of electrons from materials. Such an electron must be bound or attached to a group of atoms and 
atomic momentum is a factor in conserving momentum. The well-known relationship between the $\mathrm{x}$-ray photon energy and electron kinetic energy can be given by,

$$
\mathrm{T}=\mathrm{h} v-\phi
$$

where $h v$ is the $\mathrm{x}$-ray photon energy and $\phi$ is the binding energy of the electron.

\subsubsection{Coherent Scattering}

The name "coherent scattering" is given to that interaction in which radiation undergoes a change in direction without a change in wavelength. For this reason, the term "unmodified scattering" is sometimes used. There are two models of coherent scattering: Thomson scattering and Rayleigh scattering. In Thomson scattering a single electron is involved in the interaction. Rayleigh scattering results from a cooperative interaction with all the electrons of an atom.

The differential atomic scattering cross section for Rayleigh or elastic scattered radiation can be given by,

$$
\frac{\mathrm{d}_{\mathrm{a}} \sigma_{\mathrm{R}}}{\mathrm{d} \Omega}=\frac{\mathrm{d}_{\mathrm{e}} \sigma_{\mathrm{o}}}{\mathrm{d} \Omega} \mathrm{F}_{\mathrm{atom}}^{2}(\mathrm{x}) \quad\left(\frac{\text { area }}{\text { atom } \cdot \mathrm{sr}}\right)
$$

where $\frac{\mathrm{d}_{\mathrm{e}} \sigma_{\mathrm{o}}}{\mathrm{d} \Omega}$ is known as the classical scattering coefficient or Thomson coefficient per electron per unit solid angle and is given by,

$$
\frac{\mathrm{d}_{\mathrm{e}} \sigma_{\mathrm{o}}}{\mathrm{d} \Omega}=\frac{\mathrm{r}_{\mathrm{o}}^{2}}{2}\left(1+\cos ^{2} \theta\right) \quad\left(\frac{\text { area }}{\text { free electron } \cdot \mathrm{sr}}\right)
$$


where $\theta$ is angle of photon scattering and $r_{0}$ is the classical electron radius which is given by, $r_{o}=\frac{\mathrm{ke}^{2}}{\mathrm{~m}_{\mathrm{o}} \mathrm{c}^{2}}=2.818 \times 10^{-15} \mathrm{~m} \cdot \mathrm{F}_{\text {atom }}(\mathrm{x})$ is called the coherent scatter form factor for an atom. The square of $F_{\text {atom }}(x)$ is a scale factor on the scattered wave intensity, which turns Thomson scattering cross section from a single electron into that of an atom. The generalized form of scattering cross section for compounds and mixtures can be given by,

$$
\frac{\mathrm{d}_{\mathrm{e}} \sigma_{\mathrm{R}}}{\mathrm{d} \Omega}=\frac{\mathrm{d}_{\mathrm{e}} \sigma_{\mathrm{o}}}{\mathrm{d} \Omega} \mathrm{F}^{2}(\mathrm{x}) \quad\left(\frac{\text { area }}{\text { bound electron } \cdot \mathrm{sr}}\right)
$$

where,

$$
F^{2}(x)=\frac{F_{\text {atom }}^{2}(x)}{Z} \quad\left(\frac{\text { free electron }}{\text { bound electron }}\right) \quad .
$$

The form factor is a function of momentum transfer that occurs in the scattering process. The following discussion gives the relation between momentum transfer, energy and the scatter angle.

Figure 6 shows a parallel beam of monochromatic $\mathrm{x}$ rays having wavelength $\lambda$ incident on an arbitrarily shaped body $\mathrm{B}$. Let us consider an arbitrary defined origin $\mathrm{O}$ on the scattering body and a fraction of this incident beam has been scattered through an angle $\theta$. The incident and scattered beam are defined by the unit vectors $\hat{\mathbf{k}}_{\mathbf{i}}$ and $\hat{\mathbf{k}}_{\mathbf{s}}$ respectively. 


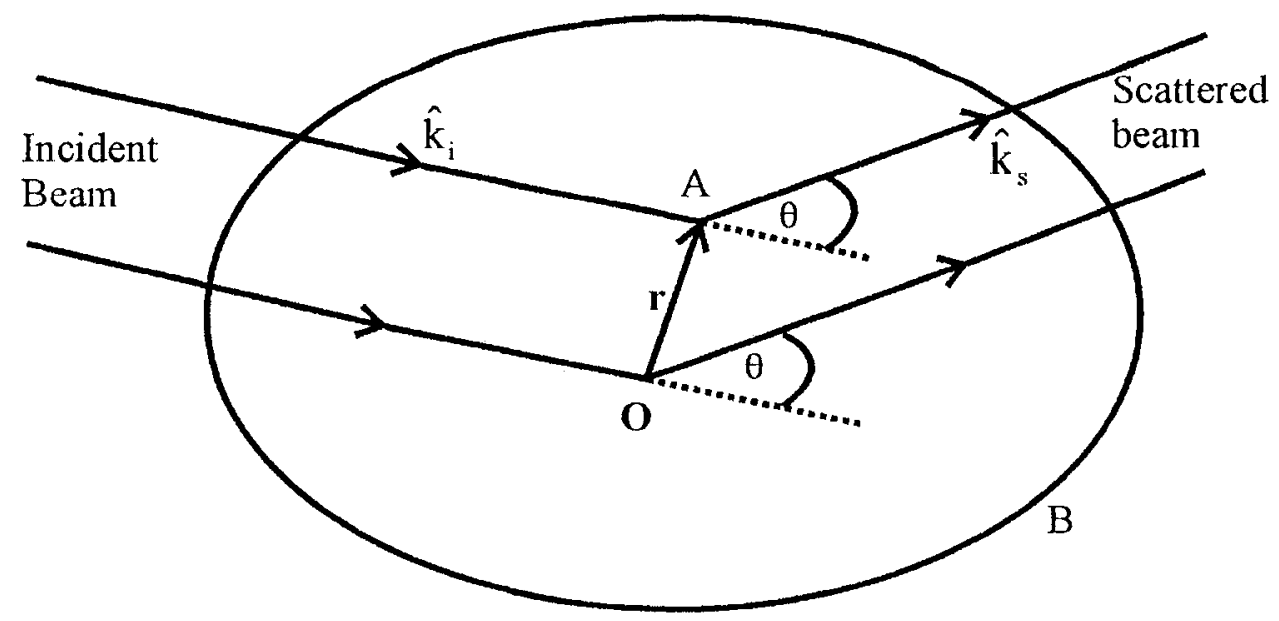

Figure 6. Diagram of path difference between incident and scattered wave.

Let us consider the scattering event in a volume element, $\Delta \mathrm{V}$, at point $\mathrm{A}$ at a location $\mathbf{r}$ from the origin $O$. The path difference between waves scattered through $\theta$ by electrons at $A$ and $O$ can be given by $[21], \mathbf{s}=\mathbf{r} \cdot\left(\hat{\mathbf{k}}_{\mathbf{s}}-\hat{\mathbf{k}}_{\mathbf{i}}\right)$.

and the corresponding phase difference can be given by, $\varphi=\left(\frac{2 \pi}{\lambda}\right) \mathbf{r} \cdot\left(\hat{\mathbf{k}}_{\mathrm{s}}-\hat{\mathbf{k}}_{\mathbf{i}}\right)$.

If there were only a single electron at A the wave scattered by the volume element would have an amplitude [21] $=S_{0} p^{1 / 2}\left(\mu_{0} / 4 \pi\right)\left(e^{2} / m R\right)$, where $S_{0}$ is the amplitude of the incident $X$-ray beam, $\mathrm{p}$ is the polarization factor, $\mu_{0}$ is the permeability of free space, $\mathrm{e}$ is the electron charge, $\mathrm{m}$ is the mass of the electron, and $\mathrm{R}$ is the modulus of the vector $\mathbf{R}$, which defines the position of the observer from the oscillatory electron at point $A$. Let us consider $\rho(\mathbf{r})$ to be the electron density at point $\mathrm{A}$, then the number of electrons at the volume $\Delta \mathrm{V}$ will be $\Delta \mathrm{V} \rho(\mathbf{r})$. If we consider interference effect, amplitudes of waves have to be added, with regard to phase differences. The electrons at $\mathrm{A}$ all have the same position in space 
and so the $\mathrm{x}$ rays they scatter in a given direction will be in phase. Therefore the amplitude scattered by these electrons is,

$$
\Delta V \rho(\mathbf{r}) S_{0} \mathrm{p}^{1 / 2}\left(\mu_{0} / 4 \pi\right)\left(e^{2} / \mathrm{mR}\right)
$$

With this amplitude and phase the wave can be represented by,

$$
\Delta V \rho(\mathbf{r}) S_{0} p^{y_{2}}\left(\mu_{0} / 4 \pi\right)\left(e^{2} / m R\right) e^{i\left(\frac{2 \pi}{\lambda}\right) r \cdot\left(\hat{k}_{s}-\hat{k}_{1}\right)}
$$

The resultant wave scattered through an angle $\theta$ by the entire body is then given by,

$$
\mathrm{S}=\mathrm{S}_{0} \mathrm{p}^{1 / 2}\left(\mu_{0} / 4 \pi\right)\left(\mathrm{e}^{2} / \mathrm{mR}\right) \int \rho(\mathbf{r}) \mathrm{e}^{\mathrm{i}\left(\frac{2 \pi}{\lambda}\right) \mathrm{r} \cdot\left(\hat{\mathrm{k}}_{\mathrm{s}}-\hat{\mathrm{k}}_{\mathrm{i}}\right)} \mathrm{dr}
$$

In equation (9) the parameters $\mathrm{e}, \mathrm{m}$ and $\mu$ are fundamental constants; the appearance of $\mathrm{R}$ simply takes into account the inverse square dependence of intensity on distance. $S_{0}$ acts only as a scale factor. All of these factors can be ignored if relative intensities of the xrays scattered in different directions by a body is considered. Therefore, the resultant wave scattered through an angle $\theta$ by the body can be represented, both in amplitude and phase by,

$$
F=\int \rho(\mathbf{r}) e^{\mathrm{i}\left(\frac{2 \pi}{\lambda}\right) \mathbf{r} \cdot\left(\hat{\mathrm{k}}_{\mathrm{s}}-\hat{\mathrm{k}}_{\mathrm{i}}\right)} \mathrm{dr}=\int \rho(\mathbf{r}) \mathrm{e}^{\mathrm{i} 2 \pi\left[2 \mathbf{r} \cdot \frac{\left(\hat{\mathrm{k}}_{\mathrm{s}}-\hat{\mathrm{k}}\right)}{2 \lambda}\right]} \mathrm{dr}
$$

The modulus of the factor in exponent $\left(\frac{1}{2 \lambda}\right)\left(\hat{k}_{s}-\hat{k}_{i}\right)$ of equation (10) is defined as the momentum transfer parameter, and is denoted as,

$$
\mathrm{X}=\left(\frac{1}{2 \lambda}\right)\left|\hat{\mathrm{k}}_{\mathrm{s}}-\hat{\mathrm{k}}_{\mathrm{k}}\right|
$$

The vector $\left(\hat{\mathrm{k}}_{\mathrm{s}}-\hat{\mathrm{k}}_{\mathrm{i}}\right)$ is illustrated in Figure 7 [22], 


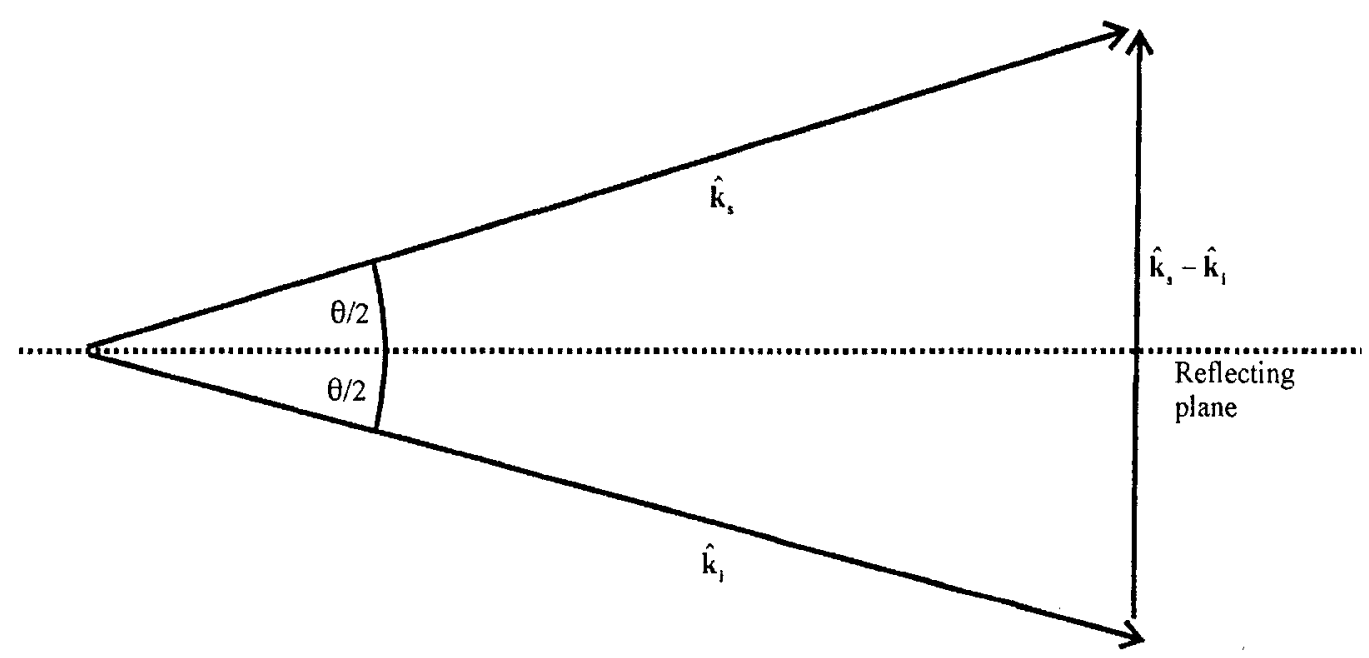

Figure 7. Construction of the normal to the reflecting plane.

From the upper triangle of Figure 7 ,

$$
\begin{aligned}
\left|\hat{\mathrm{k}}_{\mathrm{s}}-\hat{\mathrm{k}}_{\mathrm{i}}\right| & =2\left|\hat{\mathrm{k}}_{\mathrm{s}}\right| \sin \frac{\theta}{2} \\
& =2 \sin \frac{\theta}{2}
\end{aligned}
$$

[Since $\hat{\mathrm{k}}_{\mathrm{s}}$ is a unit vector]

Combining equations (11) and (12) gives,

$$
\mathrm{x}=\frac{1}{\lambda} \sin \frac{\theta}{2}=\frac{\mathrm{E}}{\mathrm{hc}} \sin \frac{\theta}{2}
$$

The form factor depends strongly on the degree of order within the material. Other than for a simple structure such as a single atom it is very difficult to calculate $F$. An easy approach is to assume no inter-atomic interference. This is called the Independent Atom Model (IAM) approach. The square of the IAM considers each atom in the molecule as 
an individual scatterer having no inter-atomic interference. The IAM form factor can be given by,

$$
F_{I A M}^{2}=\frac{\sum_{i=1}^{N} f_{i} F_{i}^{2}(x)}{\sum_{i=1}^{N} f_{i} Z_{i}} \quad\left(\frac{\text { free electron }}{\text { bound electron }}\right)
$$

where $\mathrm{N}$ is the number of elements in the molecule, and $f_{i}, F_{i}$ and $Z_{i}$ are the number of atoms, form factors and atomic number of the $\mathrm{i}$-th element in the molecule respectively.

\subsubsection{Incoherent scattering}

Inelastic or incoherent scattering of an x-ray quantum by a free stationary electron is well described by the Klein-Nishina formula. Due to the inelasticity of the process the scattered quantum has lower energy than the incident one. The energy of the scattered $x-$ ray quantum is given by

$$
E=E_{o} \frac{1}{\left[1+\frac{E_{o}}{m_{o} c^{2}}(1-\cos \theta)\right]}
$$

where $m_{0} c^{2}=$ rest energy of the electron $(511 \mathrm{keV})$.

Let us consider a system which involves an electron initially at rest. A photon undergoes collision with this electron and the scattered photon makes an angle $\theta$ with the primary direction. The energy and momentum of the photon are changed because of this collision. Klein and Nishina showed that the probability of this interaction can be given by [1], 


$$
\frac{\mathrm{d}_{\mathrm{e}} \sigma_{\mathrm{INC}}}{\mathrm{d} \Omega}=\frac{\mathrm{d}_{\mathrm{e}} \sigma_{\mathrm{o}}}{\mathrm{d} \Omega} \mathrm{F}_{\mathrm{KN}}(\mathrm{h} \nu, \theta) \quad\left(\frac{\text { area }}{\text { free electron } \cdot \mathrm{sr}}\right)
$$

Here $F_{K N}$ is the Klein-Nishina factor and can be given by [1],

$$
F_{K N}(h v, \theta)=\left(\frac{1}{1+\alpha(1-\cos \theta)}\right)^{2}\left(1+\frac{\alpha^{2}(1-\cos \theta)^{2}}{[1+\alpha(1-\cos \theta)]\left(1+\cos ^{2} \theta\right)}\right)
$$

where $\alpha\left(=\frac{h v}{m_{0} c^{2}}\right)$ is the ratio between incident energy of photon and electron rest energy. Usually $\mathrm{F}_{\mathrm{KN}}<1$, implying that photon energy is transferred to electron. When $\alpha$ is very small or $\theta$ is equal to zero $F_{\mathrm{KN}}=1$, which represents no energy exchange between photon and electron.

In the above discussion we assumed the electrons involved in the process are free and stationary. However in a real system the electrons are bound in an atom and we must consider the effect of the motion and the energy required to eject them from the atom. This involves knowledge of positions and velocities of electrons in the atom. Because the electron is bound to an atom, Compton scattering is inhibited if the energy transfer is lower than the required ionization energy. This fact leads to a modification of the KleinNishina formula at low momentum transfer values by an incoherent scatter function $\mathrm{S}(\mathrm{x})$ [1], which accounts for binding effects of the electron. The total differential Compton cross section can then be written as follows,

$$
\frac{\mathrm{d}_{\mathrm{e}} \sigma_{\mathrm{INC}}}{\mathrm{d} \Omega}=\frac{\mathrm{d}_{\mathrm{e}} \sigma_{\mathrm{o}}}{\mathrm{d} \Omega} \mathrm{F}_{\mathrm{KN}} \mathrm{S}(\mathrm{x}) \quad\left(\frac{\text { area }}{\text { bound electron } \cdot \mathrm{sr}}\right)
$$

where $S(x)=\frac{S_{\text {atom }}(x)}{Z} \quad\left(\frac{\text { free electron }}{\text { bound electron }}\right)$ 
Here $S_{\text {atom }}(x)$ is the incoherent form factor for an atom, and $S(x)$ is also tabulated for all elements. It increases from zero at $\mathrm{x}=0$ and equals the number of electrons at large $\mathrm{x}$ values. In compound matter or molecules the energy states of the outer shell electrons are changed as compared to atoms having free electrons and therefore the $\mathrm{S}$ function will be different too. However, these changes are very small and it is valid to use the tabulated data for free-atom even for solid materials in the small scattering angle region. The total scatter function can be calculated by the well-known rule,

$$
S_{m o l}(x)=\frac{\sum_{i=1}^{N} f_{i} S_{i}(x)}{\sum_{i=1}^{N} f_{i} Z_{i}} \quad\left(\frac{\text { free electron }}{\text { bound electron }}\right),
$$

where $\mathrm{N}$ is the number of elements in the molecule, $\mathrm{f}_{\mathrm{i}}$ is the number of atoms of the $\mathrm{i}$-th element and $\mathrm{S}_{\mathrm{i}}$ is its corresponding incoherent scatter function.

\subsection{Total scattering cross section}

From the above discussion it can be inferred that the total scatter cross section is the summation of the Rayleigh (elastic) and Compton scattering cross sections and can be given by,

$$
\frac{\mathrm{d}_{\mathrm{e}} \sigma}{\mathrm{d} \Omega}=\frac{\mathrm{d}_{\mathrm{e}} \sigma_{\mathrm{R}}}{\mathrm{d} \Omega}+\frac{\mathrm{d}_{\mathrm{e}} \sigma_{\mathrm{INC}}}{\mathrm{d} \Omega}
$$

Combining equations (7), (18) and (21) gives,

$$
\begin{aligned}
\frac{d_{e} \sigma}{d \Omega} & =\frac{d_{e} \sigma_{0}}{d \Omega}\left[F_{K N} S(x)+F^{2}(x)\right] \\
& =\frac{r_{o}^{2}}{2}\left(1+\cos ^{2} \theta\right)\left[F_{K N} S(x)+F^{2}(x)\right] .
\end{aligned}
$$




\section{Chapter 3}

\section{Mathematical formulation for cross section and geometry optimization}

This chapter discusses the mathematical formulation to determine the differential scatter cross section for the geometry that will be used in this experiment. It describes the form factor calculation from this differential scattering cross section. This chapter also describes the study that has been done to optimize the geometry by determining the effect of the extended scattering target.

\subsection{Measurement of differential scattering cross section}

Figure 8 is a diagram to formulate the relationship between differential scattering cross section of the target and the various parameters of the geometry.

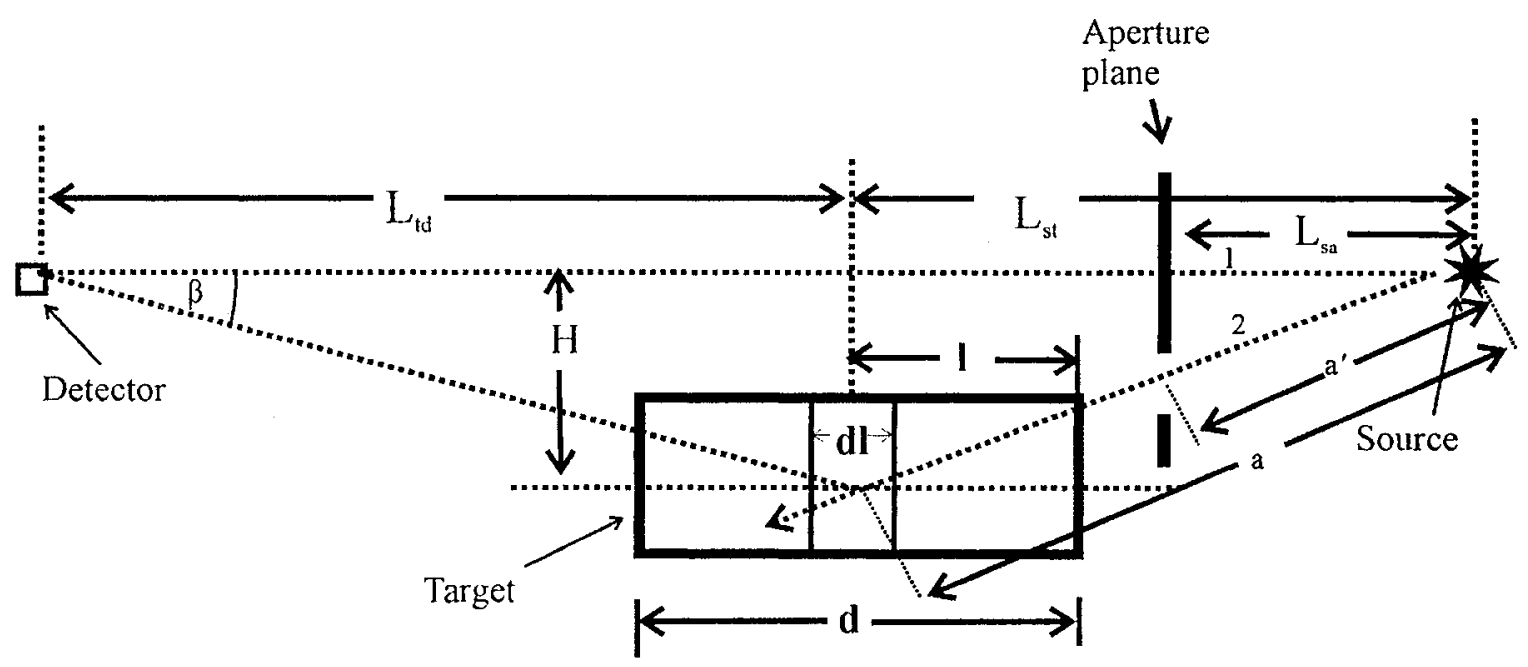

Figure 8. Diagram to determine scatter cross section.

Suppose a beam of $\mathrm{x}$ rays of photon fluence $\Phi_{c}^{\mathrm{T}}$ falls on the centre of the target at a distance $\mathrm{L}_{\mathrm{st}}$ (i.e., the distance between the focal spot and the centre of the target). $=\mathrm{L}_{\mathrm{td}}$ 
cross sectional area of the target $=A_{t}$

the active area of detection for the detector for the scattered rays $=\mathrm{A}_{d}{ }^{\mathrm{s}}$

the active area of detection for the detector for the transmitted rays $=\mathrm{A}_{d}{ }^{\mathrm{T}}$

the density of electrons in the target (per unit volume) $=\rho_{\mathrm{e}}$

the thickness of the target $=\mathrm{d}$

the distance from the source to the aperture $=\mathrm{L}_{\mathrm{sa}}$

the offset of the target $=\mathrm{H}$

the distance of the aperture hole from the source $=a^{\prime}$

the distance of the target centre from the source $=\mathrm{a}$

the photon emission rate per second by the focal spot for transmitted signal $=S^{T}$

the photon emission rate per second by the focal spot for scattered signal $=S^{s}$

the angle made by the scattered ray to a normal to the detector $\quad=\beta$

the time to measure the transmission signal $=\mathrm{t}^{\mathrm{T}}$

the time to measure the scatter signal $=t^{\mathrm{s}}$

the fluence rate at the aperture plane at a distance $a^{\prime}=\Phi_{0}^{s}$

the fluence rate at the aperture plane at a distance $L_{\mathrm{sa}} \quad=\Phi_{\mathrm{o}}^{\mathrm{T}}$

$\mu_{t}(h v)$ is the linear attenuation coefficient of the target at energy hv.

Using the inverse square law, for the scatter case, the fluence rate at the centre of the target for the $\mathrm{x}$-ray beam following path 2 is,

$$
\Phi_{\mathrm{c}}^{\mathrm{s}}=\Phi_{\mathrm{o}}^{\mathrm{s}} \frac{\mathrm{a}^{\prime 2}}{\mathrm{a}^{2}}=\frac{\mathrm{S}^{\mathrm{s}}}{4 \pi \mathrm{a}^{\prime 2}} \frac{\mathrm{a}^{\prime 2}}{\mathrm{a}^{2}}=\frac{\mathrm{S}^{\mathrm{s}}}{4 \pi \mathrm{a}^{2}}=\frac{\mathrm{S}^{\mathrm{s}}}{4 \pi\left(\mathrm{L}_{\mathrm{st}}^{2}+\mathrm{H}^{2}\right)}
$$

$\left[\right.$ Since, $\left.\Phi_{o}^{s}=\frac{S^{s}}{4 \pi a^{\prime 2}}\right]$ 
The number of photons scattered from the object element dl at the centre of the target and reaching the detector using equation (23) is,

$$
d N^{s}=\frac{S^{s}}{4 \pi\left(L_{s t}^{2}+H^{2}\right)^{t s}} A_{t} \rho_{e} \frac{d_{e} \sigma}{d \Omega}\left(\frac{A_{d}^{s} \cos \beta}{L_{t d}^{2}+H^{2}}\right) e^{-\mu_{t} l} e^{-\mu_{t}(d-1)} d l
$$

In this equation the distances in the target for attenuation are taken as 1 and $d-1$ since the offset $\mathrm{H}$ is small. Since air attenuation at this energy is negligible, the air transmission factors can be neglected. Integrating over the length of the target,

$$
\begin{aligned}
N^{s} & =\frac{S^{s}}{4 \pi\left(L_{s t}^{2}+H^{2}\right)} t^{s} A_{t} \rho_{e} \frac{d_{e} \sigma}{d \Omega}\left(\frac{A_{d}^{s} \cos \beta}{L_{t d}^{2}+H^{2}}\right) e^{-\mu_{t} d} \int_{0}^{d} d l \\
& =\frac{S^{s}}{4 \pi\left(L_{s t}^{2}+H^{2}\right)} t^{s} A_{t} \rho_{e} \frac{d}{d \Omega}\left(\frac{A_{d}^{s} \cos \beta}{L_{t d}^{2}+H^{2}}\right) e^{-\mu_{t} d} d
\end{aligned}
$$

For the transmission case, the fluence rate at the centre of the target for the $\mathrm{x}$-ray beam following path 1 is,

$$
\begin{array}{r}
\Phi_{\mathrm{c}}^{\mathrm{T}}=\Phi_{\mathrm{o}}^{\mathrm{T}} \frac{\mathrm{L}_{\mathrm{sa}}^{2}}{\mathrm{~L}_{\mathrm{st}}^{2}}=\frac{\mathrm{S}^{\mathrm{T}}}{4 \pi \mathrm{L}_{\mathrm{sa}}^{2}} \frac{\mathrm{L}_{\mathrm{sa}}^{2}}{\mathrm{~L}_{\mathrm{st}}^{2}}=\frac{\mathrm{S}^{\mathrm{T}}}{4 \pi \mathrm{L}_{\mathrm{st}}^{2}} \\
\text { [Since, } \left.\Phi_{\mathrm{o}}^{\mathrm{T}}=\frac{\mathrm{S}^{\mathrm{T}}}{4 \pi \mathrm{L}_{\mathrm{sa}}^{2}}\right]
\end{array}
$$

From the inverse square law, the fluence rate at the entrance surface of the detector in the absence of the attenuation is,

$$
\Phi_{\mathrm{d}}=\Phi_{\mathrm{c}}^{\mathrm{T}} \frac{\mathrm{L}_{\mathrm{st}}^{2}}{\left(\mathrm{~L}_{\mathrm{st}}+\mathrm{L}_{\mathrm{td}}\right)^{2}}
$$

Putting in target attenuation, while assuming air attenuation to be negligible,

$$
\Phi_{\mathrm{d}}=\Phi_{\mathrm{c}}^{\mathrm{T}} \frac{\mathrm{L}_{\mathrm{st}}^{2}}{\left(\mathrm{~L}_{\mathrm{st}}+\mathrm{L}_{\mathrm{td}}\right)^{2}} \mathrm{e}^{-\mu_{\mathrm{t}} \mathrm{d}}
$$


From equation (26) the number of transmitted photons that will be incident on the detector is,

$$
\begin{aligned}
N^{T} & =\Phi_{c}^{T} t^{T} A_{d}^{T} \frac{L_{s t}^{2}}{\left(L_{s t}+L_{t d}\right)^{2}} e^{-\mu_{t} d} \\
& =\frac{S^{T}}{4 \pi L_{s t}^{2}} t^{T} A_{d}^{T} \frac{L_{s t}^{2}}{\left(L_{s t}+L_{t d}\right)^{2}} e^{-\mu_{t} d} \\
& =\frac{S^{T}}{4 \pi} t^{T} A_{d}^{T} \frac{1}{\left(L_{s t}+L_{t d}\right)^{2}} e^{-\mu_{t} d}
\end{aligned}
$$

Now dividing equation (24) by (27) gives,

$$
\begin{aligned}
\frac{N^{s}}{N^{T}} & =\frac{\frac{S^{S}}{4 \pi\left(L_{s t}^{2}+H^{2}\right)} t^{s} A_{t} \rho_{e} \frac{d_{e} \sigma}{d \Omega}\left(\frac{A_{d}^{s} \cos \beta}{L_{t d}^{2}+H^{2}}\right) e^{-\mu_{t} d} d}{\frac{S^{T}}{4 \pi} t^{T} A_{d}^{T} \frac{1}{\left(L_{s t}+L_{t d}\right)^{2}} e^{-\mu_{t} d}} \\
\text { or, } \quad \frac{d_{e} \sigma}{d \Omega} & =\frac{A_{d}^{T}}{d \rho_{e} A_{t} A_{d}^{s} \cos \beta} \frac{\left(L_{s t}^{2}+H^{2}\right)\left(L_{t d}^{2}+H^{2}\right)}{\left(L_{s t}+L_{t d}\right)^{2}} \frac{t^{T}}{t^{s}} \frac{S^{T}}{S^{s}} \frac{N^{s}}{N^{T}}\left(\frac{\mathrm{cm}^{2}}{e^{-} \cdot s r}\right)
\end{aligned}
$$

\subsection{Necessary angles and respective $x$-ranges}

Table 1 shows the necessary spectra, energy, scatter angles and their corresponding $\mathrm{x}$ ranges.

Table 1 . Necessary spectra, energy range, scatter angle and $x$ range.

\begin{tabular}{|c|c|c|c|}
\hline Spectrum & $\begin{array}{c}\text { Energy range of } \\
\text { Photon }(\mathrm{keV})\end{array}$ & Nominal angle & x-range $\left(\mathrm{nm}^{-1}\right)$ \\
\hline $86 \mathrm{kV}$ & $17-75$ & $1.0^{\circ}$ & $0.12 \leq \mathrm{x} \leq 0.53$ \\
\hline $106 \mathrm{kV}$ & $17-100$ & $3.0^{\circ}$ & $0.36 \leq \mathrm{x} \leq 2.10$ \\
\hline $121 \mathrm{kV}$ & $17-110$ & $15.0^{\circ}$ & $1.79 \leq \mathrm{x} \leq 11.55$ \\
\hline
\end{tabular}


However, due to the extended length, width and height of the target and due to the aperture size the scatter angle varied. The following shows how the optimum scatter angle and associated geometric parameters were obtained.

\subsection{Study of variation of scatter angle with the extended target geometry}

To determine the effect of an extended target on the scattering angle it is important to determine the average angle for that target and the variation of the angles created by each of the scattering volumes inside the target. Figure 9 shows the diagram to determine the average scattering angle and standard deviation for an extended target. In Figure 9 ray a makes an angle $\alpha$ with the line from source to detector and fall in plane $\mathrm{p}$ inside the target. The ray is scattered at plane $\mathrm{p}$ with scattering angle $\theta$ and emerges as ray $\mathrm{b}$, which is detected by the detector. This ray makes an angle $\beta$ with the normal to the detector. The target offset is $\mathrm{H}$ as shown in Figure 9. $\mathrm{H}^{\prime}$ is the distance between the line from source to detector and the point at which the ray is falling on the plane $\mathrm{p}$. 


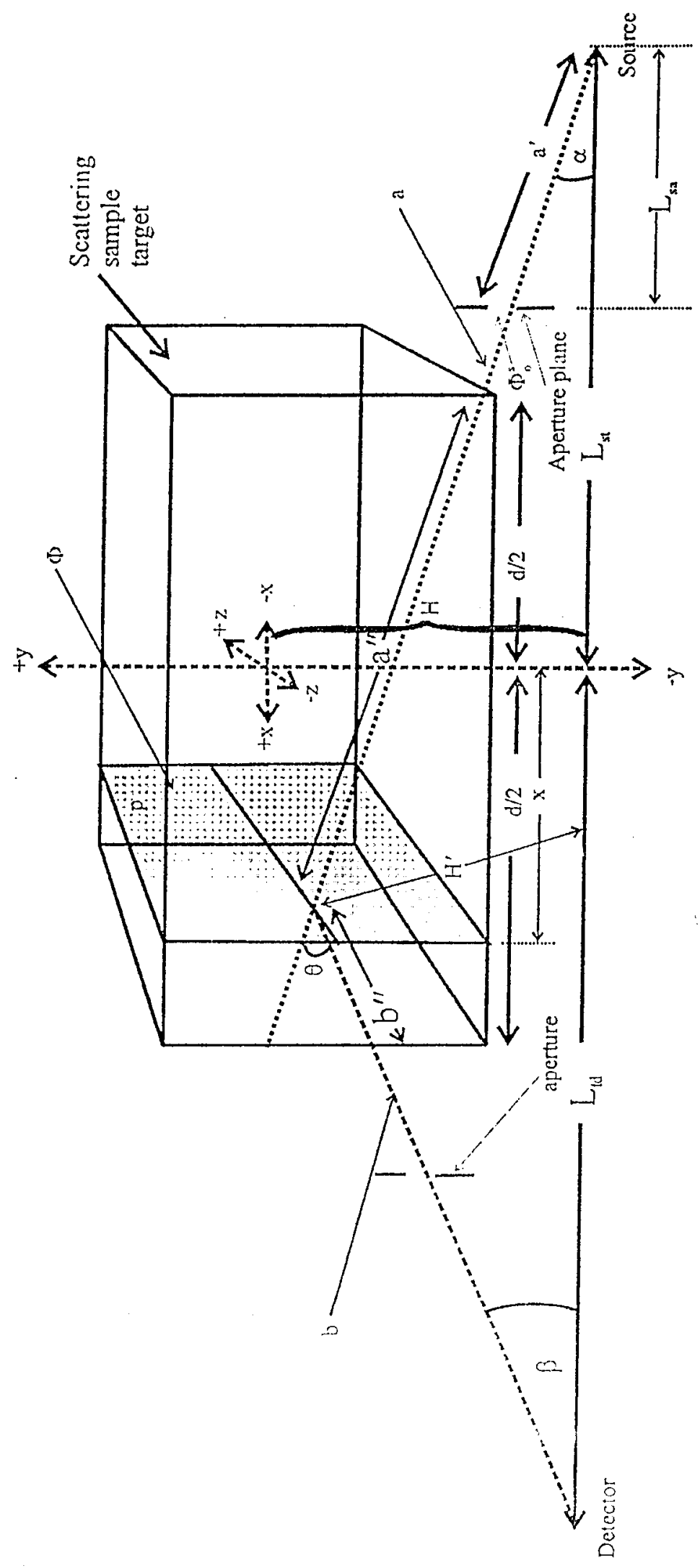

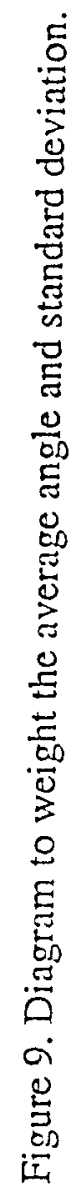


From sine rule,

$$
\begin{aligned}
& \frac{a}{\sin \beta}=\frac{L_{t d}+L_{s t}}{\sin \theta} \\
& \text { or, } \sin \theta=\frac{L_{t d}+L_{s t}}{a} \sin \beta
\end{aligned}
$$

Since, $\sin \beta=\frac{\mathrm{H}^{\prime}}{\mathrm{b}}$, we have

$$
\theta=\sin ^{-1}\left(\frac{\mathrm{L}_{\mathrm{td}}+\mathrm{L}_{\mathrm{st}}}{\mathrm{ab}} \mathrm{H}^{\prime}\right)
$$

Equation (29) can be written to be useful for numerical calculation as follows,

Scatter angle, $\theta=\sin ^{-1}\left(\frac{\left(L_{t d}+L_{s t}\right) \sqrt{(H+y)^{2}+z^{2}}}{\sqrt{\left(L_{s t}+x\right)^{2}+(H+y)^{2}+z^{2}} \sqrt{\left(L_{t d}-x\right)^{2}+(H+y)^{2}+z^{2}}}\right)$

\subsection{Calculation for weighting the average angle and standard deviation}

The previous analysis assumed that the x-ray beam was parallel. However, in reality the photon flux is being reduced because of the inverse square effect. This is why it is necessary to weight each of the angles created by each voxel of target with the corresponding weighting factor. Figure 9 shows a few additional things: two apertures in the source and detector side, flux $\Phi_{\mathrm{o}}^{\mathrm{s}}$ at the source aperture, flux $\Phi$ at the plane p. Let us consider the area of each voxel's side at the plane $\mathrm{p}$ is $\mathrm{a}_{\mathrm{v}}$ and the thickness is $\mathrm{t}$.

The number of photons that reach the detector after being scattered in a voxel at the plane p can be given by,

$$
\mathrm{N}_{\mathrm{d}}=\Phi \mathrm{a}_{\mathrm{v}} \mathrm{e}^{-\mu_{\mathrm{t}}\left(\mathrm{a}^{*}+\mathrm{b}^{*}\right)} \rho_{\mathrm{e}} \frac{\mathrm{d}_{\mathrm{e}} \sigma}{\mathrm{d} \Omega}\left(\frac{\mathrm{A}_{\mathrm{d}}^{\mathrm{s}} \cos \beta}{\mathrm{b}^{2}}\right) \mathrm{t}
$$


Now, $\frac{a^{\prime \prime}}{a}=\frac{d / 2+x}{L_{s t}+x}$

$$
\text { or, } a^{\prime \prime}=\left(\frac{d}{2}+x\right) \frac{a}{L_{s t}+x} \text {, }
$$

similarly, $b^{\prime \prime}=\left(\frac{d}{2}-x\right) \frac{b}{L_{t d}-x}$.

Again from inverse square law the flux at the plane $\mathrm{p}$ can be given by,

$$
\Phi=\Phi_{\mathrm{o}}^{\mathrm{s}}\left(\frac{\mathrm{a}^{\prime 2}}{\mathrm{a}^{2}}\right)=\Phi_{\mathrm{o}}^{\mathrm{s}}\left(\frac{\mathrm{L}_{\mathrm{sa}}^{2}}{\left(\mathrm{~L}_{\mathrm{st}}+\mathrm{x}\right)^{2}}\right), \quad \text { Since, } \frac{\mathrm{a}^{\prime}}{\mathrm{a}}=\frac{\mathrm{L}_{\mathrm{sa}}}{\mathrm{L}_{\mathrm{st}}+\mathrm{x}}
$$

Using the relations of parameters $a^{\prime \prime}, b^{\prime \prime}$ and $\Phi$ equation (31) can be written to make useful for numerical calculation as follows,

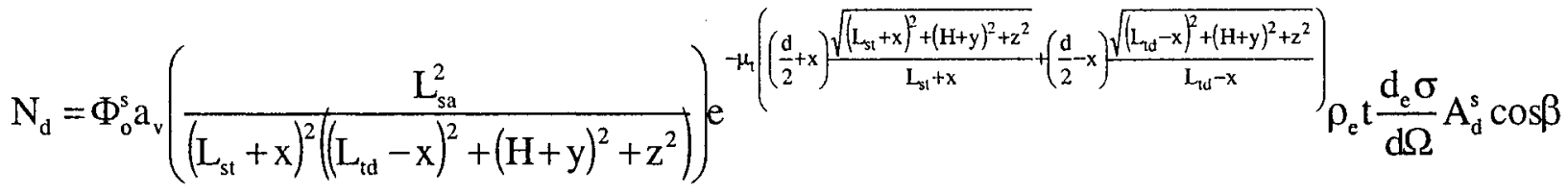

\subsubsection{Proof that exponential factor is simply a constant}

Analyzing exponent of equation (32) gives,

$$
\begin{aligned}
& \mu_{\mathrm{t}}\left(\frac{\sqrt{\left(\mathrm{L}_{\mathrm{st}}^{2}+\mathrm{x}\right)^{2}+(\mathrm{H}+\mathrm{y})^{2}+\mathrm{z}^{2}}}{\mathrm{~L}_{\mathrm{st}}+\mathrm{x}}\left(\frac{\mathrm{d}}{2}+\mathrm{x}\right)+\frac{\sqrt{\left(\mathrm{L}_{\mathrm{td}}-\mathrm{x}\right)^{2}+(\mathrm{H}+\mathrm{y})^{2}+\mathrm{z}^{2}}}{\mathrm{~L}_{\mathrm{td}}-\mathrm{x}}\left(\frac{\mathrm{d}}{2}-\mathrm{x}\right)\right) \\
& =\mu_{\mathrm{t}}\left[\left(1+\frac{(\mathrm{H}+\mathrm{y})^{2}+\mathrm{z}^{2}}{\left(\mathrm{~L}_{\mathrm{st}}+\mathrm{x}\right)^{2}}\right)^{\frac{1}{2}}\left(\frac{\mathrm{d}}{2}+\mathrm{x}\right)+\left(1+\frac{(\mathrm{H}+\mathrm{y})^{2}+\mathrm{z}^{2}}{\left(\mathrm{~L}_{\mathrm{td}}-\mathrm{x}\right)^{2}}\right)^{\frac{1}{2}}\left(\frac{\mathrm{d}}{2}-\mathrm{x}\right)\right] \\
& \approx \mu_{\mathrm{t}}\left[\left(1+\frac{(\mathrm{H}+\mathrm{y})^{2}+\mathrm{z}^{2}}{2\left(\mathrm{~L}_{\mathrm{st}}+\mathrm{x}\right)^{2}}\right)\left(\frac{\mathrm{d}}{2}+\mathrm{x}\right)+\left(1+\frac{(\mathrm{H}+\mathrm{y})^{2}+\mathrm{z}^{2}}{2\left(\mathrm{~L}_{\mathrm{td}}-\mathrm{x}\right)^{2}}\right)\left(\frac{\mathrm{d}}{2}-\mathrm{x}\right)\right]
\end{aligned}
$$

(using binomial expansion) 


$$
\begin{aligned}
& \approx \mu_{\mathrm{t}}\left[\frac{\mathrm{d}}{2}+\mathrm{x}+\frac{\mathrm{d}}{2}-\mathrm{x}\right] \\
& \qquad\left[\text { since, } \frac{(\mathrm{H}+\mathrm{y})^{2}+\mathrm{z}^{2}}{2\left(\mathrm{~L}_{\mathrm{st}}+\mathrm{x}\right)^{2}} \ll<1 \text { and } \frac{(\mathrm{H}+\mathrm{y})^{2}+\mathrm{z}^{2}}{2\left(\mathrm{~L}_{\mathrm{st}}-\mathrm{x}\right)^{2}} \ll<1\right] \\
& =\mu_{\mathrm{t}} \mathrm{d}
\end{aligned}
$$

which implies that the only weighting factor of equation (32) is the inverse square part, i.e.,

$\left(\frac{1}{\left(L_{s t}+x\right)^{2}\left(\left(L_{t d}-x\right)^{2}+(H+y)^{2}+z^{2}\right)}\right)$

3.4.2 List of steps in the numerical calculation to determine average angle and standard deviation

The average angle and the standard deviation were calculated using the program zhavevar.cpp. The following discussion summarizes the steps in that calculation.

Part 1.

1. Determination of the pixels inside the target as covered by the cone made by the source

2. Determination of the pixels inside the target as covered by the cone made by the detector

3. Verifying which pixels are common in these two sets

4. Calculating scatter angles only for the common pixels using equation (30)

5. Summing all the scatter angles after being weighted by the factor in equation (32) and average angle was calculated

Part 2.

1. Repeating step 1, 2 and 3 of part 1

2. Subtracting average value of the angle from each common scatter angle

3. Weighted and solved for variance and standard deviation for all angles. 


\subsubsection{Results and Discussions}

The program gives good information of the variation of average angle and standard deviation with the parameters of the geometry. Here source to target distance $\left(\mathrm{L}_{\mathrm{st}}\right)$, target to detector distance $\left(\mathrm{L}_{\mathrm{dd}}\right)$, source to aperture distance $\left(\mathrm{L}_{\mathrm{sa}}\right)$ were taken to be $70 \mathrm{~cm}$ and 76 $\mathrm{cm}$ and $65 \mathrm{~cm}$ respectively. The aperture distances were $0.77 \mathrm{~cm}, 1.75 \mathrm{~cm}$, and $9.40 \mathrm{~cm}$ for $1.3^{\circ}, 3.1^{\circ}$ and $15.4^{\circ}$ respectively.

\subsubsection{Effect of length on average angle and standard deviation}

Table 2 shows the other dimensions of the target that were used in this study.

Table 2. Dimensions of target used to analyze the variation of scatter angle with length.

\begin{tabular}{|c|c|c|c|}
\hline Height $(\mathrm{cm})$ & Width $(\mathrm{cm})$ & $\begin{array}{l}\text { Aperture radius in } \\
\text { source side }(\mathrm{cm})\end{array}$ & $\begin{array}{l}\text { Aperture radius in } \\
\text { detector side }(\mathrm{cm})\end{array}$ \\
\hline 5.0 & 5.0 & 0.2 & 0.2 \\
\hline
\end{tabular}

Figure 10 shows how the average angle and standard deviation vary with the length of the target for three nominal angles chosen.

Figure 10 shows that average angle and standard deviation both decrease as the length of the target increase in the nominal $1^{\circ}$ and $3^{\circ}$ cases. In both of these cases the average scatter angle and the standard deviation do not vary significantly. Figure 10 shows a slight increase at the $0.75 \mathrm{~cm}$ of the target length. This is because the angular variation is large in this length as compared to the number of voxels inside the cone created by the $\mathrm{x}$ ray tube and the detector. As the length of the target increases the voxel number is also increased but the variation remains almost the same as before and consequently the average angle and the standard deviation are reduced. For high scatter angle $>15^{\circ}$ the 
variation of length has different nature than that of the low scatter angle. The angle remains steady at the beginning and goes down to $15.25^{\circ}$ at length $3 \mathrm{~cm}$ and then goes up as the length is increased. The same reason applies in here, i.e. the at the beginning the angle variation and the number of voxels increases steadily, then the number of voxel does not vary as compared to the scatter angle and at the end the average angle varies whereas the number of voxel does not vary very much. At the same length the standard deviation was found to be maximum as the scatter angle variation is maximum.
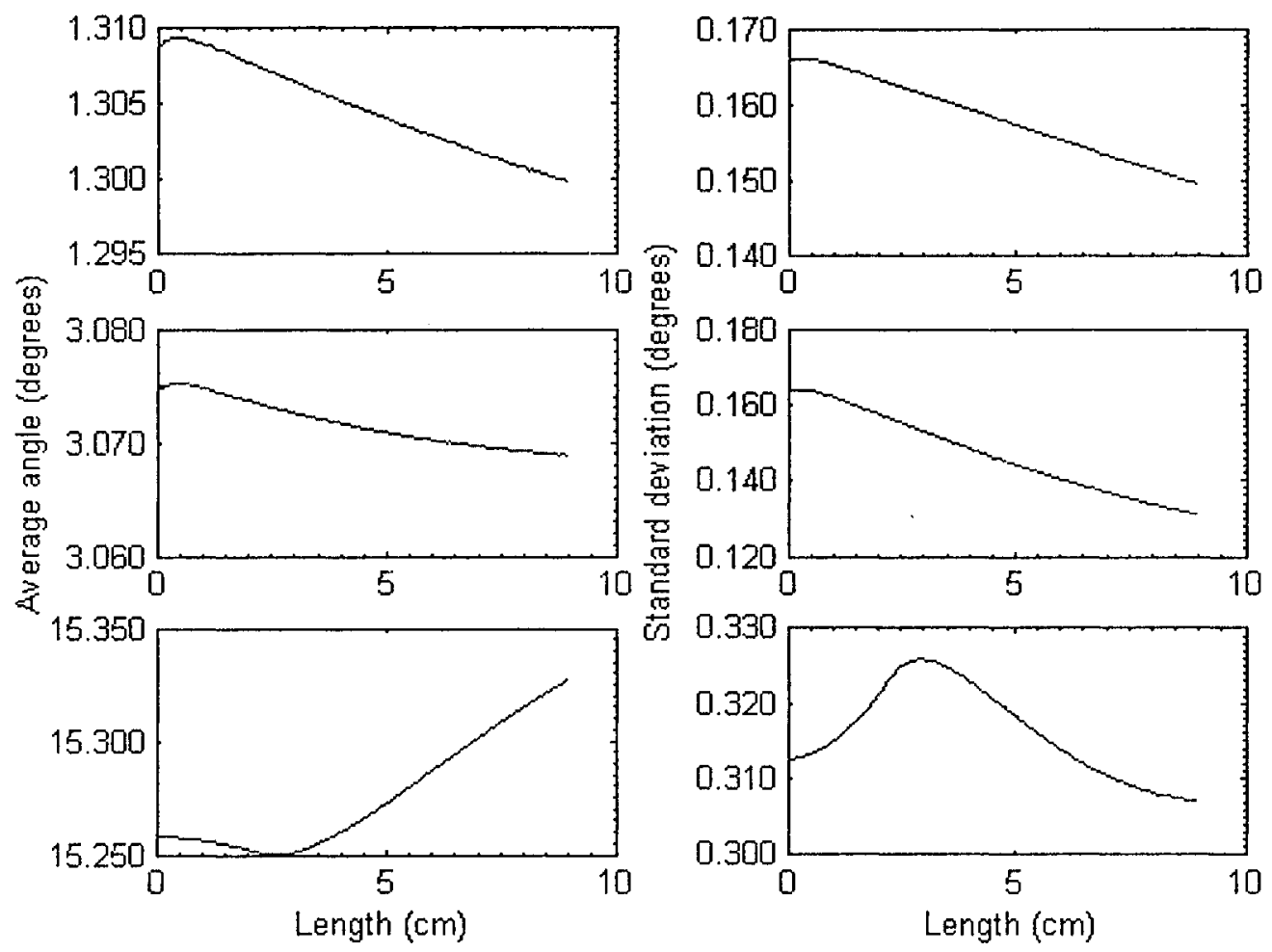

Figure 10. Variation of average angle and $\sigma$ with length of the target . First row: nominal angle $=1^{\circ}$

Second row: nominal angle $=3^{\circ}$

Third row: nominal angle $=15.0^{\circ}$ 


\subsubsection{Effect of aperture radii on average angle and standard deviation}

Table 3 shows the other dimensions of the target that were used in this study.

Table 3. Dimensions of target used to analyze the variation of scatter angle with aperture radii.

\begin{tabular}{|c|c|c|}
\hline Length $(\mathrm{cm})$ & Width $(\mathrm{cm})$ & Height $(\mathrm{cm})$ \\
\hline 7.0 & 2.0 & 1.0 \\
\hline
\end{tabular}

Figure 11 shows how average angle and standard deviation vary with the radius of the aperture. The two apertures had a common radius value.
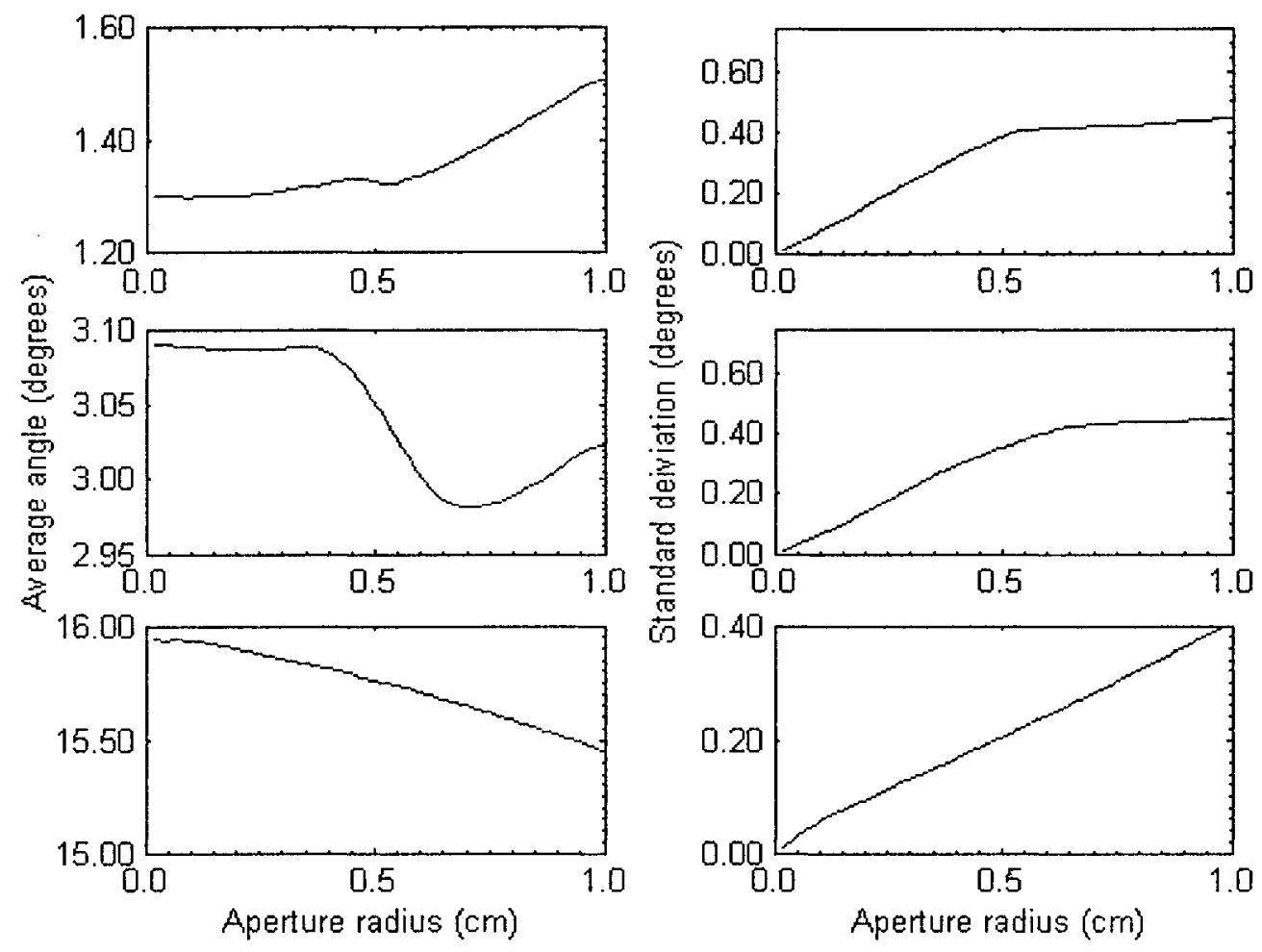

Figure 11. Variation of average angle and $\sigma$ with the aperture radius.

First row: nominal angle $=1^{\circ}$

Second row: nominal angle $=3^{\circ}$

Third row: nominal angle $=15.0^{\circ}$

In the first row of Figure 11 shows that the average scatter angle increases slowly as the aperture radii are increased and after a particular value of the radii $(0.55 \mathrm{~cm})$ it starts 
increasing. This is because as the aperture radii are increased more and more parts of the target are illuminated at the same time the detector is getting more and more scatter photon which is causing the variation in scatter angle as the number of voxels covered by the cone is increased. The standard deviation consequently goes up but after particular radius $0.6 \mathrm{~cm}$ it makes plateau because even though the radii are increased, it is covering maximum volume of the target and scatter angle variation remains the same as the number inside that volume remains the same.

The second row of Figure 11 shows that the average scatter angle remains steady at the beginning and gradually goes down after the radii of $0.45 \mathrm{~cm}$ and then goes up. The standard deviation of the angle have the same as the previous one. The third row in Figure 11 also shows the average angle gradually decreases with the increment of the radii of the aperture. This is because the number of voxel is covered by the cone of the $x$ ray tube and detector is increased much as comparison to the variation of scatter angles created by these voxels.

\subsection{Selection of the Target Dimension and Aperture radii}

Analysis shows that the width and length of the target do not affect the average angle and standard deviation significantly. But height has significant effect on the standard deviation. However, fixing target dimensions can make problem to illuminate it exactly all over its surface. It might be done with rectangular apertures. However, the easy way to do it is by using two circular defining apertures: one at the source side to illuminate a particular part of the target, and the other one to allow the scattered beam to go to the 
detector. That is why the study of variation of average angle and standard deviation with aperture radii was done. The dimensions of the target were chosen from the study of the standard deviations of the scatter angle. It was found that at the higher values of length of the target the standard deviation is lower. This is why the common length was chosen to be $7 \mathrm{~cm}$ for all the angles. The width and height of the target do not come into consideration here as the aperture in front of the target is defining the area of illumination of the target. Thus width and height were chosen so that the face of the target covers the aperture hole completely. These dimensions are given in chapter 4. Fixing these dimensions the three scatter angles were calculated which are different than the nominal ones as shown in table 1 . Table 4 summarizes the $\mathrm{x}$ ray spectra that were used in the experiment, the energy range of the spectra, the optimized scattering angles, offsets that are creating the scatter angle and the corresponding $\mathrm{x}$ ranges that each of those spectra covering.

Table 4. Summary of $x$ ray spectrum, energy ranges, scatter angles and $x$ ranges.

\begin{tabular}{|c|c|c|c|c|c|c|}
\hline Spectrum & $\begin{array}{l}\text { Energy } \\
\text { range of } \\
\text { Photon } \\
(\mathrm{keV})\end{array}$ & $\mathrm{H}$, offset & Average & Standard & $\mathrm{x}$-range $\left(\mathrm{nm}^{-1}\right)$ & Standard \\
& & & & & & deviation \\
& & & & & & \\
\hline $86 \mathrm{kV}$ & $17-75$ & 0.77 & $\left.1.32^{\circ}\right)$ & $0.16^{\circ}$ & $0.15 \leq \mathrm{x} \leq 0.68$ & 0.11 \\
\hline $106 \mathrm{kV}$ & $17-100$ & 1.83 & $3.13^{\circ}$ & $0.17^{\circ}$ & $0.40 \leq \mathrm{x} \leq 2.23$ & 0.12 \\
\hline $121 \mathrm{kV}$ & $17-110$ & 9.57 & $15.41^{\circ}$ & $0.31^{\circ}$ & $1.83 \leq \mathrm{x} \leq 11.87$ & 0.21 \\
\hline
\end{tabular}


In addition to these three spectra, a fourth spectrum was also obtained at $4.31^{\circ}$ scatter angle and $113 \mathrm{kV}$ of the tube potential as a check on the other three spectra. The angle of the fourth spectrum was obtained by placing the target at the $3.1^{\circ}$ angle position and moving the whole aperture assembly $1 \mathrm{~mm}$ transversely.

The next chapter describes the optimum dimensions of the target and the aperture radii, and the offsets of the target. 


\section{Chapter 4}

\section{Apparatus and Materials}

This chapter describes the apparatus that has been used to carry out this experiment. It also illustrates the operational method of the experiment.

\subsection{Top view of the experimental setup:}

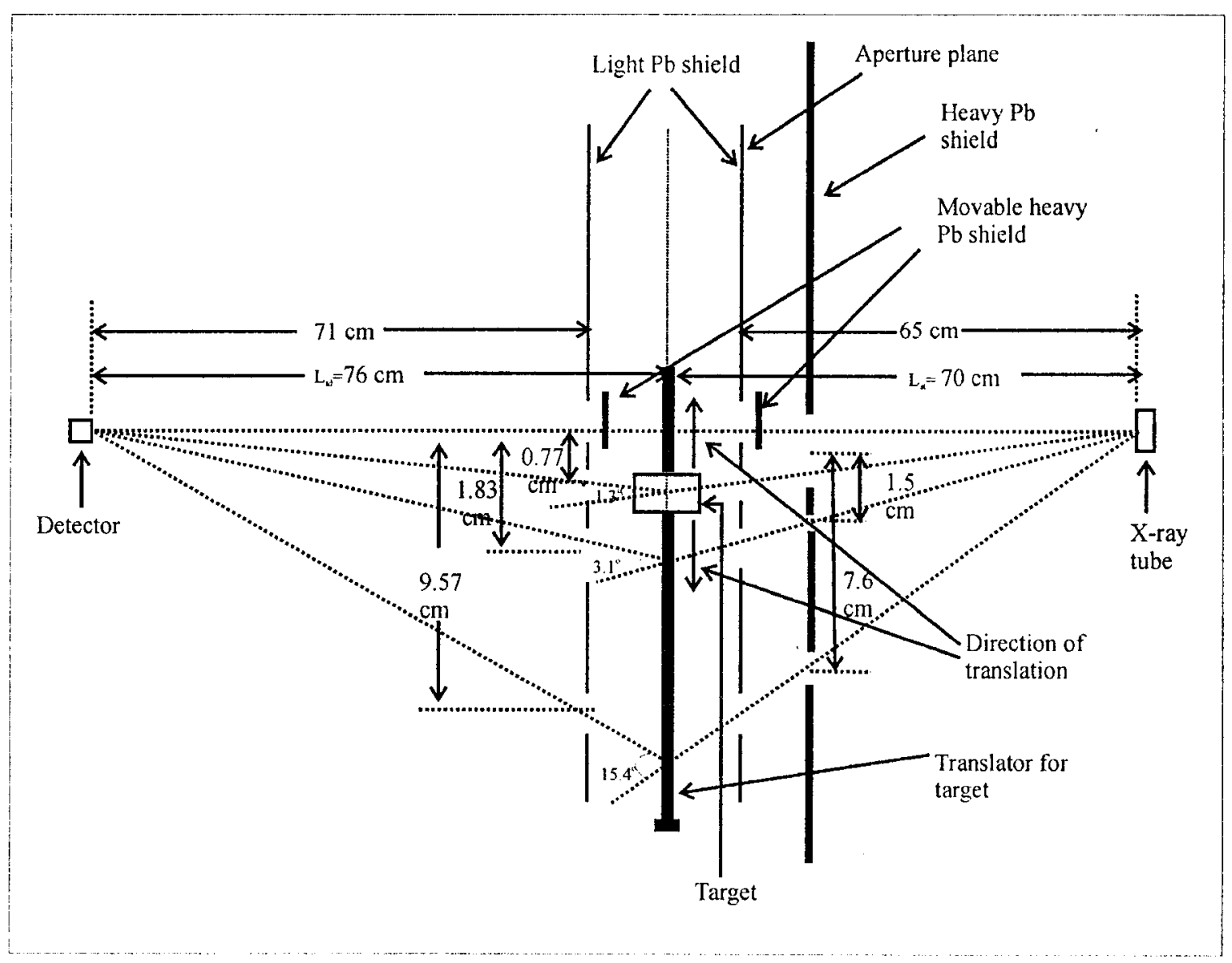

Figure 12. Schematic of experimental setup, top view.

\subsection{Description of apparatus}

The following is a discussion of the apparatus that has been used in the experiment. 


\section{$\mathrm{X}$-ray tube and generator}

X-ray tube $\quad: \quad$ Machlett Dynamax rotating W-anode (model 62R)

Focal spot size $=1.2 \times 1.2 \mathrm{~mm}$

X-ray generator $\quad: \quad$ Picker $1-\phi$

X-ray tube current $\quad: \quad 0.2$ to $3 \mathrm{~mA}$

\section{X-ray tube positioning}

The X-ray tube was rotated to in its mounting reduce the heel effect. The heel effect is described briefly in the following discussion. Figure 13 (a) shows the anode of an x-ray tube. As the electron falls on the anode $\mathrm{x}$ rays are produced. Photon $\mathrm{A}$ has to pass through a much greater thickness of anode material before escaping from the $\mathrm{x}$-ray tube than does photon $\mathrm{B}$. This is why the intensity at the anode side ( $\mathrm{x}$ ray $\mathrm{A}$ ) is reduced in comparison to the intensity at the cathode side ( $\mathrm{x}$ ray $\mathrm{B}$ ). As the angle of the anode is increased, the anode heel effect increases. Figure 13 (b) shows the x-ray intensity profile with the position in the $\mathrm{x}$ direction. 


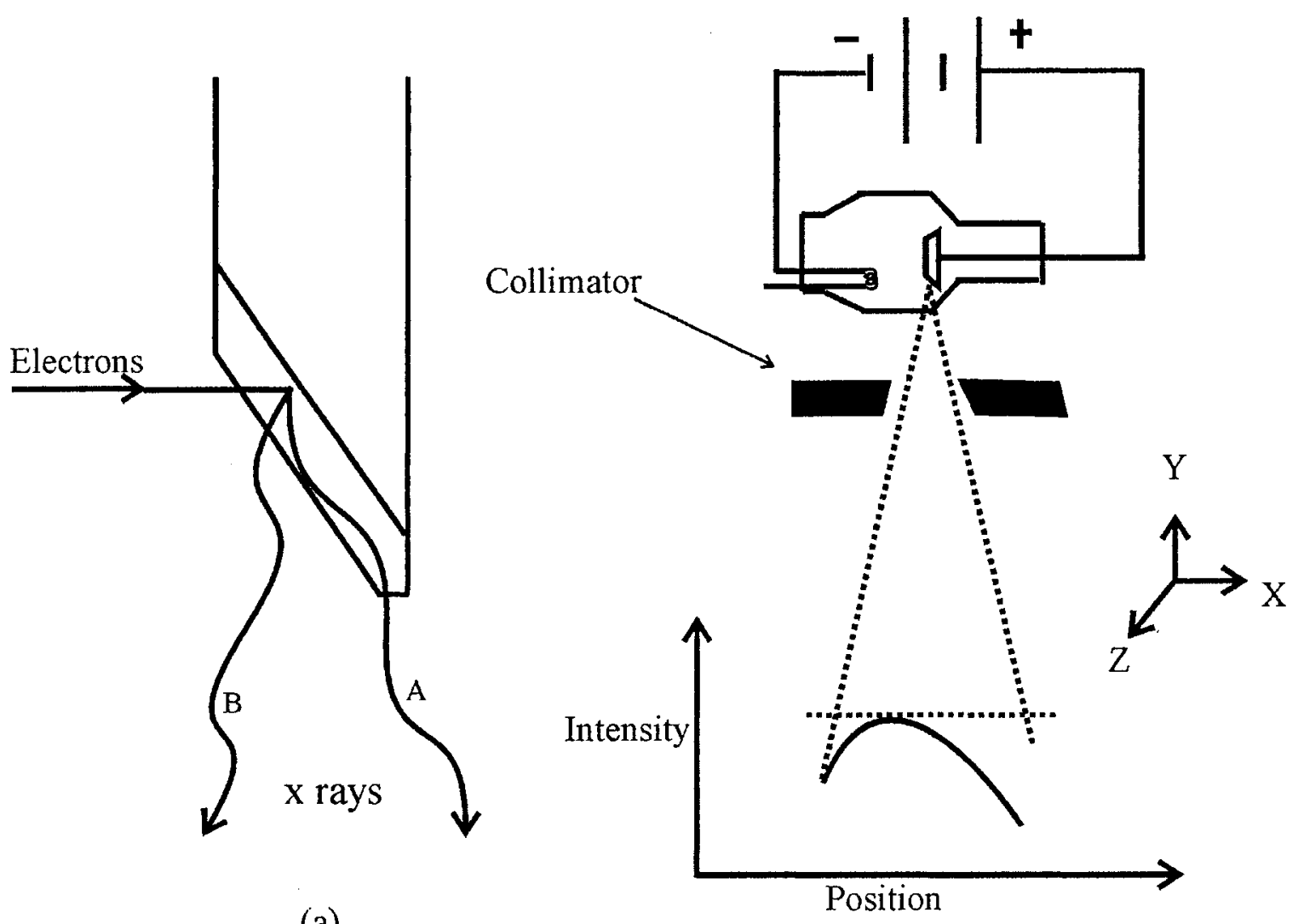

(a)

(b)

Figure 13. Heel effect in $x$-ray tube.

At the beginning the scattering target translation was in the same plane where the heel effect occurred. The tube was rotated $90^{\circ}$ in its mounting along y-axis. This caused the heel effect to occur perpendicular to the plane of the target and the target translation did not see the heel effect caused by the anode.

\section{X-ray tube current measurement}

$\mathrm{X}$-ray tube current measurement was an important factor in form factor measurement. A voltage divider (Varian-Dynalyzer) was used for the accurate measurement of tube 
current. Figure 14 shows how the voltage divider was connected between the x-ray tube and power generator.

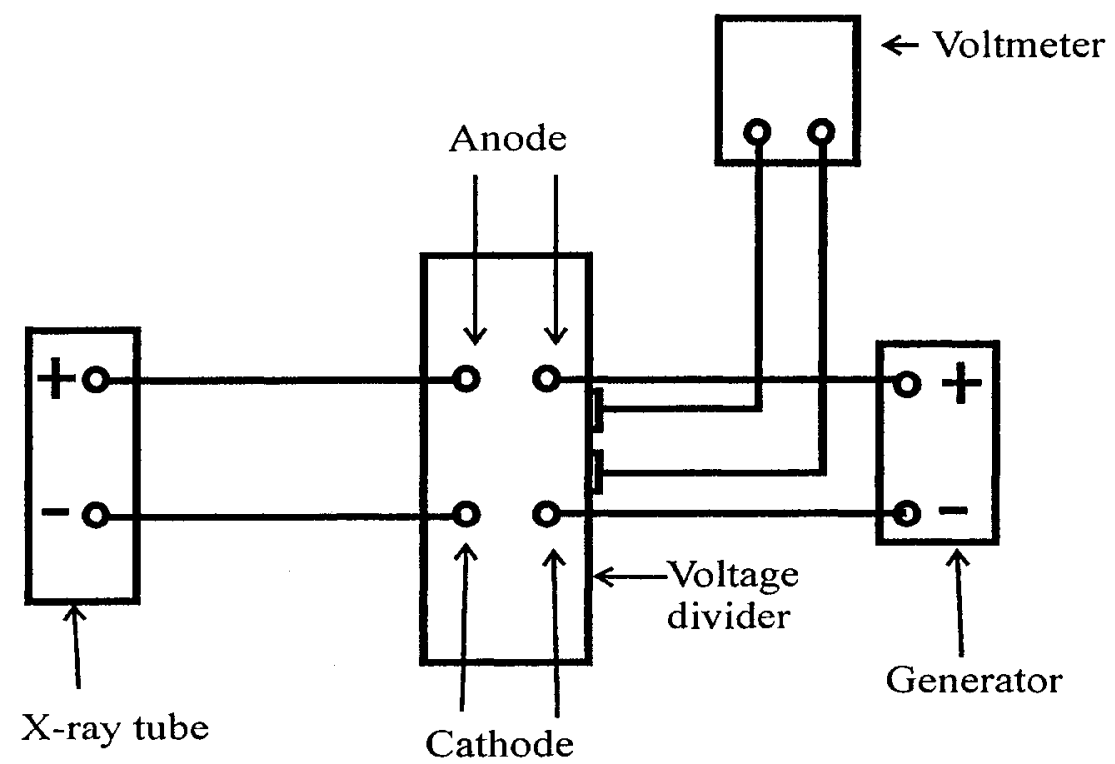

Figure 14. Schematic of connection of $\mathrm{x}$-ray voltage generator, voltage divider and $\mathrm{x}$-ray tube.

\section{Shielding and collimator}

Heavy lead shield: A heavy lead shield (6 $\mathrm{mm}$ thick) was placed after the $\mathrm{x}$-ray tube as shown in Figure 12. It is $70 \mathrm{~cm}$ high and $55 \mathrm{~cm}$ wide. It has three holes through it having diameters $1.6 \mathrm{~cm}, 0.32 \mathrm{~cm}$ and $0.8 \mathrm{~cm}$ as shown in Figure 12 . 


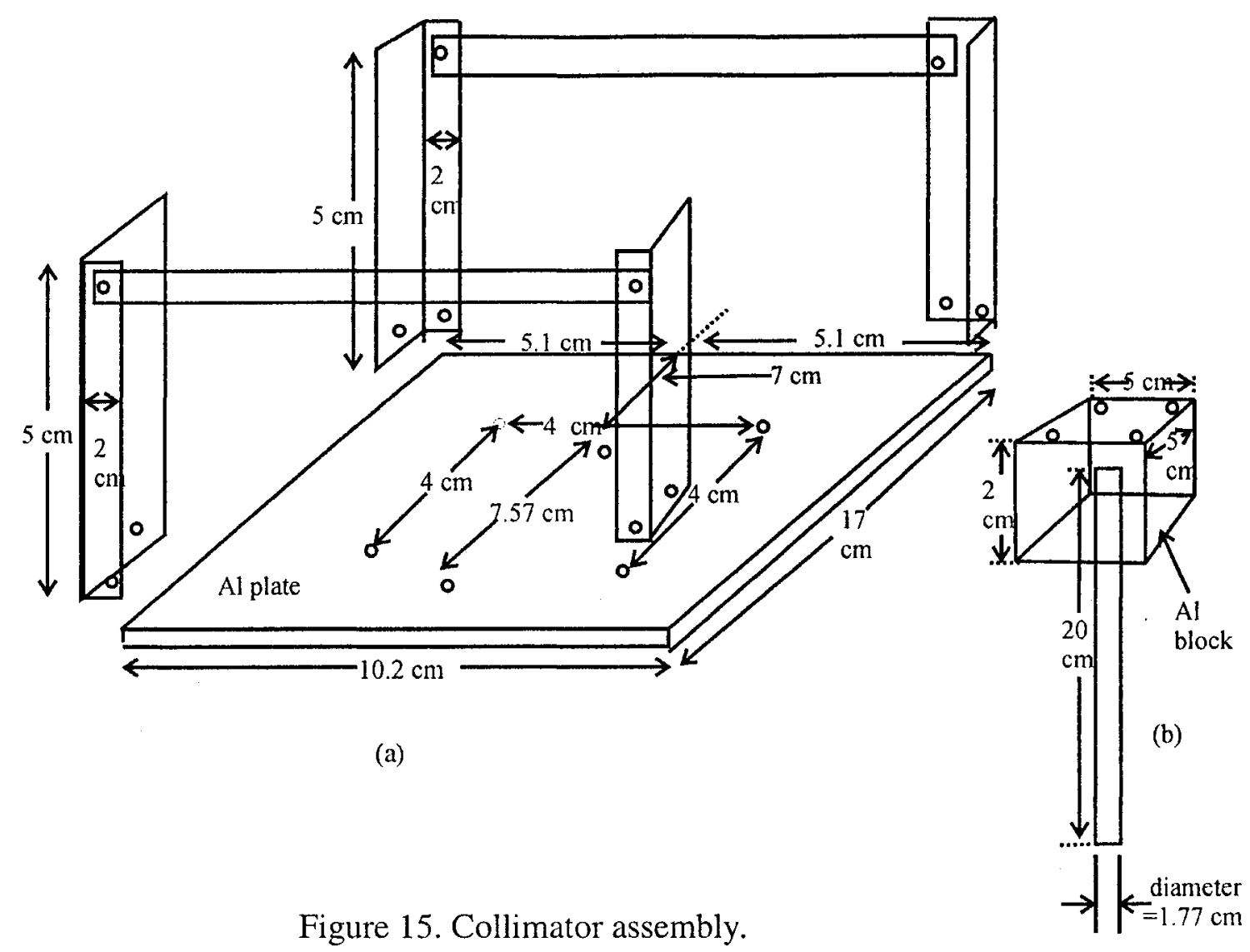

Collimator: Figure 12 shows two light lead shields $(2 \mathrm{~mm}$ thick) before and after the target which made the collimator assembly. Figure 15(a) shows the detailed view of the collimator assembly. Four L-shaped aluminum bars are attached to a thick $(0.6 \mathrm{~cm}) \mathrm{Al}$ plate to make the assembly. Screws were used to attach these bars with the Al plate through the holes shown as circles in Figure 15(a). Each two of those bars was again supported by two other aluminum bars as shown to make the assembly strong. The two lead sheets of $2 \mathrm{~mm}$ thick as shown in Figure 12 were placed on the left and right sides of the assembly. Each of the lead sheets has four holes on it as given in Figure 12. Table 5 summarizes the diameters of each of these holes as a result of the geometry optimization in Chapter 3. 
Table 5. The diameters of the holes in the lead sheets.

\begin{tabular}{|l|c|c|c|c|}
\hline & $\begin{array}{l}\text { Aperture } \\
\text { diameter for } \\
\text { primary }(\mathrm{mm})\end{array}$ & $\begin{array}{l}\text { Aperture } \\
\text { diameter for } \\
1.32^{\circ} \text { scatter } \\
\text { angle (mm) }\end{array}$ & $\begin{array}{l}\text { Aperture } \\
\text { diameter for } \\
3.13^{\circ} \text { scatter } \\
\text { angle (mm) }\end{array}$ & $\begin{array}{l}\text { Aperture } \\
\text { diameter for } \\
15.41^{\circ} \text { scatter } \\
\text { angle }(\mathrm{mm})\end{array}$ \\
\hline $\begin{array}{l}\text { Lead shield on } \\
\text { the source side } \\
\text { in Figure 12 }\end{array}$ & 1.0 & 2.0 & 2.0 & 8.0 \\
\hline $\begin{array}{l}\text { Lead sheet on } \\
\text { the detector side } \\
\text { in Figure 12 }\end{array}$ & 1.0 & 2.0 & 2.0 & 10.0 \\
\hline
\end{tabular}

Figure 15(b) shows the assembly holder. The holder was made from an Al block of dimensions $5 \mathrm{~cm} \times 5 \mathrm{~cm} \times 2 \mathrm{~cm}$ shown in Figure 15. A $20 \mathrm{~cm}$ metal rod of $1.77 \mathrm{~cm}$ diameter was inserted inside the Al block. The metal block was finally mounted to the optical bench.

The holder in Figure 15(b) was attached with screws to the Al plate in Figure 15(a) through the four holes. The two other holes in the mid line of the Al plate in Figure 15(a) were to attach the translator to move the target to different transverse positions.

\section{Target dimension and materials}

Geometry has been optimized and results are shown in Chapter 3. The chosen dimensions of the target are:

Length: $\quad \quad \quad 7.0 \mathrm{~cm}$

Height: $\quad 1.0 \mathrm{~cm}$

Width: $\quad 2.0 \mathrm{~cm}$ 
Electron densities of the target materials have been calculated [Ref [1],Table A-3b, A-3f, A-3g]. Table 6 below shows the values for the six target materials with their chemical formula, mass density, electron per unit mass, and electron density.

Table 6. Name and chemical formula of target materials

\begin{tabular}{|l|l|l|l|l|}
\hline Name of the & Chemical & Mass density, $\rho$ & Electrons per unit & Electron \\
target material & formula & $\left(\mathrm{g} \mathrm{cm}^{-3}\right)$ & $\left.\mathrm{g}^{-1}\right)$ & $\begin{array}{l}\text { density } \\
\left(\mathrm{cm}^{-3}\right)\end{array}$ \\
\hline Water & $\mathrm{H}_{2} \mathrm{O}$ & 0.998 & $0.334 \times 10^{23}$ & $3.343 \times 10^{23}$ \\
\hline Polyethylene & $\left(\mathrm{C}_{2} \mathrm{H}_{4}\right)_{\mathrm{n}}$ & 0.920 & $0.343 \times 10^{23}$ & $3.16 \times 10^{23}$ \\
\hline Polystyrene & $\left(\mathrm{C}_{8} \mathrm{H}_{8}\right)_{\mathrm{n}}$ & 1.04 & $0.324 \times 10^{23}$ & $3.38 \times 10^{23}$ \\
\hline Lexan & $\left(\mathrm{C}_{16} \mathrm{H}_{14} \mathrm{O}_{3}\right)_{\mathrm{n}}$ & 1.20 & $0.317 \times 10^{23}$ & $3.81 \times 10^{23}$ \\
\hline Nylon & $\left(\mathrm{C}_{6} \mathrm{H}_{11} \mathrm{NO}_{\mathrm{n}}\right.$ & 1.13 & $0.329 \times 10^{23}$ & $3.65 \times 10^{23}$ \\
\hline PMMA & $\left(\mathrm{C}_{5} \mathrm{H}_{8} \mathrm{O}_{2}\right)_{\mathrm{n}}$ & 1.18 & $0.325 \times 10^{23}$ & $3.83 \times 10^{23}$ \\
\hline
\end{tabular}

${ }^{a}$ Polymethylmethacrylate (trade names: Lucite, Perspex, Plexiglas)

\section{Target holder}

Figure 16 shows the target holder that was built to hold the different target materials. The holder was built using five plastic sheets of $0.5 \mathrm{~cm}$ thick. The outer wall dimensions were 


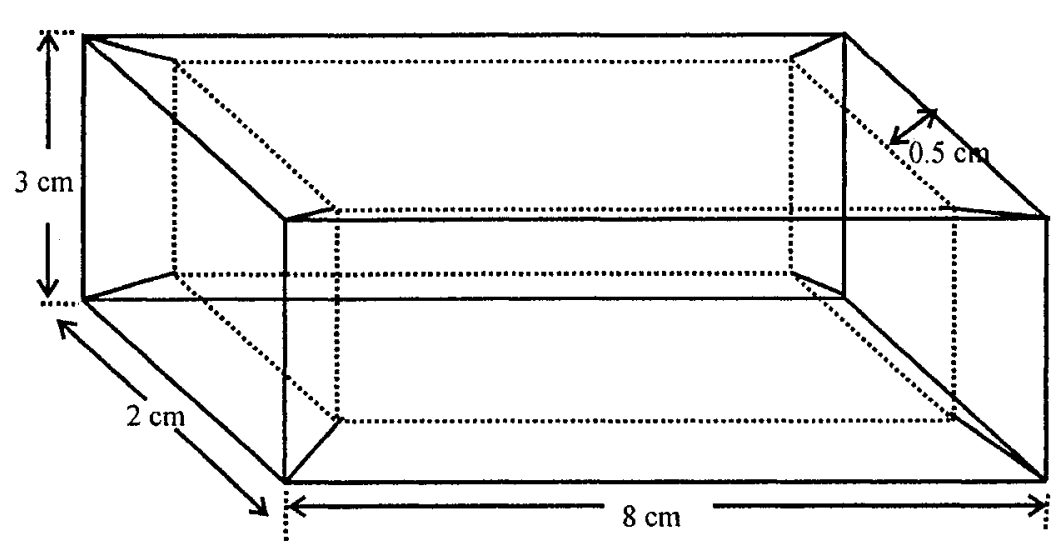

(a) Perspective view

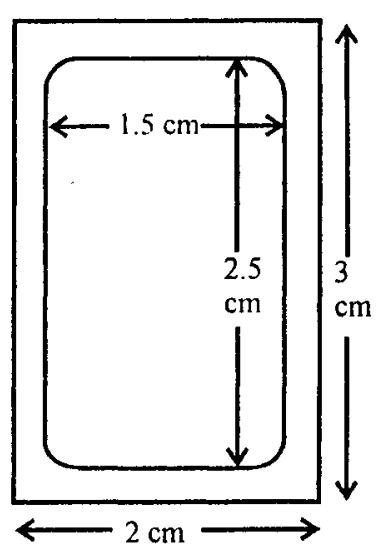

(b) End view

Figure 16. Target holder.

$8 \mathrm{~cm} \times 2 \mathrm{~cm} \times 3 \mathrm{~cm}$. The entrance and exit windows were milled to be $0.2 \mathrm{~cm}$ thick.

\section{Support for Target Holder}

Figures 17(a) (cross sectional view) and (b) show the notch inside the holder that was made to hold the target holder. The notch was attached with the translator, which moved

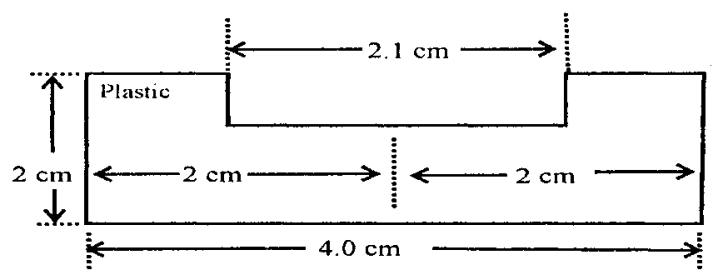

(a)

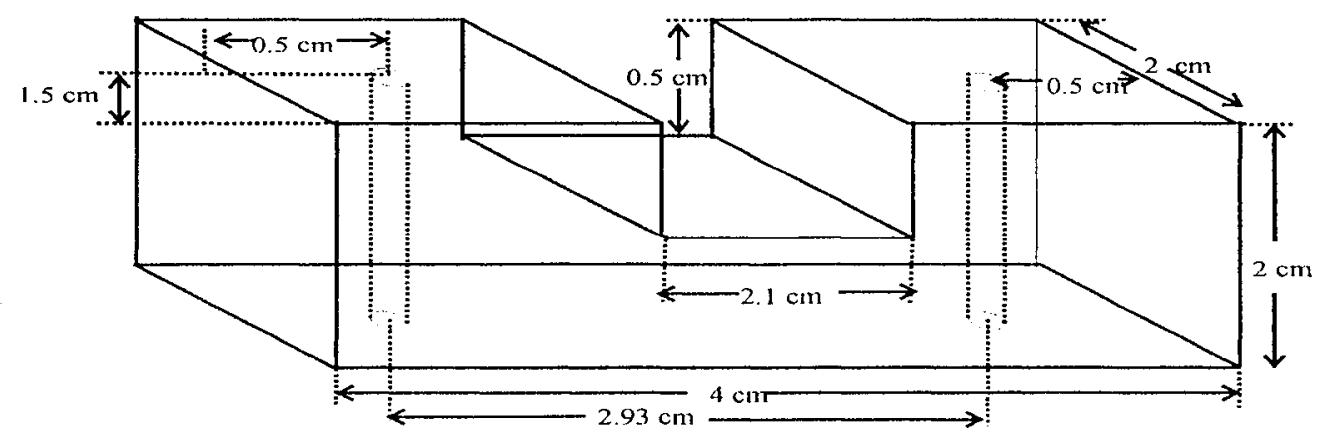

(b)

Figure 17. Support for target holder 
the target. The notch was $2.1 \mathrm{~cm}$ in width and $3 \mathrm{~cm}$ in length and $0.5 \mathrm{~cm}$ in height so that it could exactly hold the target container. Figure 18 shows the translator, target holder and target together for better visualization of the geometry.

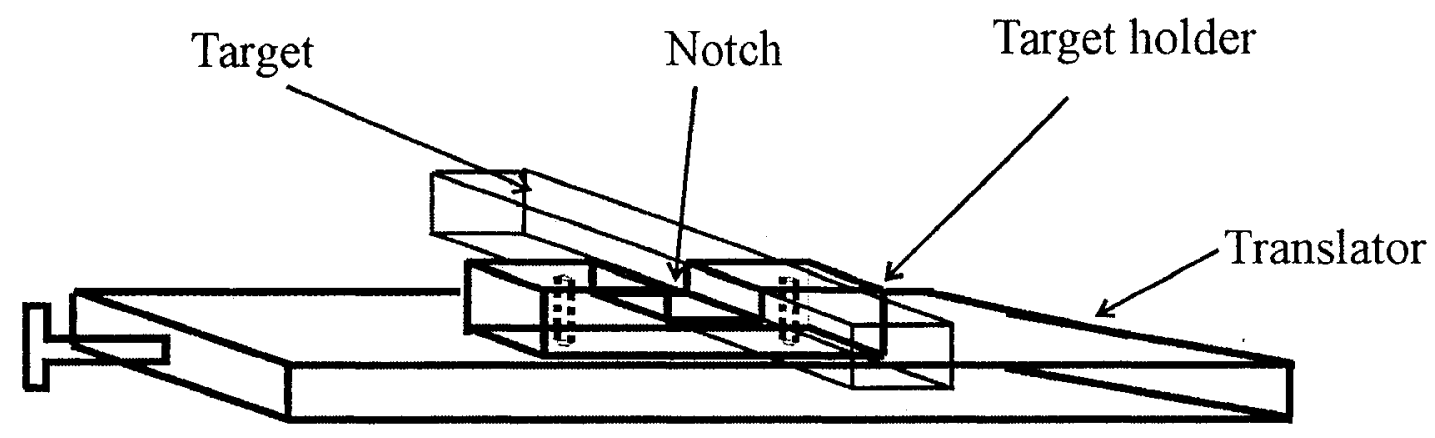

Figure 18. Translator, target holder and target.

Detector $\quad$ : $\quad$ Ortec high purity Ge (LEPS) (model GLP 16195/10-P) -beryllium entrance window, thickness $=0.127 \mathrm{~mm}$ -active diameter $=16 \mathrm{~mm}$ -sensitive thickness $=10 \mathrm{~mm}$ -energy range $=3 \mathrm{keV}-1 \mathrm{MeV}$ -FWHM at $133 \mathrm{keV}=0.495 \mathrm{keV}$

Detector power supply $\quad$ : Ortec high voltage power supply (model 659) - Bias potential $=1500 \mathrm{~V}$ (negative)

Fast Spectroscopy Amplifier: Canberra (model 2024) -input polarity: (-) -output: unipolar -shaping time constant: $2 \mu \mathrm{s}$ 
-baseline restorer: threshold - auto/mode-asymmetric

-coarse gain: 30

-fine gain: 5

-pileup rejecter: unipolar

Analogue to Digital Converter (ADC) : Canberra (model 8077)

-Wilkinson type (450 $\mathrm{MHz}$ clock rate)

-range/gain : $2 \mathrm{k}$

-offsets: off

-peak detect: auto

-pulse height analysis selected

-LLD: $0.86 \mathrm{~V}$

$\begin{array}{ll}\text { Multichannel Analyzer (MCA) } & : \text { Aptec series } 2000 \text { (PCMCA/WIN) } \\ \text { Number of Channels used } & : 1550 \\ \text { Energy per Channel } & : 0.0822 \mathrm{keV}\end{array}$

\subsection{Operation Method}

Radiation produced by the $\mathrm{x}$-ray tube is allowed to fall on the target. For the transmission measurement $\mathrm{x}$ rays were attenuated and fell on the detector. For the scatter measurement because of the diffraction nature of the various targets $x$ rays were scattered and were detected by the detector.

Free charges that are created from thermal energy usually reduce the system resolution significantly. It is a common practice to lower the crystal temperature of the detector to 
eliminate thermally excited free charge. Therefore, the detector system is chilled to $77 \mathrm{~K}$ with liquid nitrogen to ensure that the free charges being created are due to $\mathrm{x}$-ray interaction with the crystal. The liquid nitrogen is kept in a thermally insulated container called a dewar and the detector has contact with it by a thermally conductive rod called a cryostat.

The free charges that have been created with $\mathrm{x}$-ray interactions are collected by the charge sensitive stage of the preamplifier as high voltage is applied across the detector crystal. The preamplifier then makes a voltage pulse that is proportional to the amount of charge collected.

The signal that has been generated by the preamplifier is reshaped in some predetermined fashion to reduce pulse pileup by the amplifier. To ensure that complete charge collection occurs, preamplifiers are adjusted to provide a decay time for the pulse [23], which is quite long (typically $50 \mu$ s). The pulse is then sent to the Analogue to Digital Converter (ADC), to digitize the pulse amplitude. The Multichannel Analyzer (MCA) then sorts the pulse into a memory location (channel) based on its digitized value. Each new pulse from $\mathrm{ADC}$ to the MCA increments the particular memory location by one count. Our experiment uses 1550 channels over $0-130 \mathrm{keV}$ energy range. 


\section{Chapter 5}

\section{Methods and Results}

This chapter gives the procedure to extract the coherent form factor from the total cross section. It also describes how continuous form factor data were obtained from three different data sets.

\subsection{Acquiring the transmitted and scattered spectra}

Transmitted spectra were obtained by measuring the $\mathrm{x}$ rays that pass through the target.

Figures 19 and 20 show two transmitted spectra (of different tube potentials) of a randomly chosen material (polyethylene). The channel width was $0.082 \mathrm{keV}$. The average acquisition time for each these spectra was 2 minutes.

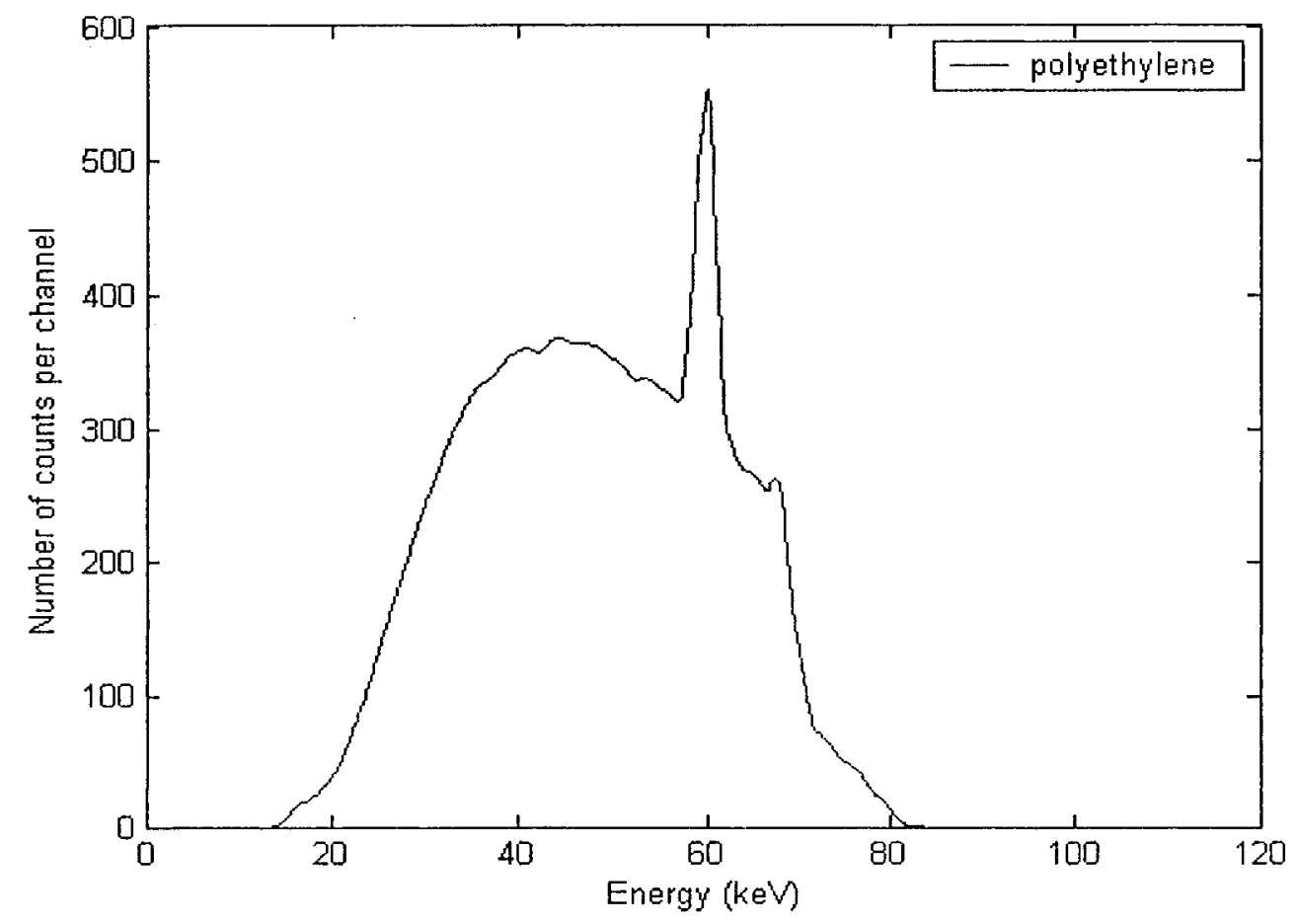

Figure 19. Transmitted $\mathrm{x}$-ray spectrum of tungsten target at $86 \mathrm{kV}$ potential. 


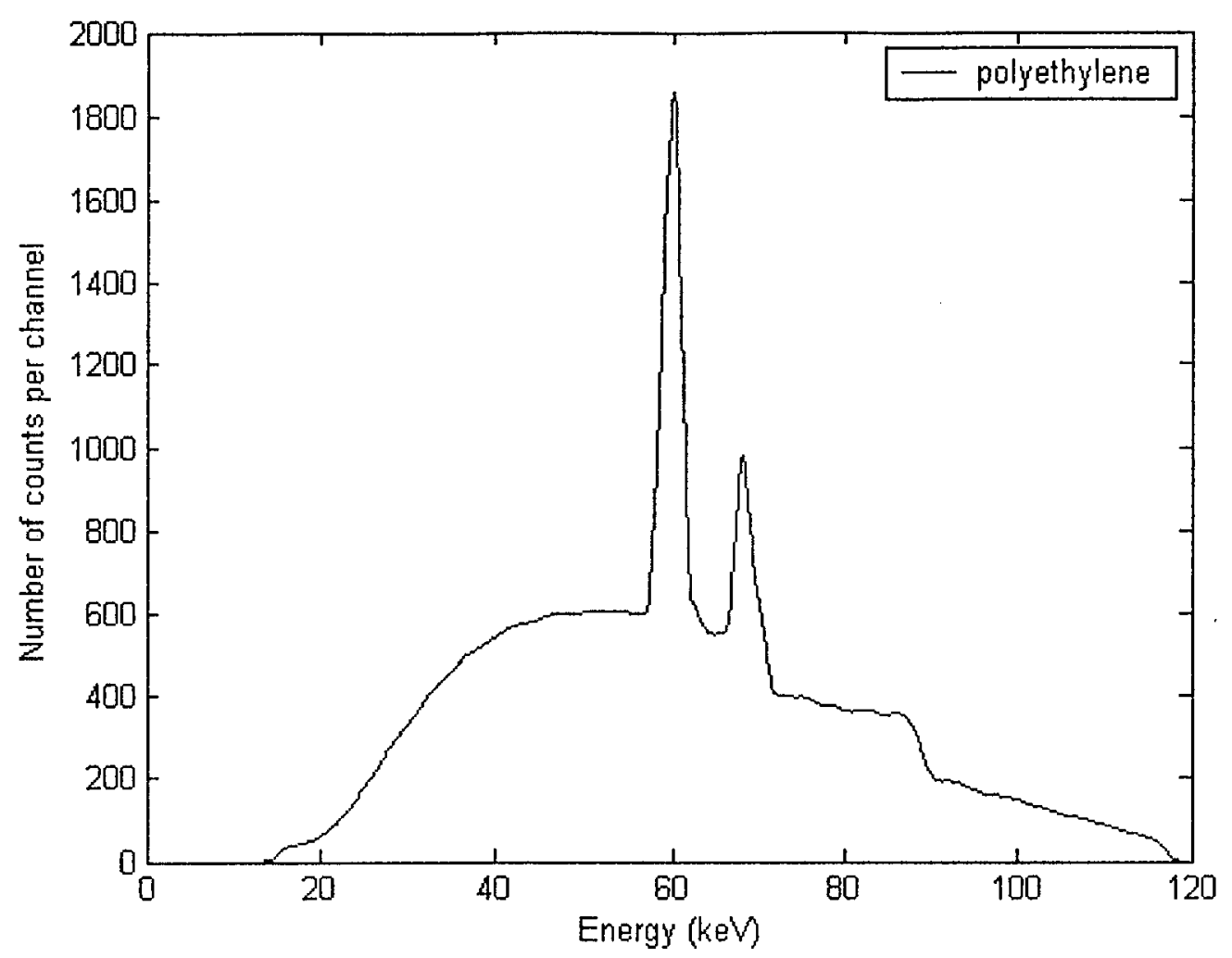

Figure 20. Transmitted $\mathrm{x}$-ray spectrum of tungsten target at $121 \mathrm{kV}$ potential.

Figures 21 and 22 show two scatter polyethylene spectra at obtained at $1.32^{\circ}$ and $15.41^{\circ}$. The corresponding tube potentials were $86 \mathrm{kV}$ and $121 \mathrm{kV}$. The data have been smoothed with a 39-point triangular averaging function. The average acquisition time of each of these spectra was 5 minutes. 


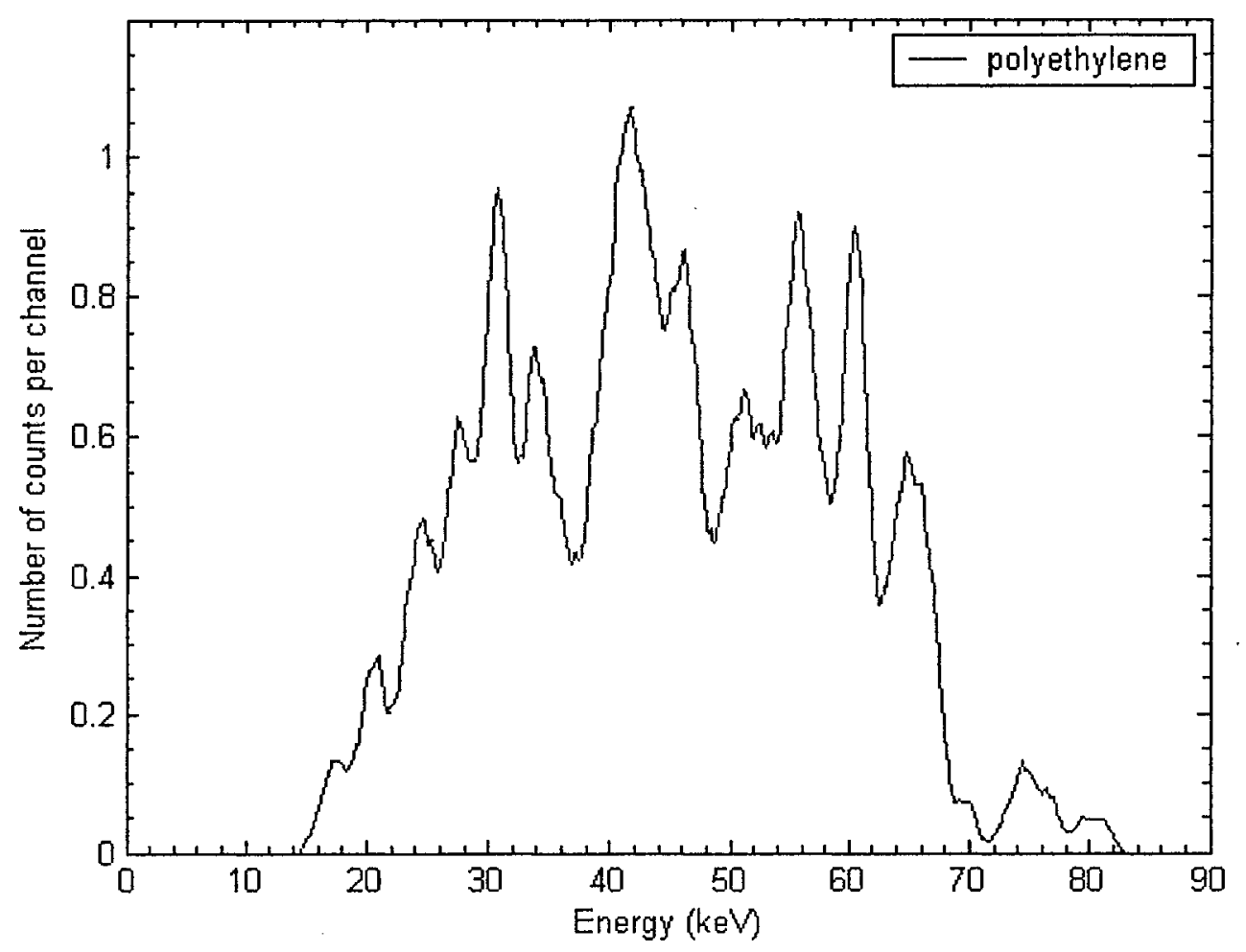

Figure 21. Scatter spectrum of polyethylene at $86 \mathrm{kV}, 1.32^{\circ}$.

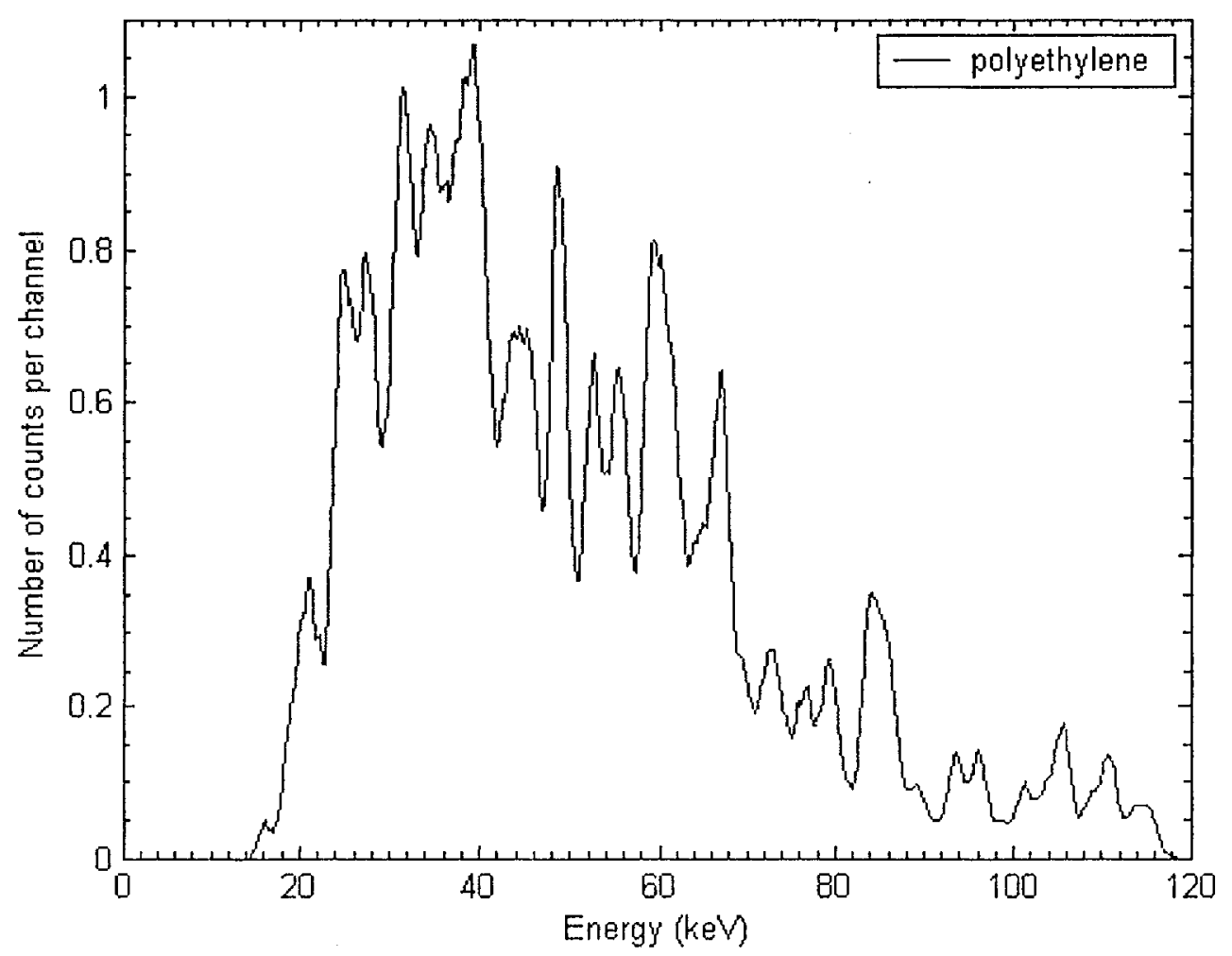

Figure 22. Scatter spectrum of polyethylene at $121 \mathrm{kV}, 15.41^{\circ}$. 
The average transmission photon count rate was $120 \mathrm{~s}^{-1}$. The average exposure time for the measurement of the transmitted signals was 2 minutes. All these spectra have been smoothed by a 39 point averaging function. Initially the holes for primary in the aperture arrangement as shown in the Figure 13 of chapter 4 were aligned with the focal spot of the $\mathrm{x}$-ray tube using a laser pointer. To make it more precise alignment was done in the primary $\mathrm{x}$-ray beam direction measuring the photon count rate. The primary hole of the aperture arrangement was translated gently toward right and left and at the same time count rate was checked for each position of the primary hole. The position which gave the maximum count rate was chosen for transmitted measurement with the target at zero degree angle with the $\mathrm{x}$-ray beam.

The scatter spectra were obtained by measuring the x-rays that are scattered at various angles. Six target materials have been used in this experiment. The three common angles at which the scattering was done are given in Table 4 . The average photon count rates for scatter measurement were $2.472 \mathrm{~s}^{-1}$ for $1.3^{\circ}, 6.064 \mathrm{~s}^{-1}$ for $3.1^{\circ}$ and $4.263 \mathrm{~s}^{-1}$ for $15.4^{\circ}$. The count rates varied due to the different tube potential applied at the different scatter angle [Table 4]. The average exposure time for the scatter signal was 5 minutes. The alignment for scatter signal was based on the primary alignment. The holes in the aperture arrangement were built in such a way that once the primary holes were aligned exactly with the x-ray focal spot, the other holes would go at those particular angular positions. Only the target was moved transversely to get those desired angles. After each of the scatter signal was taken the target was removed from the translator and the $\mathrm{x}$-ray machine was run at the same exposure time at which the scatter signal was taken to get the 
background signal. The background signal was then subtracted from the total scatter signal.

\subsection{Extraction of Coherent Form Factor}

Combining equation (22) and (28) gives,

$$
\begin{aligned}
& \frac{A_{d}^{T}}{\rho_{e} A_{t} d A_{d}^{s} \cos \beta} \frac{\left(L_{s t}^{2}+H^{2}\right)\left(L_{t d}^{2}+H^{2}\right)}{\left(L_{s t}+L_{t d}\right)^{2}} \frac{t^{T}}{t^{s}} \frac{S^{T}}{S^{s}} \frac{N^{s}}{N^{T}}=\frac{r_{o}^{2}}{2}\left(1+\cos ^{2} \theta\right)\left[F_{K N} S(x)+F^{2}(x)\right] \\
& \text { or, } \quad F(x)=\left[\frac{G}{\rho_{e} t^{s}} \frac{S^{T}}{S^{s}} \frac{N^{s}}{N^{T}} \frac{2}{r_{o}^{2}\left(1+\cos ^{2} \theta\right)}-F_{K N} S(x)\right]^{\frac{1}{2}}
\end{aligned}
$$

where, $\mathrm{G}$ is a constant that is coming from the geometrical parameters, and is given by,

$$
G=\frac{A_{d}^{T}}{A_{t} d A_{d}^{s} \cos \beta} \frac{\left(L_{s t}^{2}+H^{2}\right)\left(L_{t d}^{2}+H^{2}\right)}{\left(L_{s t}+L_{t d}\right)^{2}} .
$$

Table 7 shows the calculated values for this geometric constant for the four different offsets which correspond to the four angular positions.

Table 7. Values of constant $\mathrm{G}$.

\begin{tabular}{|c|c|c|}
\hline Scatter angle & H, offset $(\mathrm{cm})$ & Value of $\mathrm{G}\left(\mathrm{cm}^{-1}\right)$ \\
\hline $1.32^{\circ}$ & 0.77 & 60.39 \\
\hline $3.13^{\circ}$ & 1.83 & 60.46 \\
\hline $4.31^{\circ}$ & 2.82 & 60.48 \\
\hline $15.41^{\circ}$ & 9.57 & 62.43 \\
\hline
\end{tabular}


This form factor was extracted with the Matlab program zhfext.m. Equation (33) shows the relationship between the coherent form factor and the scatter to transmission signal ratio and the incoherent form factor. Usually the coherent form factor is extracted by normalizing data in the IAM form factor region [Ref. [20]]. In this experiment, however, all the parameters were known, so rather than using the IAM data the exact values of the geometrical parameters could be used.

\subsubsection{Calculating the electron densities}

The first part of the right hand side of equation (33) has electron density factor, which was calculated and given in Table 6.

\subsubsection{Calculating parameters from the experimental setup}

The various distances such as source to target and target to detector distances, and target length are already given in the chapter $4 . \mathrm{A} 0.5 \mathrm{~cm}$ diameter aperture was placed in front of the detector for the scatter measurement and accordingly a correction factor $A_{d}^{s}$ appeared in equation (33). In transmission measurement a $0.5 \mathrm{~mm}$ diameter of aperture was placed in the light shield on the detector side to reduce the transmitted photon number. The area $\mathrm{A}_{\mathrm{d}}^{\mathrm{T}}$ in equation (33) appears as a correction factor for this.

\subsubsection{Calculating the polarization factor}

A polarization factor appeared in equation (33), which consists of classical electron radius $\mathrm{r}_{\mathrm{o}}{ }^{2}$ which is equal to $7.94 \times 10^{-26} \mathrm{~cm}^{2}$ and $\theta$ which is simply the scatter angle [Table 4]. 


\subsubsection{Calculating scatter to transmission ratio}

The scatter and transmitted count have been obtained by the detector. A function (zhsttr.m, which is called by the main program zhfext.m) calculates the scatter to transmission ratio.

\subsubsection{Correction for tube current}

X-ray tube currents were changed during the time of scatter and transmitted signal measurements. Table 8 shows the various tube currents that were used to measure the transmitted and scatter signal at various tube potentials. The ratios of the tube currents used as a correction factor in equation (33) are also shown.

Table 8. X-ray tube current

\begin{tabular}{|c|c|c|c|}
\hline $\begin{array}{c}\text { Tube potential } \\
(\mathrm{kV})\end{array}$ & $\begin{array}{c}\text { Current for } \\
\text { Transmission }(\mathrm{mA})\end{array}$ & $\begin{array}{c}\text { Current for } \\
\text { Scatter }(\mathrm{mA})\end{array}$ & $\frac{\mathrm{S}^{\mathrm{T}}}{\mathrm{S}^{\mathrm{s}}}$ \\
\hline 86 & 0.15 & 1.15 & 0.13 \\
\hline 106 & 0.20 & 1.25 & 0.16 \\
\hline 113 & 0.20 & 1.25 & 0.16 \\
\hline 121 & 0.20 & 1.25 & 0.16 \\
\hline
\end{tabular}




\subsubsection{Correction for exposure time}

Transmitted and scatter spectra were taken for 2 minutes and 5 minutes respectively. The value that was used for the correction factor $\frac{t^{T}}{t^{s}}$ is therefore 0.4 for all the form factor calculations.

\subsubsection{Calculating Klein-Nishina coefficient}

The second part of equation (33) consists of Klein-Nishina coefficient. A function zhklnis.m inside the main program calculates this coefficient. The function needs energy and scatter angle as input and it gives the corresponding coefficient as output.

\subsubsection{Incoherent form factor}

Since the incoherent form factor has been tabulated by the previous investigators (such as, Hubbell et al [7]), the main program zhfext.m reads the factors from the tables of the particular range of $\mathrm{x}$ (momentum transfer parameter) which corresponds to particular angle and interpolating points inside it to make it equal to the number of data set of scatter to transmission ratio. Figures 23-24 show the incoherent form factor of the six different types of material which were used to extract the coherent form factor. 


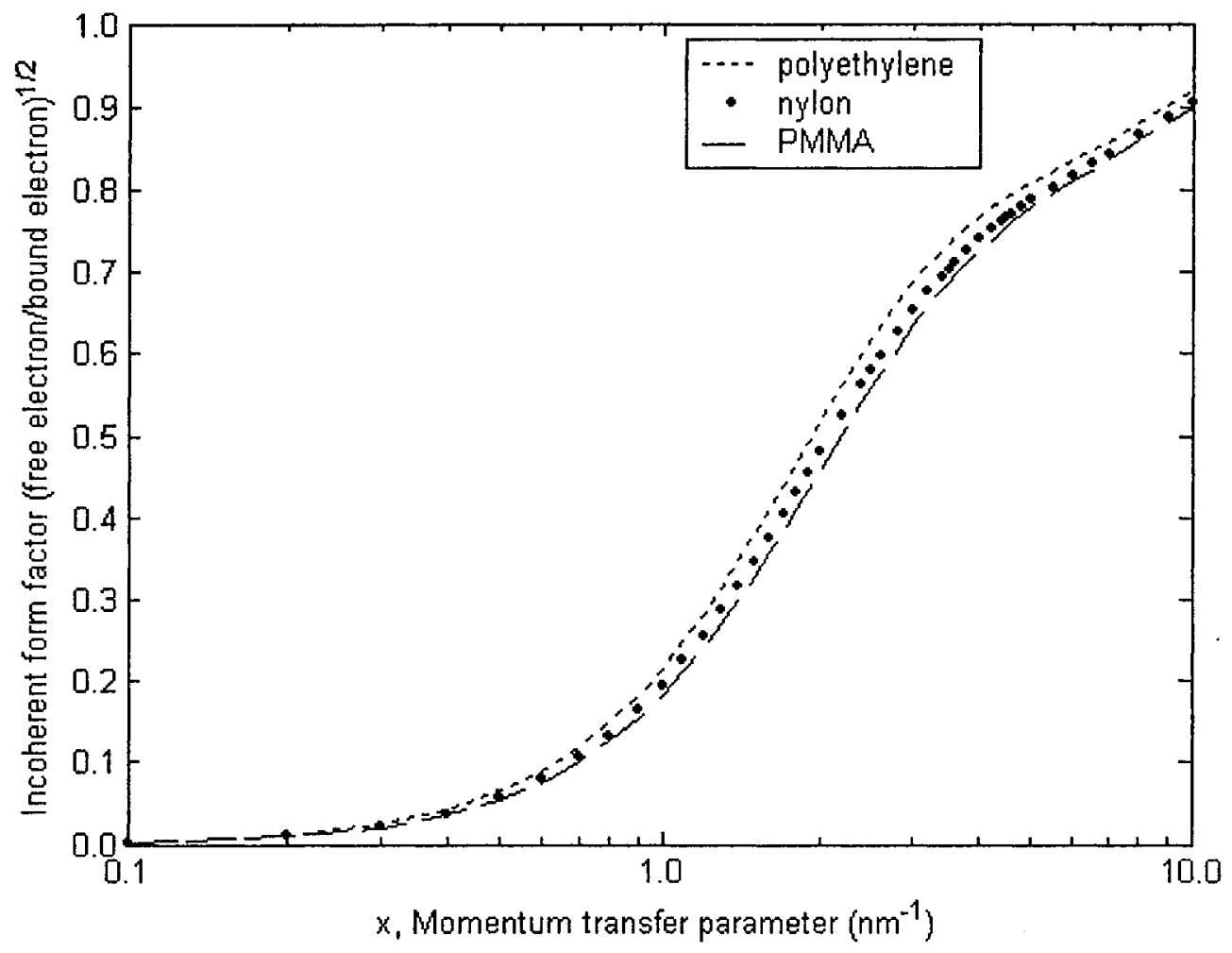

Figure 23. Incoherent form factors for polyethylene, nylon, PMMA [7].

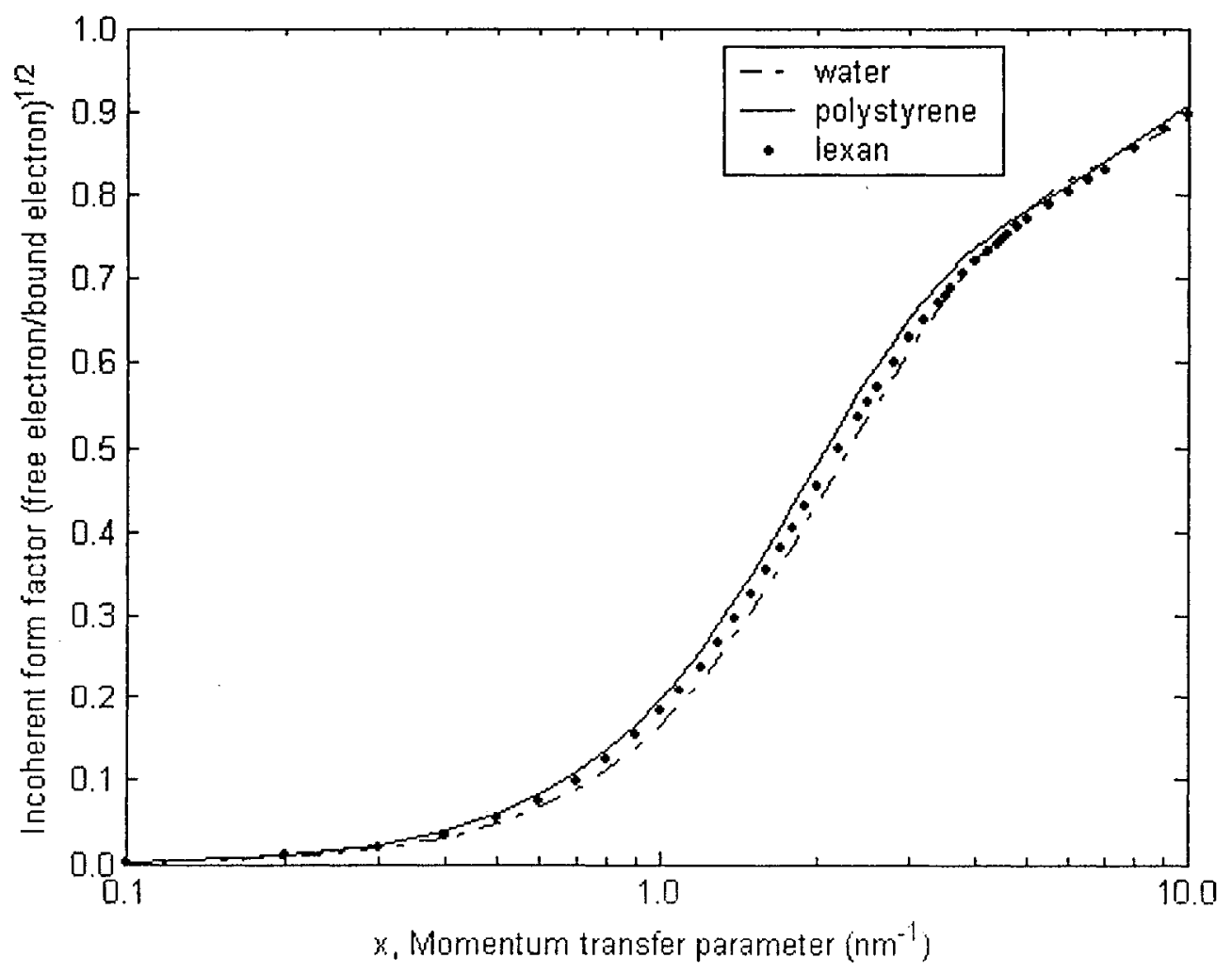

Figure 24. Incoherent form factors for water, polystyrene, and lexan [7]. 


\subsubsection{Subtraction of incoherent form factor}

A function zhtotins.m inside the main program zhfext.m subtracted the product of incoherent form factor and Klein-Nishina factor from the total cross section i.e. the left part of the right hand side of equation (33). Ultimately the main program is doing the square root of the subtracted quantity to make the coherent form factor and plotting it against the corresponding momentum transfer parameter expressed in $\mathrm{nm}^{-1}$.

\subsection{Results}

Figures 25-30 show the form factor results as plotted by main program zhfext.m. Each of these plots contains four form factor datasets as obtained from different scattering angles and different potentials. The fourth dataset comes from the scatter measurement at $4.3^{\circ}$ at $113 \mathrm{kV}$ tube potential. This was done to check the other data.

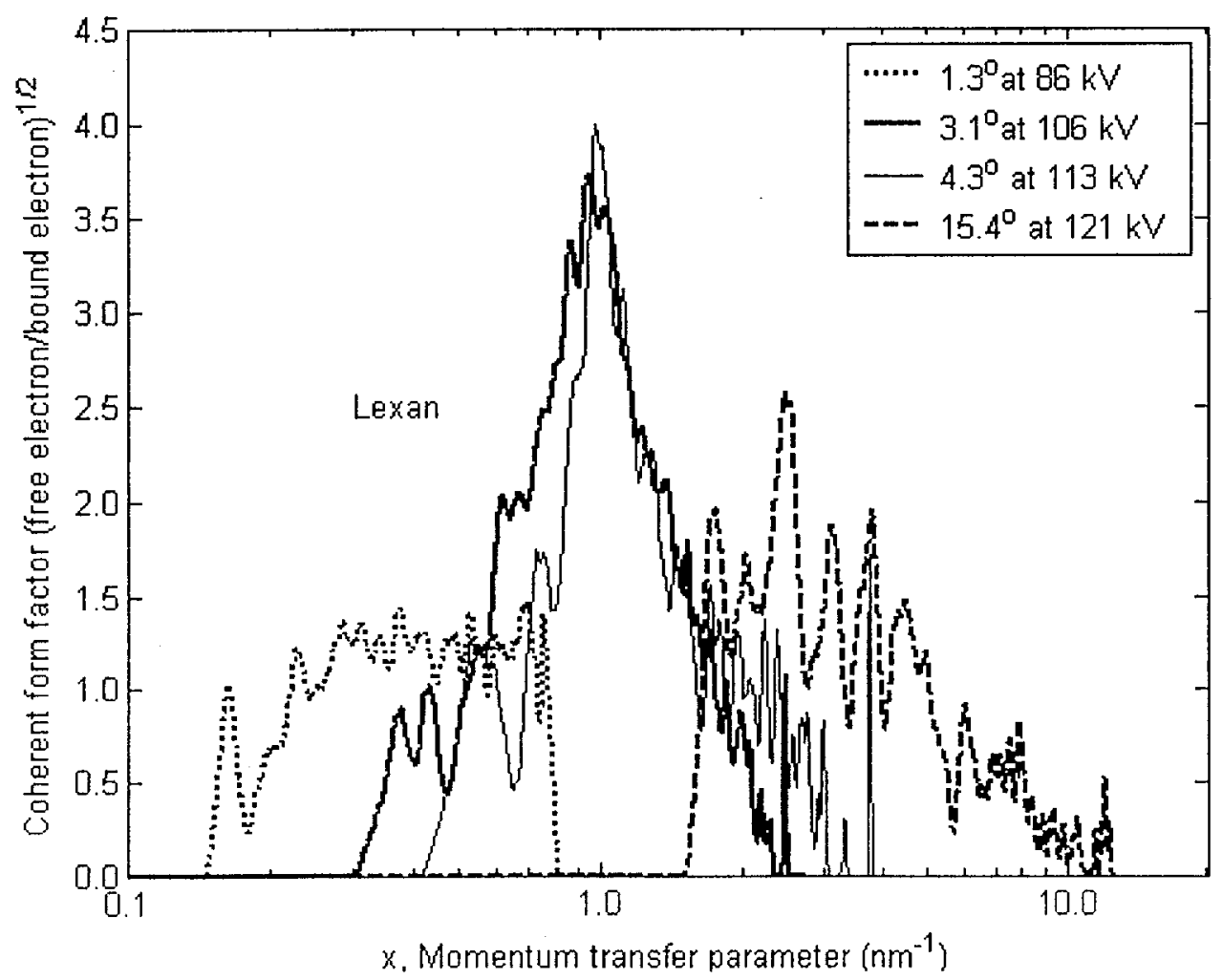

Figure 25. Form factors of lexan at different angles and potentials. 


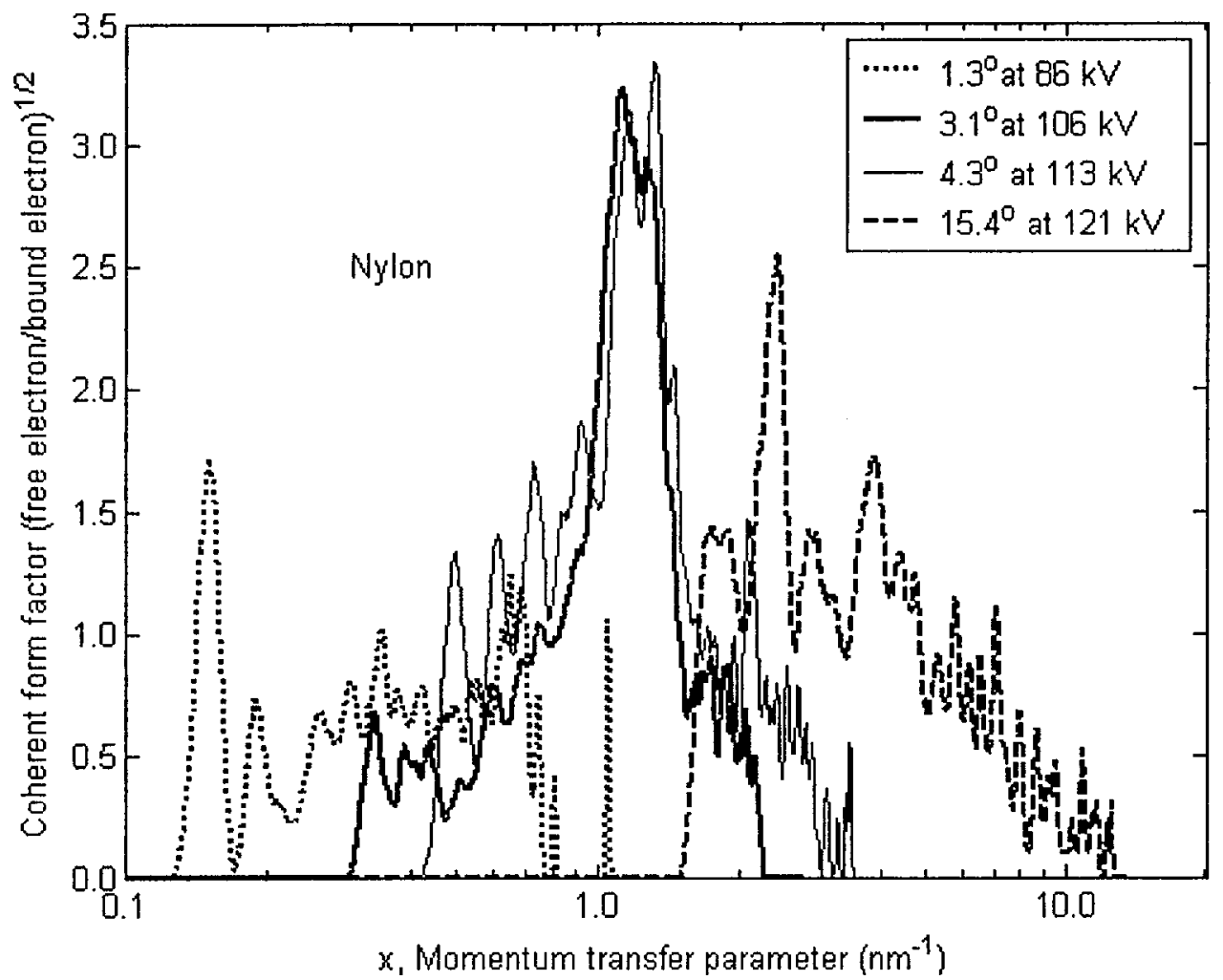

Figure 26. Form factors of nylon at different angles and potentials.

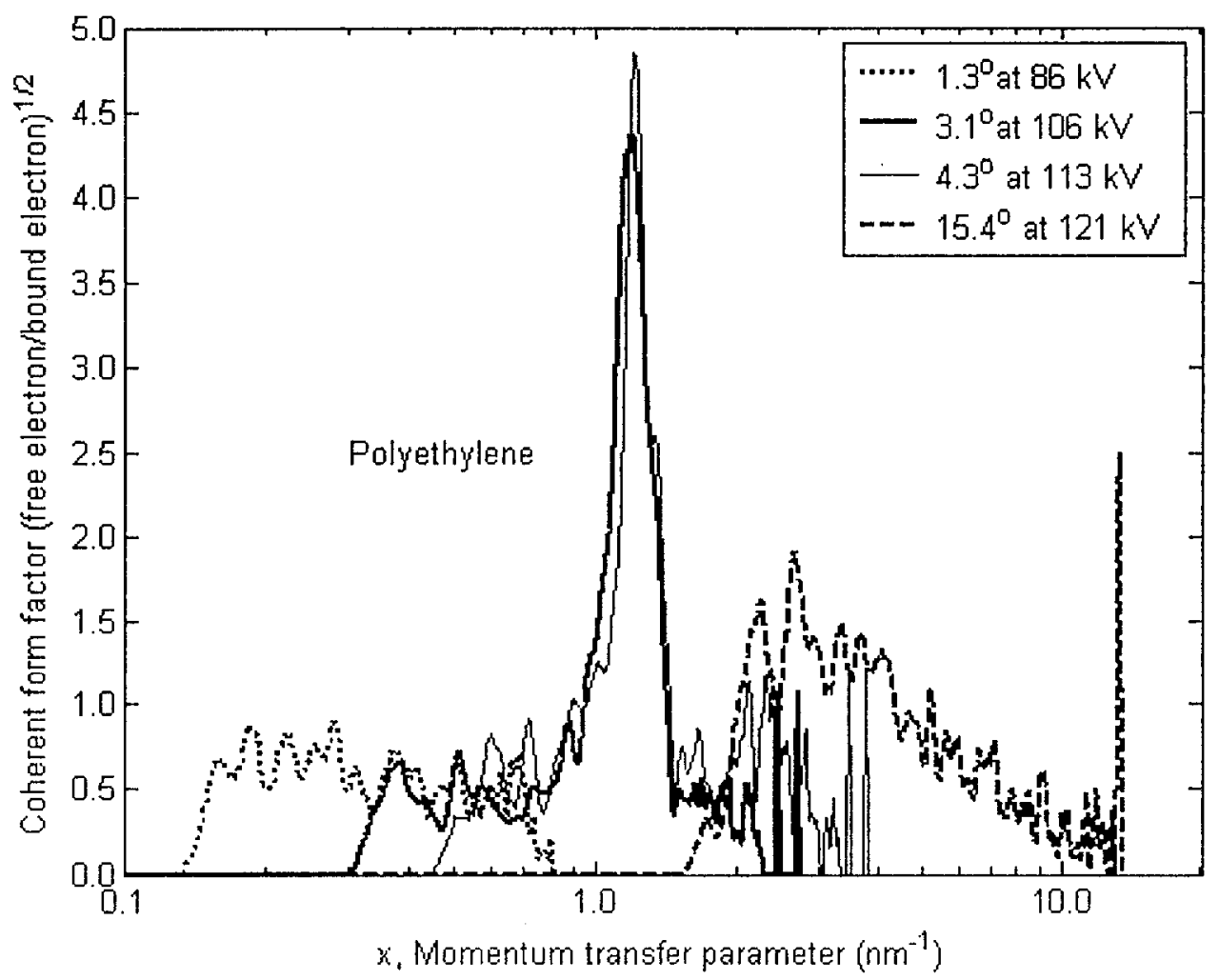

Figure 27. Form factors of polyethylene at different angles and potentials. 


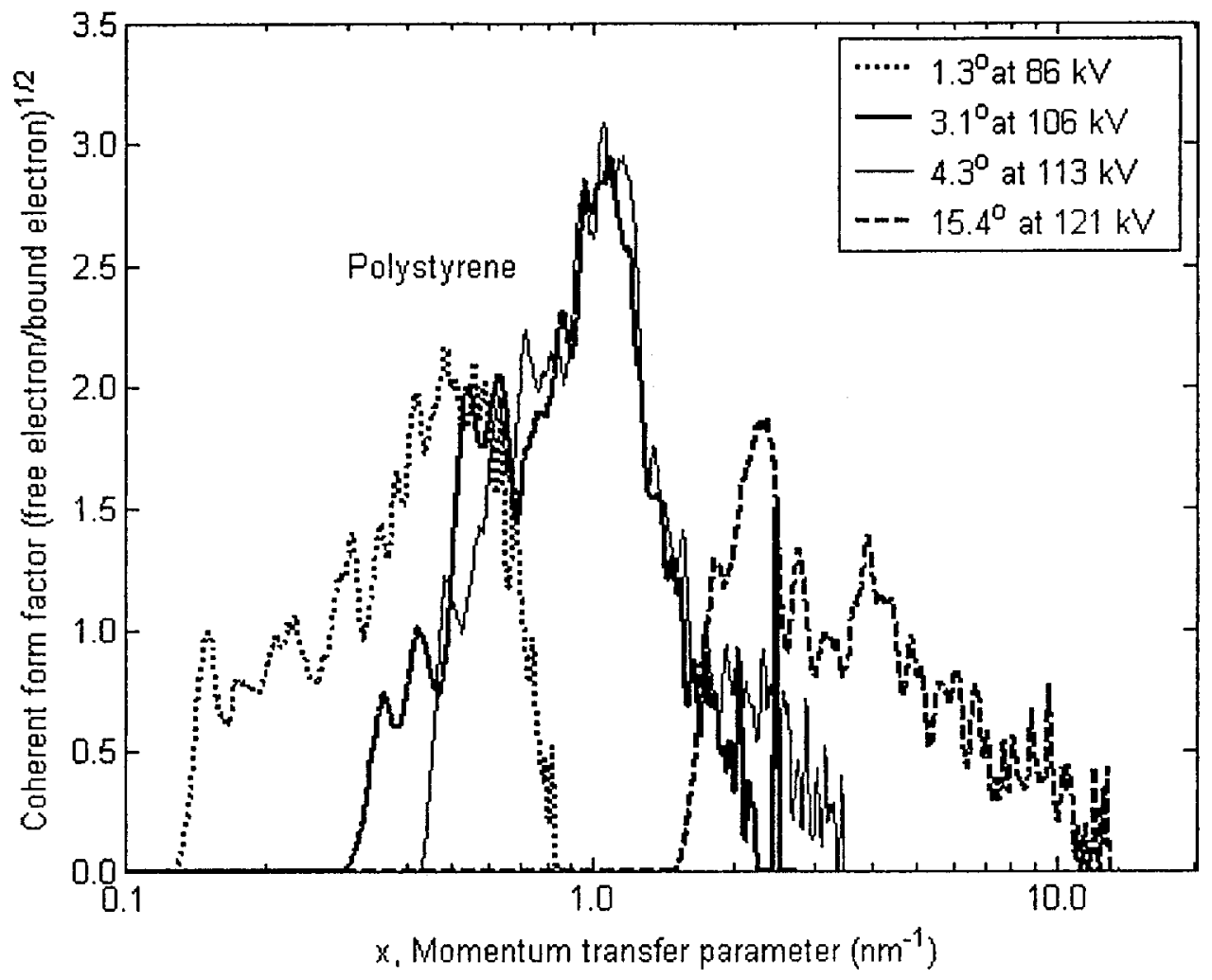

Figure 28. Form factors of polystyrene at different angles and potentials.

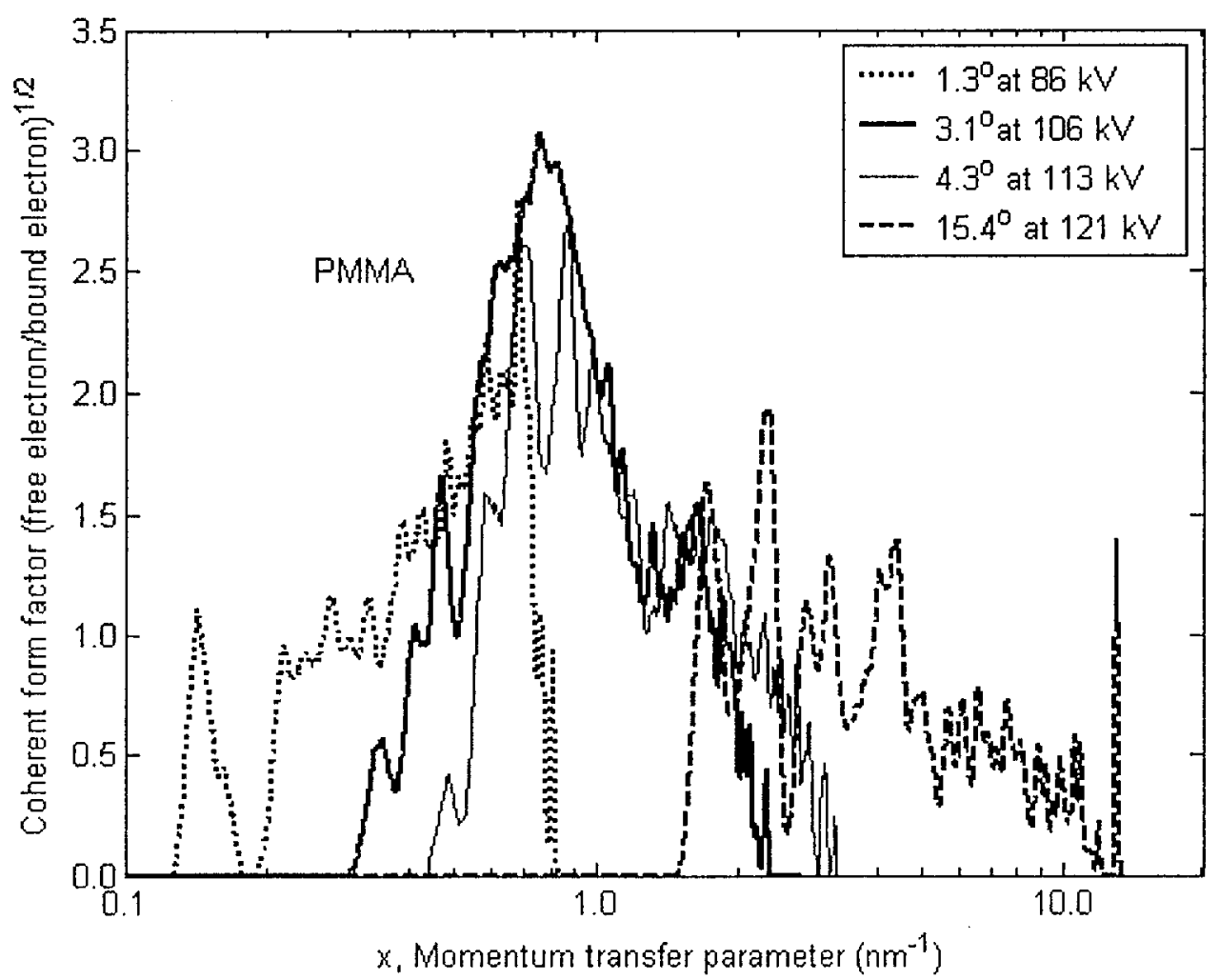

Figure 29. Form factors of PMMA at different angles and potentials. 


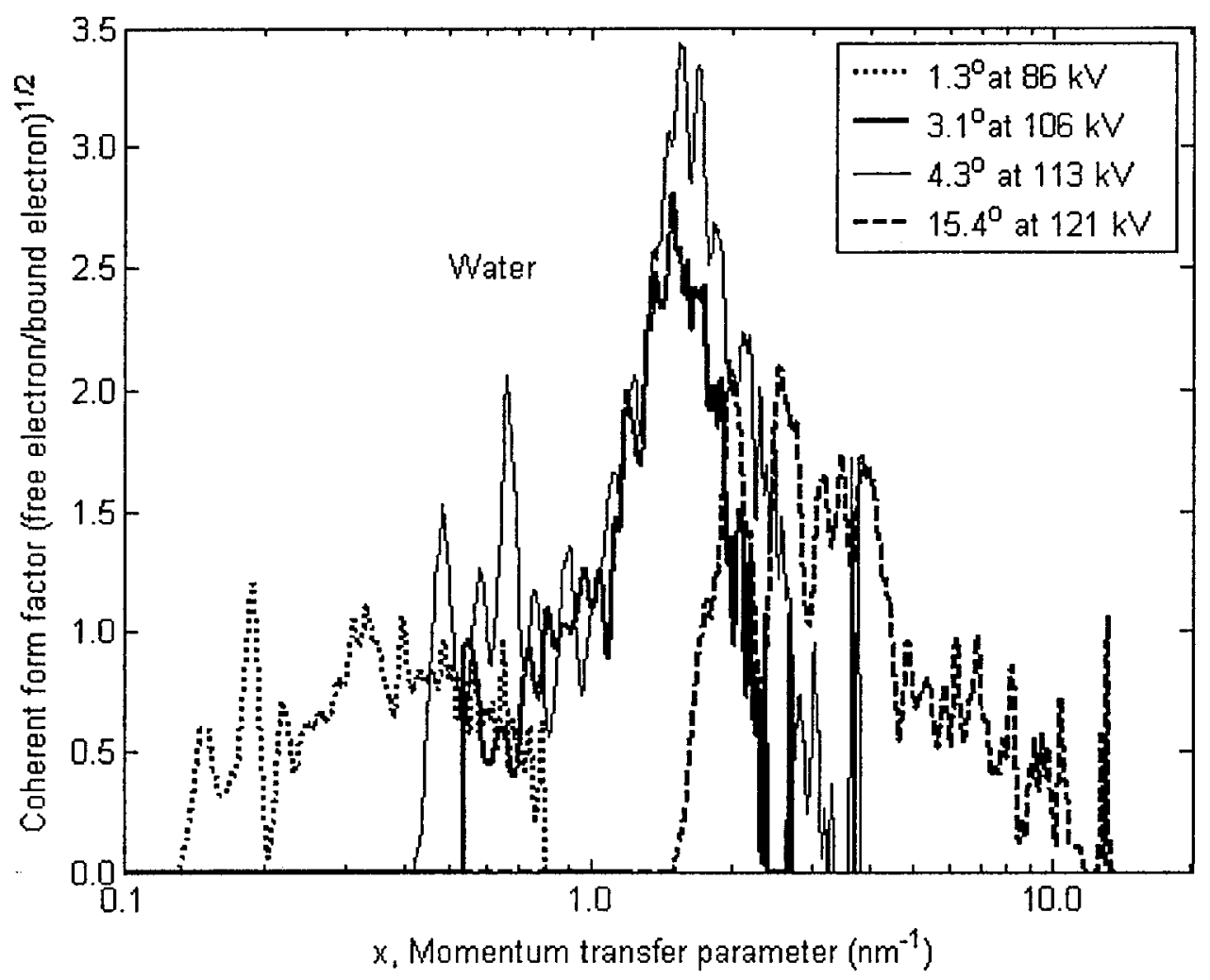

Figure 30. Form factors for water at different angles and potentials.

\subsection{Getting a continuous form factor}

The form factors that have been obtained so far do not have continuity between the results from the different spectra and angles. In the intersecting regions, however, the results from two spectra carry the same information of form factor. To get a continuous form factor curve out of these three spectra, weighted averaging was done at the intersecting region and was taken as common form factor for the adjacent spectra. A program zhave.m did this weighted average and plotted the form factor against momentum transfer parameter. 


\subsubsection{Calculating the weighted average}

The main program zhave.m searches for the form factors associated with the common $\mathrm{x}$ value of two adjacent spectra and using zhfoerr.m function it calculates the error for each of those bins and another function zhweiave.m does the weighted average using the simple relation, average $=\frac{\frac{\mathrm{x}}{\sigma_{\mathrm{x}}^{2}}+\frac{\mathrm{y}}{\sigma_{\mathrm{y}}^{2}}}{\frac{1}{\sigma_{\mathrm{x}}^{2}}+\frac{1}{\sigma_{\mathrm{y}}^{2}}}$, where $\mathrm{x}$ and $\mathrm{y}$ represent the form factor of two overlapping datasets and $\sigma_{x}^{2}$ and $\sigma_{y}^{2}$ represent their respective errors. Table 9 shows some typical values of errors of common bins values of the $1.3^{\circ}$ and $3.1^{\circ}$ form factors for lexan.

Table 9. Typical values of errors.

\begin{tabular}{|c|c|c|}
\hline $\mathrm{x}\left(\mathrm{nm}^{-1}\right)$ & Error for $1.3^{\circ}$ form factor & Error for 3.1 ${ }^{\circ}$ form factor \\
\hline 0.34 & 0.39 & 1.32 \\
\hline 0.35 & 0.55 & 1.25 \\
\hline 0.48 & 0.44 & 1.02 \\
\hline 0.52 & 0.51 & 0.91 \\
\hline
\end{tabular}

\subsubsection{Calculating the error of each bin}

Basically the error arises because of the counting noise, which is governed by Poisson statistics and can be given by $\sqrt{\mathrm{N}}$, where $\mathrm{N}$ is the number of quanta. During the calculation of form factor the scatter and transmission signals were obtained from the 
detector and therefore counting noise arises for each count. A function zhfoerr.m (called by the main program zhave.m) calculates the error associated with the form factor coming from the scatter and transmitted signal of two overlapping form factor data points using the error propagation formula.

\subsubsection{Coherent form factor of two target materials}

Weighting was done in a particular region of two adjacent spectra. Table 10 shows the intersecting region where weighting has been done for Figures 25 and 27 .

Table 10. Weighting region.

\begin{tabular}{|l|l|}
\hline Sample material & Intersection region $\left(\mathrm{nm}^{-1}\right)$ \\
\hline Polystyrene & 0.3 to 0.8 and 1.6 to 2.4 \\
\hline Lexan & 0.3 to 0.8 and 1.6 to 2.0 \\
\hline
\end{tabular}

Figures 31-32 show the form factors of lexan and polystyrene $0.15 \leq \mathrm{x} \leq 11.5 \mathrm{~nm}^{-1}$ after being averaged at the intersecting regions. 


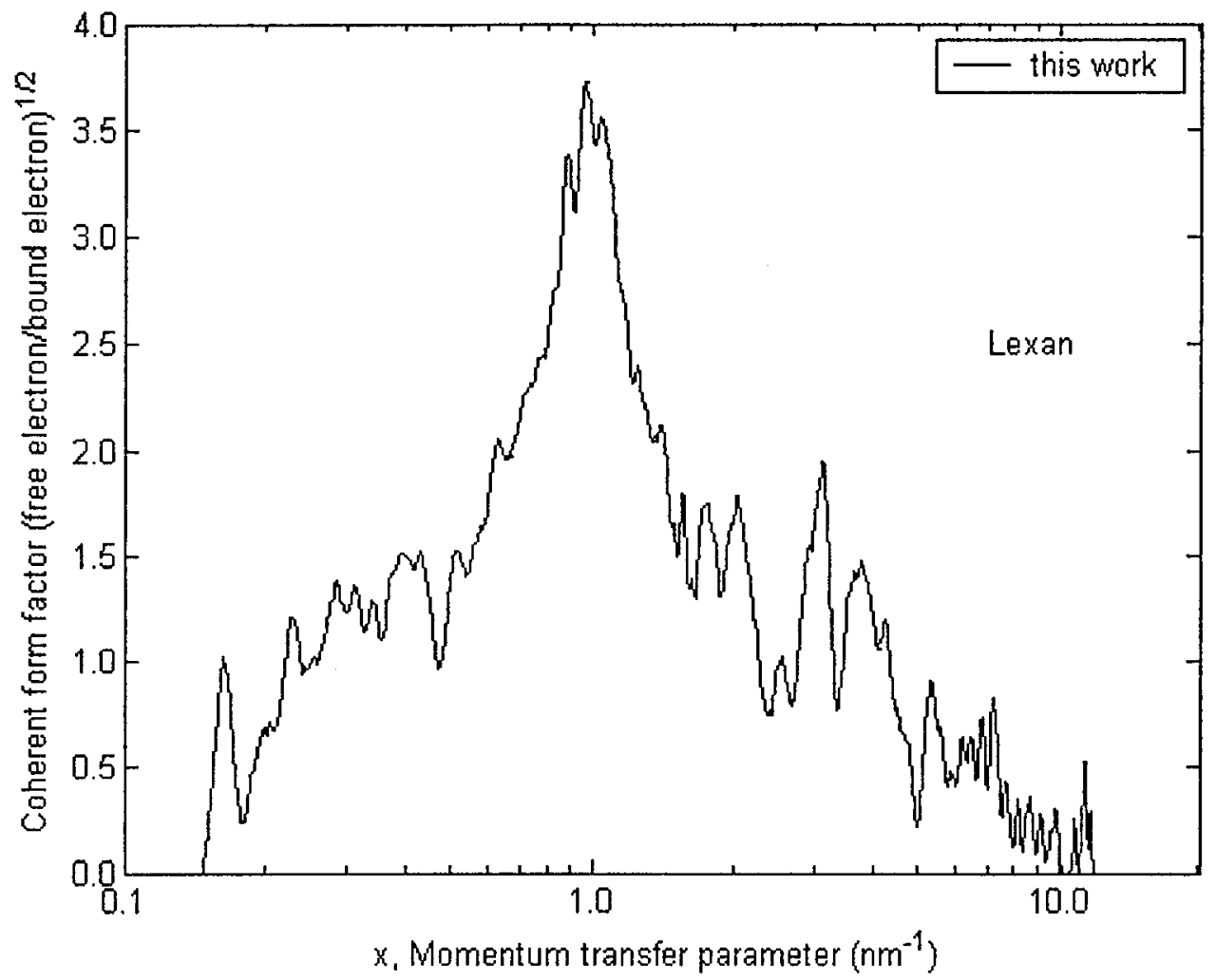

Figure 31. Form factor for lexan with weighting at the overlapping regions.

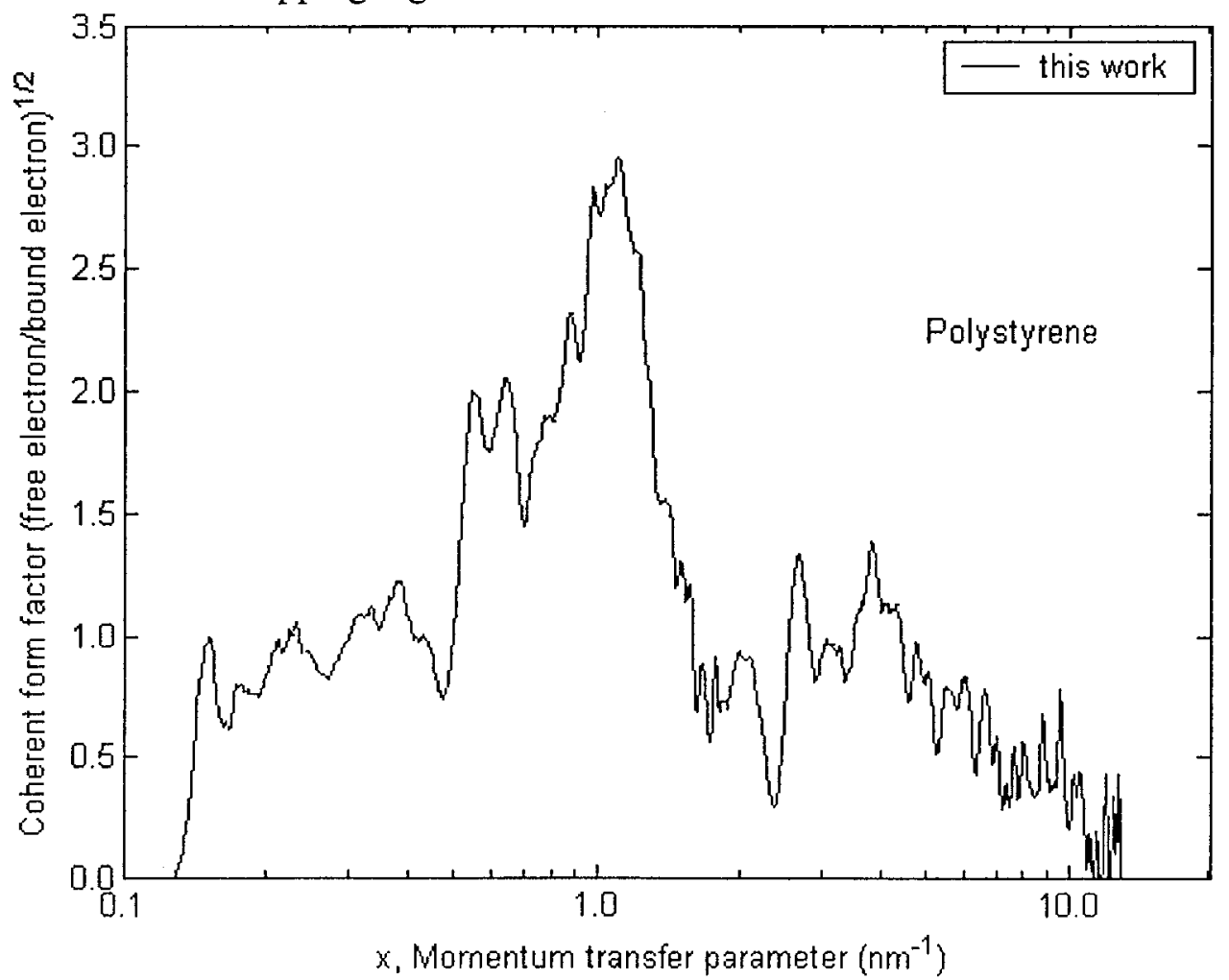

Figure 32 . Form factor for polystyrene with weighting at the overlapping regions. 


\section{Chapter 6}

\section{Comparison and Conclusions}

This chapter gives the comparison of the experimental data with the previous investigators' data in terms of percentage difference. Discussion and some suggestions to develop this technique are given.

\subsection{Comparison with the data of the previous investigations}

The tabulated form factor data of various plastic sample and water were compared with the previous investigators data such as Kosanetzky et al [12] using the relation, average relative absolute difference $=\frac{1}{n} \sum_{k=1}^{n} \frac{\left.\left.\mid N_{k} \text { (this work }\right)-N_{k} \text { (published data }\right)}{N_{k}(\text { published data })}$

A program zhcompar.m is calculating this difference.

\subsubsection{Comparison of coherent form factors of plastic samples}

Figures 33-37 show the form factors of various plastic samples obtained in this study. 


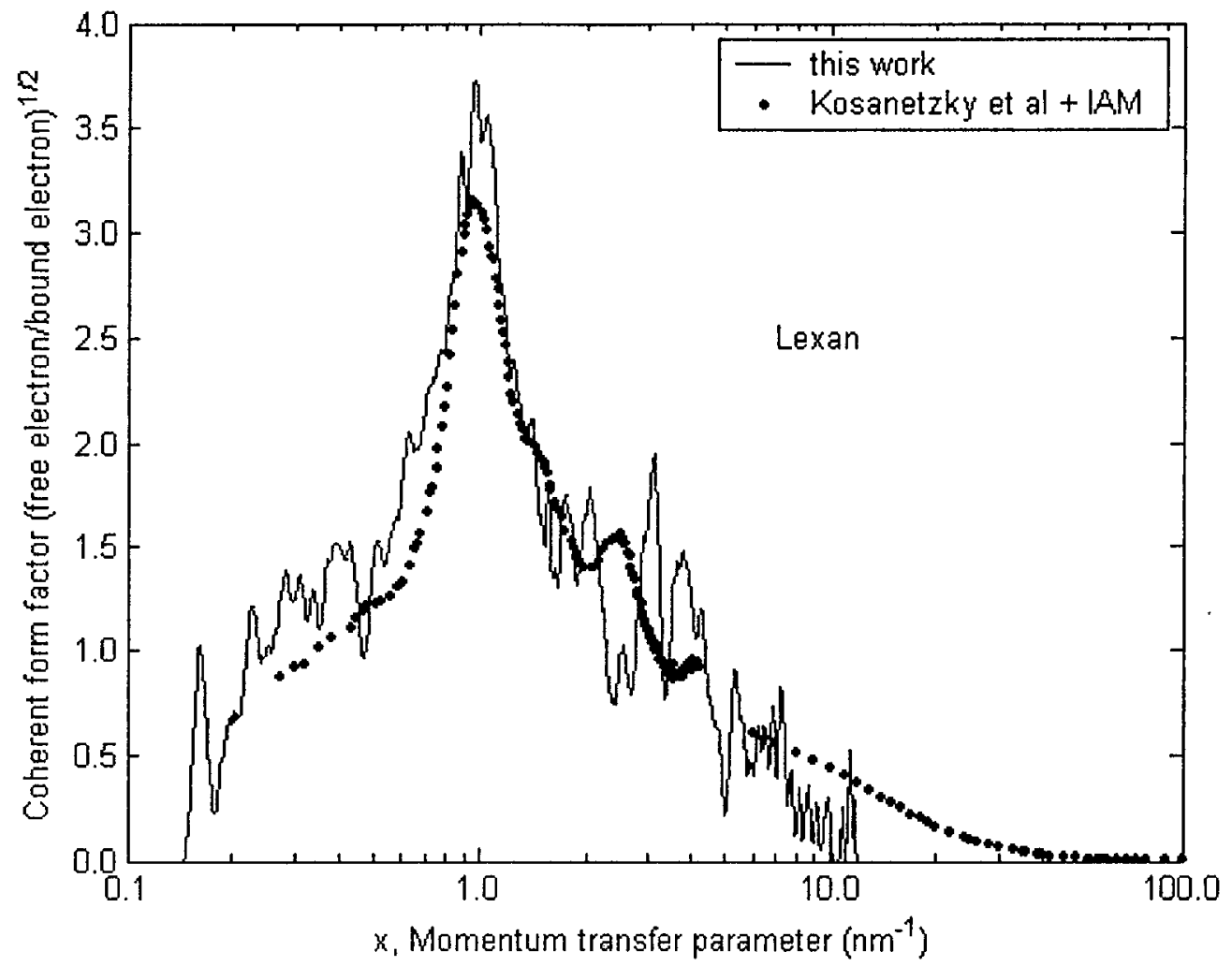

Figure 33. Form factor for lexan. Results are compared to the values extracted from the publication of Kosanetzky et al [12] for $0.3 \leq \mathrm{x} \leq 4.0 \mathrm{~nm}^{-1}$ and IAM model for $\mathrm{x} \geq 4.5 \mathrm{~nm}^{-1}$.

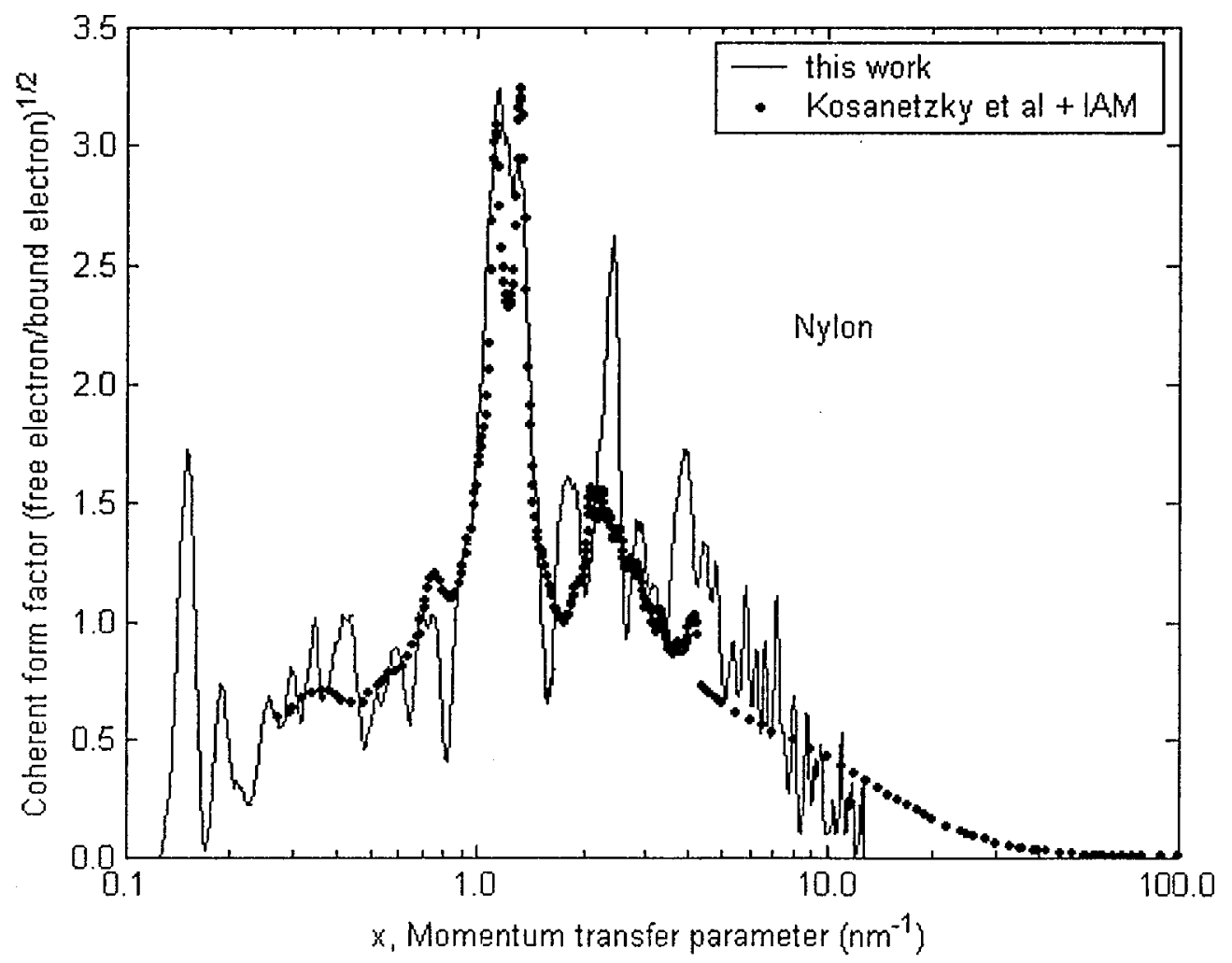

Figure 34. Form factor for nylon. Results are compared to the values extracted from the publication of Kosanetzky et al [12] for $0.29 \leq \mathrm{x} \leq 4.0 \mathrm{~nm}^{-1}$ and IAM model for $\mathrm{x} \geq 4.0 \mathrm{~nm}^{-1}$. 


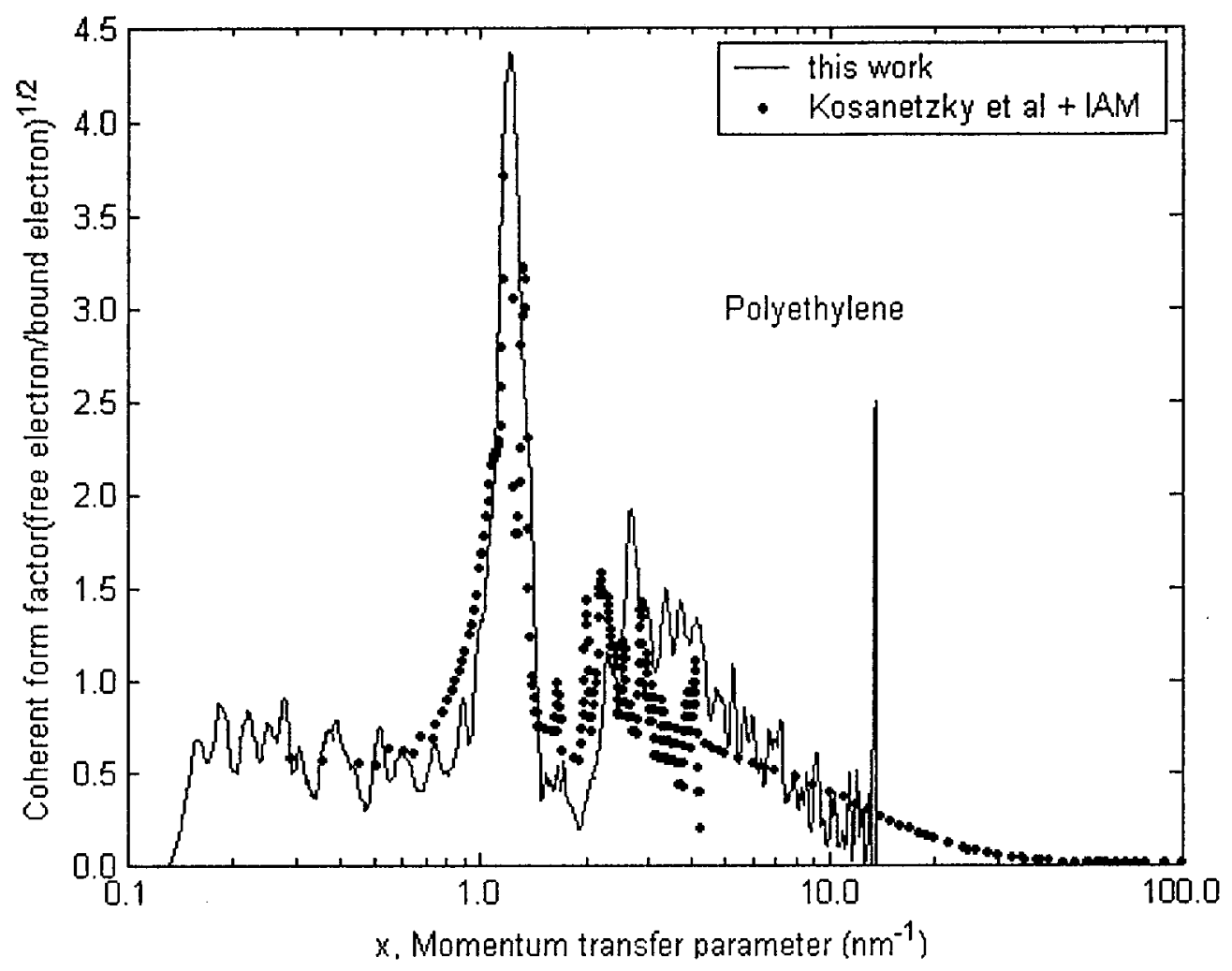

Figure 35. Form factor for polyethylene. Results are compared to the values extracted from the publication of Kosanetzky et al [12] for $0.3 \leq \mathrm{x} \leq 4.5 \mathrm{~nm}^{-1}$ and IAM model for $\mathrm{x} \geq 4.5 \mathrm{~nm}^{-1}$.

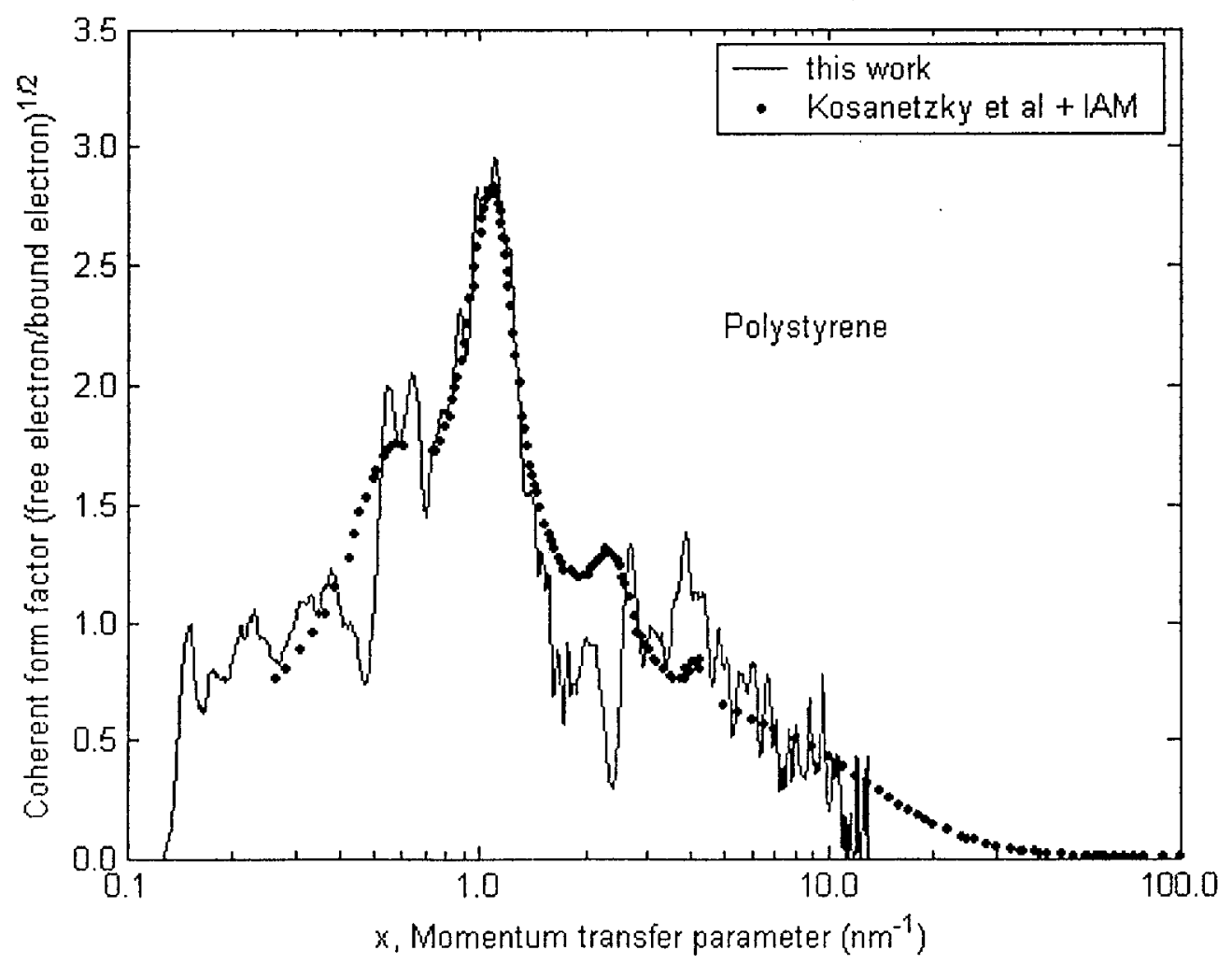

Figure 36. Form factor for polystyrene. Results are compared to the values extracted from the publication of Kosanetzky et al [12] for $0.3 \leq \mathrm{x} \leq 4.0 \mathrm{~nm}^{-1}$ and IAM model for $\mathrm{x} \geq 4.5 \mathrm{~nm}^{-1}$. 


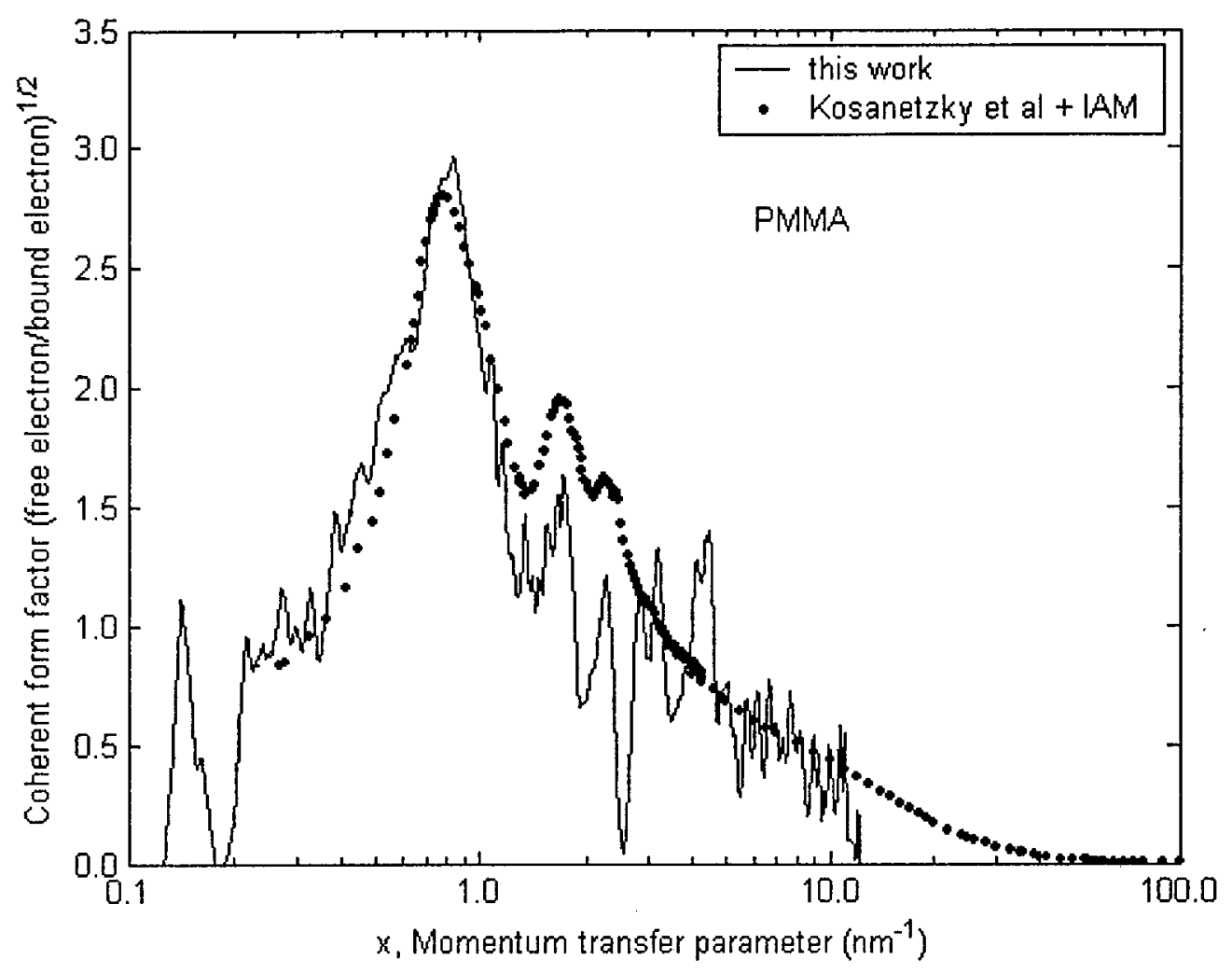

Figure 37. Form factor for PMMA. Results are compared to the values extracted from the publication of Kosanetzky et al [12] for $0.28 \leq \mathrm{x} \leq 4.0 \mathrm{~nm}^{-1}$ and IAM model for $\mathrm{x} \geq 4.0 \mathrm{~nm}^{-1}$.

The average relative absolute difference obtained for lexan, nylon, polyethylene, polystyrene, PMMA, as compared with Kosanetzky's and IAM data are given in Table 11. 
Table 11. Comparison of average relative absolute difference of different form factor data for lexan, nylon, polyethylene, polystyrene, PMMA.

\begin{tabular}{|l|l|l|l|}
\hline Sample material & Source of data & $\mathrm{x}$-range $\left(\mathrm{nm}^{-1}\right)$ & $\begin{array}{l}\text { Average relative absolute } \\
\text { difference in F }\end{array}$ \\
\hline \multirow{2}{*}{ Lexan } & Kosanetzky et al [12] & $0.3-3.0$ & 0.17 \\
\cline { 2 - 4 } & IAM & $6.0-10.5$ & 0.24 \\
\hline Nylon & Kosanetzky et al [12] & $0.29-4.0$ & 0.18 \\
\cline { 2 - 4 } & IAM & $4.27-10.1$ & 0.27 \\
\hline Polyethylene & Kosanetzky et al [12] & $0.3-4.5$ & 0.25 \\
\cline { 2 - 4 } & IAM & $4.8-10.0$ & 0.22 \\
\hline Polystyrene & Kosanetzky et al [12] & $0.3-4.0$ & 0.15 \\
\cline { 2 - 4 } & IAM & $5.0-10.0$ & 0.18 \\
\hline PMMA & Kosanetzky et al[12] & $0.28-4.0$ & 0.17 \\
\cline { 2 - 4 } & IAM & $8.0-10.3$ & 0.21 \\
\hline
\end{tabular}

As the table shows in the region $0.3-3.0 \mathrm{~nm}^{-1}$ the difference between Kosanetzky et al data and our data for lexan is $17.32 \%$. This difference is because of our very noisy form factor data, which is because of very low scatter count rate. The other reason behind it is that, since the geometry that we used does not have very good angle resolution, because of the lack of accuracy in angle measurement the coherent peaks are shifting from the particular position where it supposed to be. At high $\mathrm{x}$ region which is the IAM region our data match well. However, the $24.11 \%$ difference is coming because of our noisy form factor. 
The percent difference as obtained from the table 11 shows that at the region 0.3 to 4.0 $\mathrm{nm}^{-1}$ all the plastic samples such as nylon, polyethylene, polystyrene and PMMA are giving variation as high as $24.8 \%$ between the measured value and previous investigators' data. The same reasons are applicable in this case. In our measurement the scatter count rate was too low in compared to the transmitted count. This made the form factor data noisy. On the other hand the angle was calculated separately (as shown in chapter 3) using the parameters of the geometry. This calculation implies that if a little shift from the assumed geometry occurs in the real measurement, the scatter angle would definitely be different. But during calculating the form factor instead of using the real angle occurred at the laboratory the calculated angle was used to determine form factor which might shift the coherent form factor from the particular position.

The higher $\mathrm{x}$-range $\left(>4.0 \mathrm{~nm}^{-1}\right)$ measurements were comparatively better, having a difference of approximately $22 \%$ with the IAM data.

\subsubsection{Comparison of water sample}

Figure 38 shows the form factor data of water obtained in our lab with the Narten [10], Kosanetzky et al [12] and IAM data. Results are compared in Table 12 to the values extracted from the publication of Narten [10] for $0.1 \leq \mathrm{x} \leq 13.0 \mathrm{~nm}^{-1}$, Kosanetzky et al [12] for $0.3 \leq x \leq 3.0 \mathrm{~nm}^{-1}$ and the IAM model for $x \geq 4.5 \mathrm{~nm}^{-1}$. 


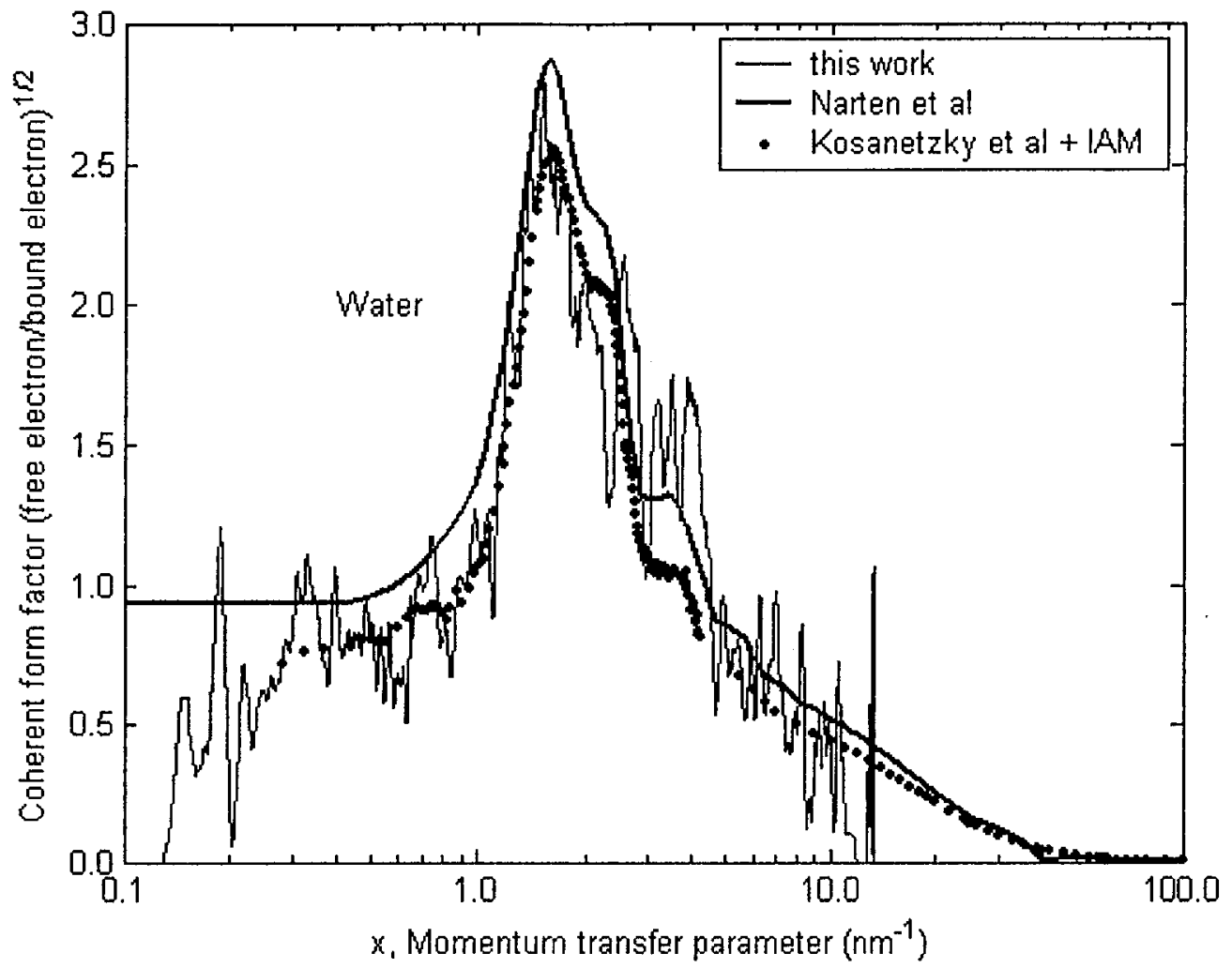

Figure 38. Form factor for water. Results are compared to the values extracted from the publication of Narten [10] for $0.1 \leq \mathrm{x} \leq 13.0 \mathrm{~nm}^{-1}$, Kosanetzky et al [12] for $0.3 \leq \mathrm{x} \leq 4.0 \mathrm{~nm}^{-1}$ and IAM model for $\mathrm{x} \geq 4.5 \mathrm{~nm}^{-1}$.

Table 12 shows the average relative absolute difference of form factor data of water of our lab and other investigators. 
Table 12. Comparison of average relative absolute difference of different form factor data for water sample.

\begin{tabular}{|l|l|l|l|}
\hline Target material & Source of data & x-range $\left(\mathrm{nm}^{-1}\right)$ & Average relative \\
& & & absolute difference in F \\
\hline \multirow{3}{*}{ Water } & Narten [10] & $0.3-3.0$ & 0.24 \\
\cline { 2 - 4 } & Kosanetzky [12] & $0.3-3.0$ & 0.16 \\
\cline { 2 - 4 } & IAM & $5.5-10.0$ & 0.23 \\
\hline
\end{tabular}

Table 12 shows the percent difference in $0.3-3.0 \mathrm{~nm}^{-1}$ region is $16.13 \%$ with the data of Kosanetzky et al and $24.37 \%$ with the Narten's data. The differences for water are of the same order as that obtained in plastic samples.

\subsection{Discussion}

Kosanetzky et al [12] measured the form factor by a powder diffractometer which had very good angle resolution. From $5^{\circ}$ to $100^{\circ}$ they took the steps of $0.05^{\circ}$. On the other hand they used a monochromatic beam for their measurement. In this experiment polychromatic $\mathrm{x}$-ray radiation is used which needs very good energy resolution. The detector that has been used for this experiment definitely has very good energy resolution. However, this geometry still lacks angle resolution. The angle was calculated separately from the apparatus. This is shifting the coherent peaks from their exact positions. The geometry also lacks alignment. Diffractometer has very good alignment facility. Here in this experiment only way to align is to depend on the photon count rate. Multi-scatter events inside the target were not considered in this experiment. 
The angle dispersive form factor measurement using a monochromatic beam is a wellknown technique. However, due to many corrections as discussed in Chapter 1 it needs longer exposure time.

In an angle dispersive technique, the angle is kept fixed. Since the $\mathrm{x}$-ray tube is giving a spectrum of energy and all the wavelengths are scattered at the same time and reaching the detector simultaneously. It takes less time compared to angle dispersive technique. Table 13 shows the time required to get a complete form factor of $0.15-11.87 \mathrm{~nm}^{-1} \mathrm{x}-$ range.

Table 13. Time to perform form factor experiment.

\begin{tabular}{|l|l|}
\hline Event & Time \\
\hline Time to align for transmitted spectra & 15 minutes \\
\hline Time to get three transmitted spectra & $3 \times 2$ minutes $=6$ minutes \\
\hline Time to align three scatter spectra & $3 \times 15$ minutes $=45$ minutes \\
\hline Time to get three scatter spectra & $3 \times 5$ minutes $=15$ minutes \\
\hline Total time & 1 hour and 21 minutes \\
\hline
\end{tabular}

Considering measurement, alignment time and other aspects this is a very simple and fast technique. The form factor obtained by this technique is, however, noisier than the conventional angle dispersive technique. This is why it needs much development. 


\subsection{Conclusion and Future work}

Considering the shortcomings of this energy dispersive form factor measurement technique the following suggestions can be stated to develop it as future work.

\subsubsection{Exact alignment}

The main problem in this technique is the exact alignment. If the $\mathrm{x}$-ray tube to target and target to detector is not exactly aligned, it is not possible to get good scatter spectra. If the target stays slightly off from the position where it supposed to be to get the particular scatter angle it is very hard to get good scatter signal. This will definitely ruin the whole measurement. One way to align it is by using some material for which somebody already knows the scatter count rate. In this case one has to get the background first and then will put the material in the target position and see the count rate. The geometry could be considered to be aligned for scatter measurements for that particular position if this count rate matches the known value after being corrected for the inverse square factor.

\subsubsection{Exact scatter angle calculation}

To get coherent peak position at the very particular positions, one has to calculate the scatter angle very accurately. Otherwise the peak positions will shift. In this experiment the scatter angle and variance were calculated numerically as a function of the dimensions of the extended target. That numerical calculation also takes into account of all other parameters of the geometry. However, in this calculation, the x-ray tube and detector were considered to be points, whereas they are also extended. To get more exact scatter angle $\mathrm{x}$-ray tube and detector could be segmented to small pieces. 


\subsubsection{Calculation of multiple scatter events}

During the scattering of photon with the target multiple scattering is happening inside the target which we are not taking into account. Only the single scattering is considered. Monte Carlo calculation may be done to know these multiple scatter events and this can be subtracted from the total scatter count to get only the single scatter count event.

\subsubsection{Variable aperture}

The experiment has apertures that have fixed hole size and direction, which is not a good approach for good alignment, as the aperture condition cannot be changed in any case. It would be good if a variable aperture could be used that can be varied in direction. 


\section{References}

[1] H.E. Johns and J.R. Cunningham, The Physics of Radiology, 4th Edition, C.C. Thomas, Springfield Ill. U.S. (1983).

[2] R.H. Morgan, "An analysis of the physical factors controlling the diagnostic quality of Roentgen images, Part III. Contrast and the intensity distribution function of a Roentgen image", Am. J. Roentgenol. 55, 67-89 (1946).

[3] J.W. Motz and M. Danos, "Image information content and patient exposure", Med. Phys. 5, 8-22 (1978).

[4] P.P. Dendy, B. Heaton, "Physics for Diagnostic Radiology", 2nd Edition, Institute of Physics, Bristol, U.K. (1999).

[5] P.C. Johns and M.J. Yaffe, "Coherent scatter in diagnostic radiology", Med. Phys. 10, $40-50$ (1983).

[6] R.J. Leclair and P.C. Johns, "A semianalytic model to investigate the potential applications of x-ray scatter imaging", Med. Phys. 25, 1008-1020 (1998).

[7] G. Harding and J. Kosanetzky, "X-ray diffraction computed tomography", Med. Phys. $14,515-525$ (1987).

[8] M. S. Westmore, A. Fenster, and I.A Cunningham, "Tomographic imaging of the angular dependent coherent-scatter cross section", Med. Phys. 24, 3-10 (1997).

[9] R.D. Luggar and W.B. Gilboy, “Application of Rayleigh scattered photons to substance identification", Nucl. Instr. and Meth. in Phys. Res. A 353, 650-653 (1994). 
[10] A.H. Narten, "X-ray diffraction data on liquid water in the temperature range $4^{\circ} \mathrm{C}-$ $200^{\circ} \mathrm{C} "$, Report ORNL-4578, Oak Ridge National Laboratory, Oak Ridge, Tennessee, 1970.

[11] J.H. Hubbell, W.J. Veigele, E.A. Briggs, R.T. Brown, D.T. Cromer, and R.J. Howerton, "Atomic form factors, incoherent scattering functions and photon scattering cross sections", J. Phys. Chem. Ref. Data 4, 471-538 (1975); Errata 6, 615-616 (1977).

[12] J. Kosanetzky, B. Knoerr, G. Harding and U. Neitzel, "X-ray diffraction measurements of some plastic materials and body tissues", Med. Phys. 14, 526-532 (1987).

[13] J.H. Hubbell and I. Øverbø, "Relativistic atomic form factors and photon coherent scattering cross sections", J. Phys. Chem. Ref. Data 8, 69-105 (1979).

[14] R.J. Leclair and P.C. Johns, "Analysis of spectral blur effects in x-ray scatter imaging", Med. Phys. 26, 1811-1816 (1999).

[15] R.J. Leclair and P.C. Johns, "X-ray forward-scatter imaging: Experimental validation of model", Med. Phys. 28, 210-219 (2001).

[16] R.J. Leclair and P.C. Johns, "Optimum momentum transfer arguments for X-ray forward scatter imging", Med. Phys. 29, 2881-2890 (2002).

[17] D.L. Batchelar and I.A. Cunningham, "Material-specific analysis using coherentscatter imaging", Med. Phys. 29, 1651-1660 (2002).

[18] S.H. Evans, D.A. Bradley, D.R. Dance, J.E. Bateman and C.H. Jones, "Measurement of small-angle photon scattering for some breast tissues and tissue substitute materials", Phys. Med. Biol. 35, 7-18 (1991). 
[19] D.E. Peplow and K. Verghese, "Measured molecular coherent scattering form factors of animal tissues, plastics and human breast tissue", Phys. Med. Biol. 43, 24312452 (1998).

[20] M.P. Wismayer, "Measurement of the amorphous coherent scatter form factor by using an x-ray powder diffractometer", M.Sc Thesis, Dept. of Physics, Carleton University (2001).

[21] D. W. L. Hukins, X-ray Diffraction by Disordered and Ordered Systems, Pergamon Press, Oxford, U.K. (1981).

[22] C. Kittel, Elementary Solid State Physics, John Wiley \& Sons, Inc., New York (1962).

[23] G. F. Knoll, Radiation Detection and Measurement, 2nd Edition, John Wiley \& Sons, Inc., New York (1989). 


\section{Appendix}

\section{Computer routines for form factor calculation}

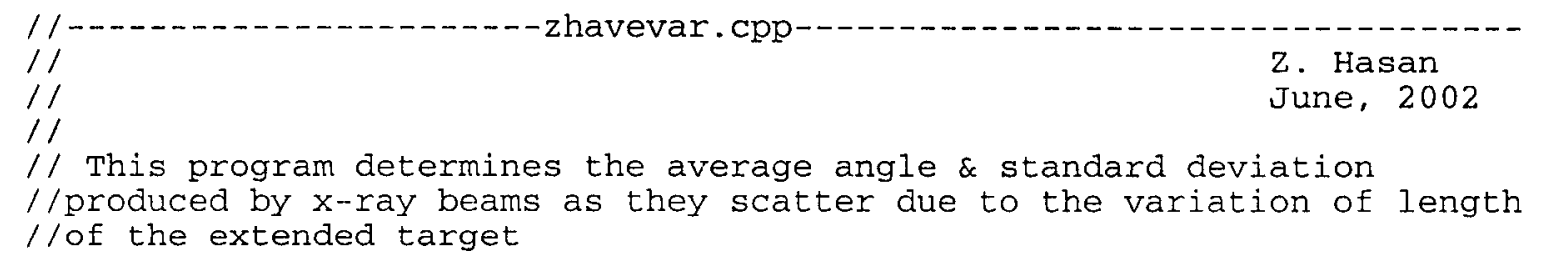

\#include<staio.h $\mathrm{h}$

$\#$ include<iostream.h>

\#include<conio.h>

\#include<math.h>

\#define Length $0.01 / /$ Initial value of length $(\mathrm{cm}) / /$

\#define Height 5.0 //Height of the target $(\mathrm{cm}) / /$

\#define width 5.0 //Width of the target $(\mathrm{cm}) / /$

\#define Pi 3.1415926

\#define Lst 70

//Source to target distance (cm)//

\#define Lta 76

//Target to detector distance $(\mathrm{cm}) / /$

\#define N 256

//Number of fractionation//

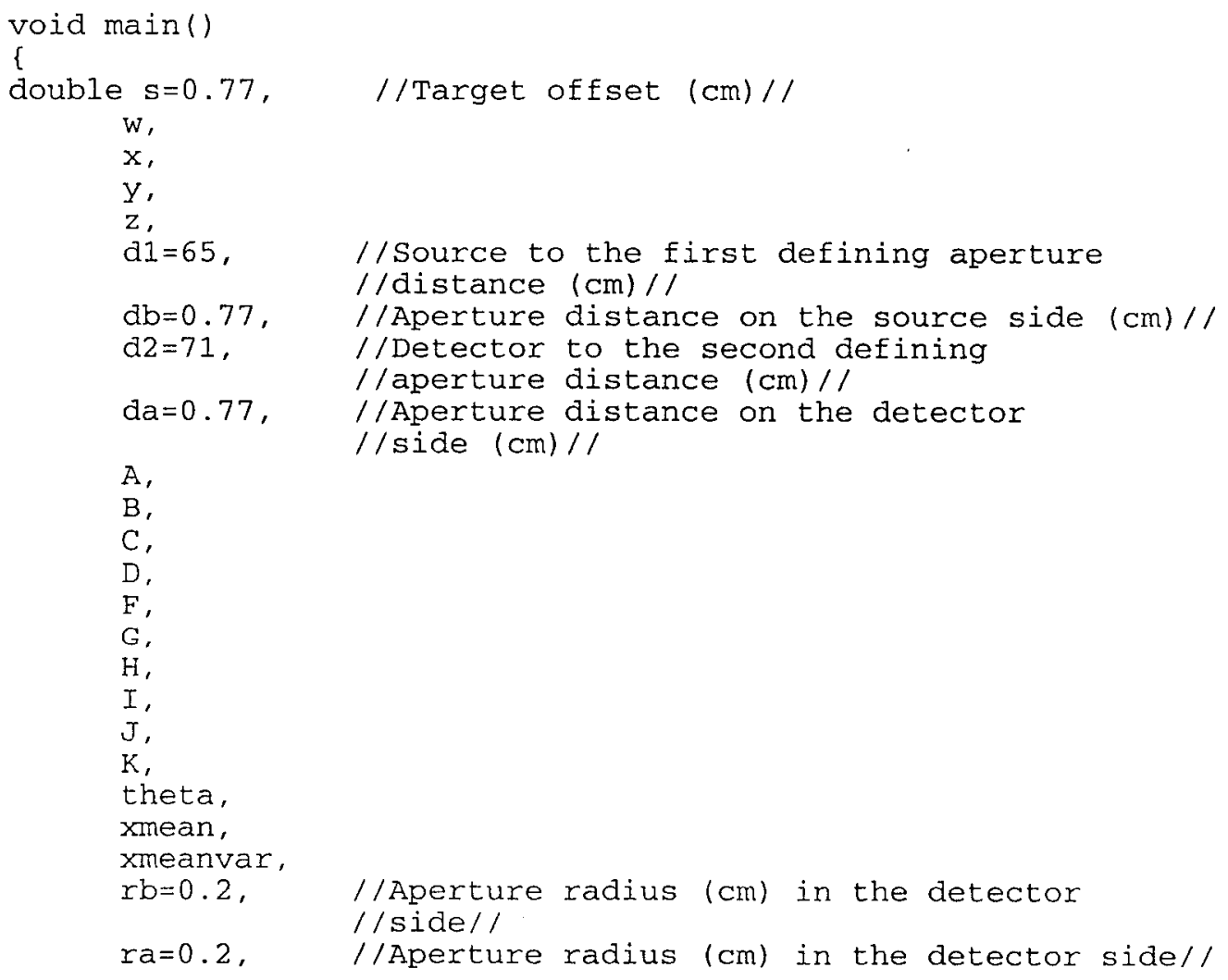




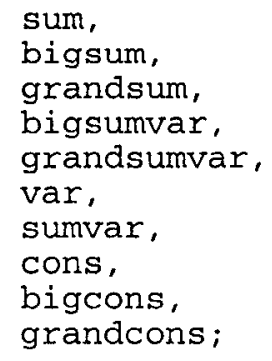

//Determination of pixels on the detector side//

$C=z^{*} z+(y+s-((L t d-x) / d 2) * d a) *(y+s-(($ Ltd $-x) / d 2) * d a)-(r a *(L t d-$ x) $/ \mathrm{d} 2) *(r a *($ Ltd $-\mathrm{x}) / \mathrm{d} 2)$;

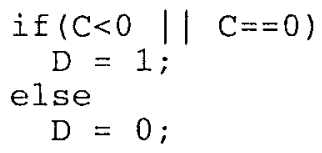




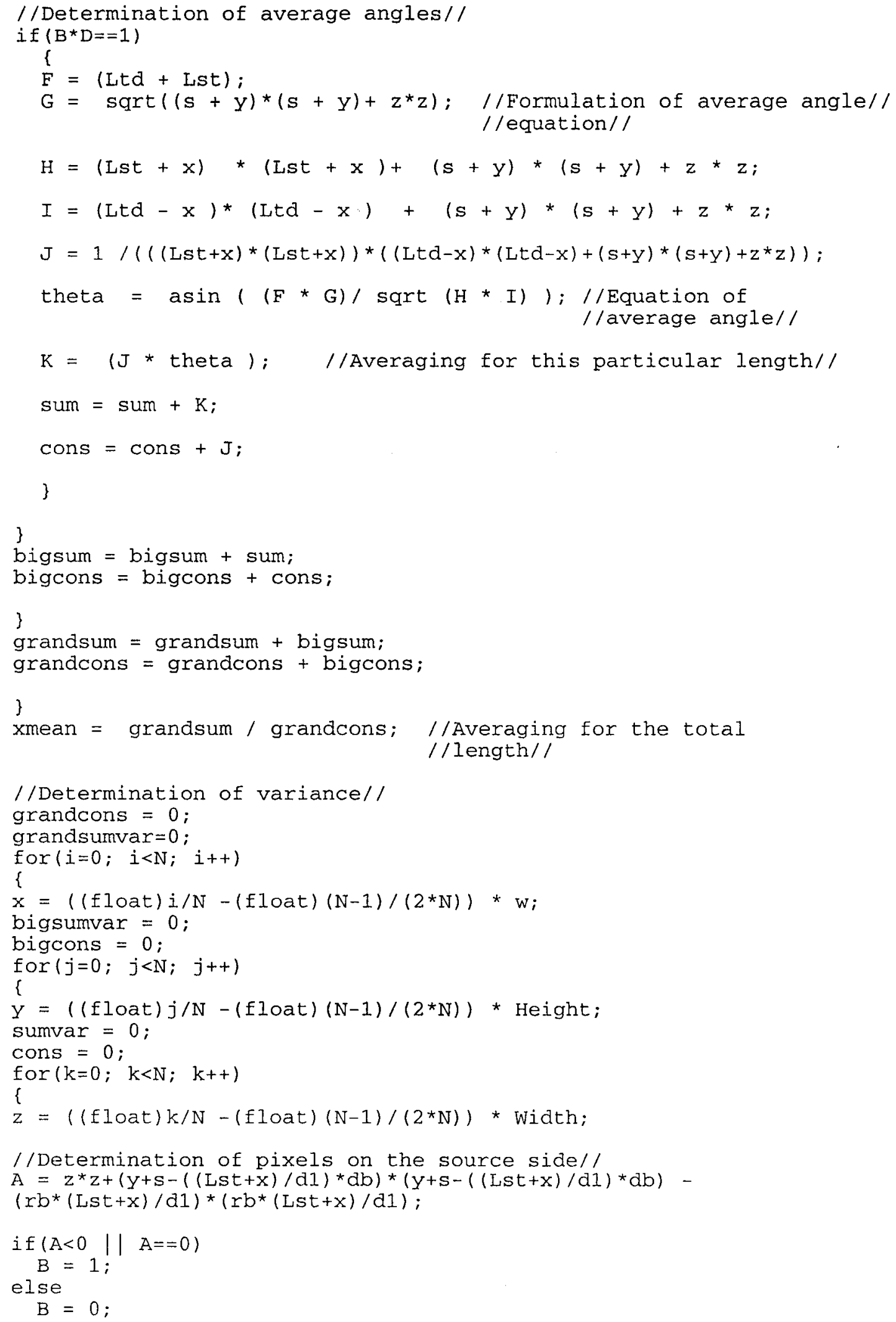




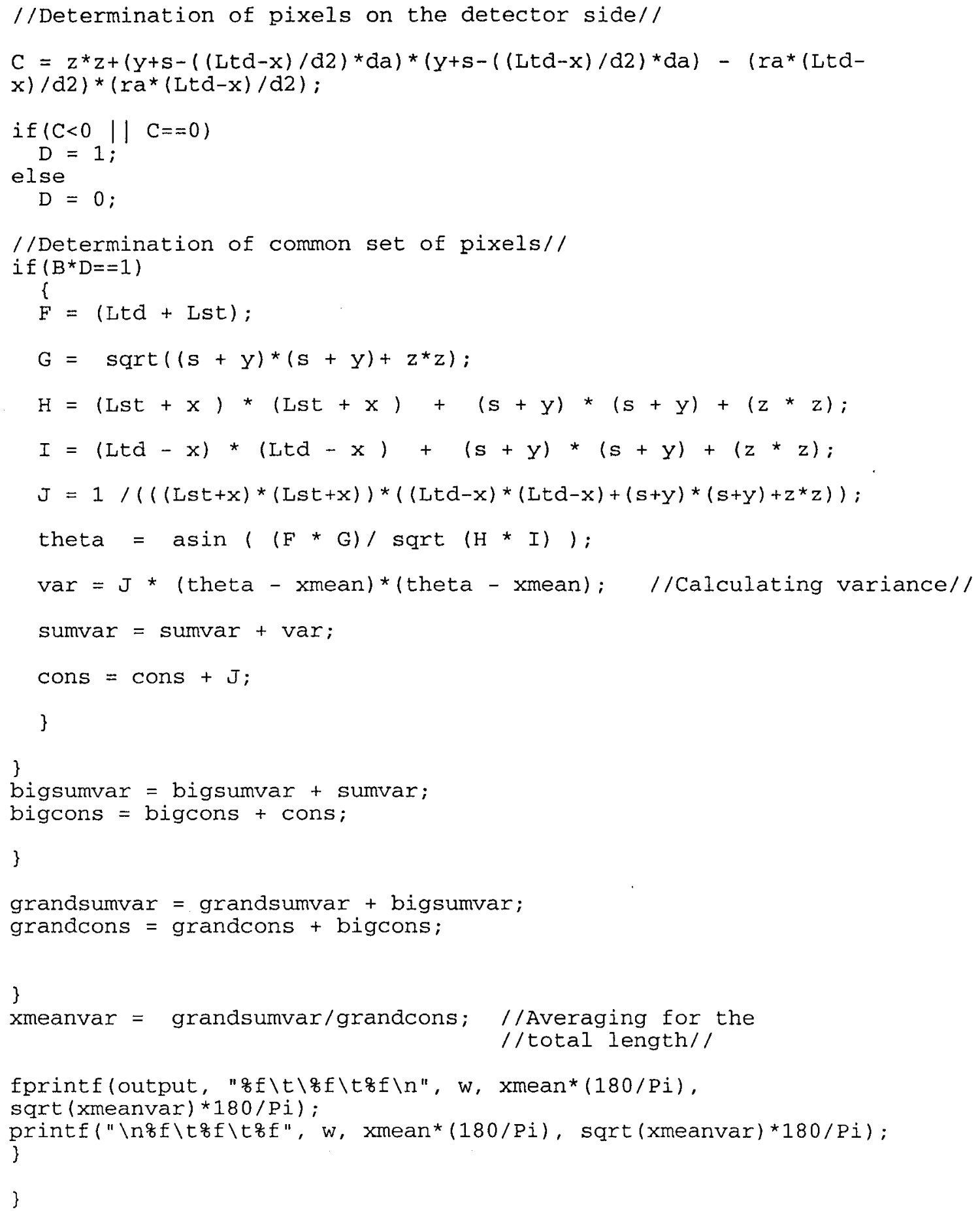




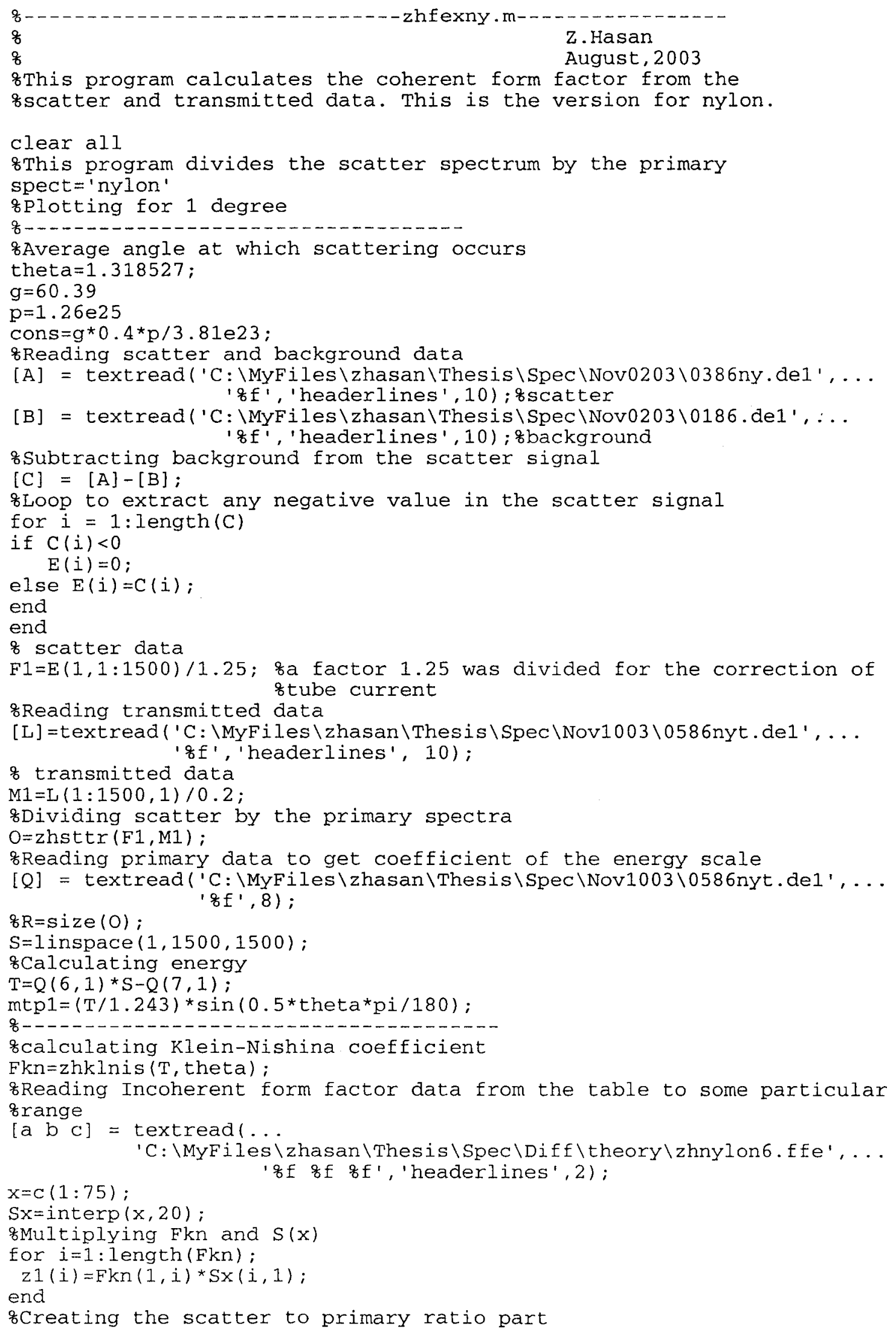




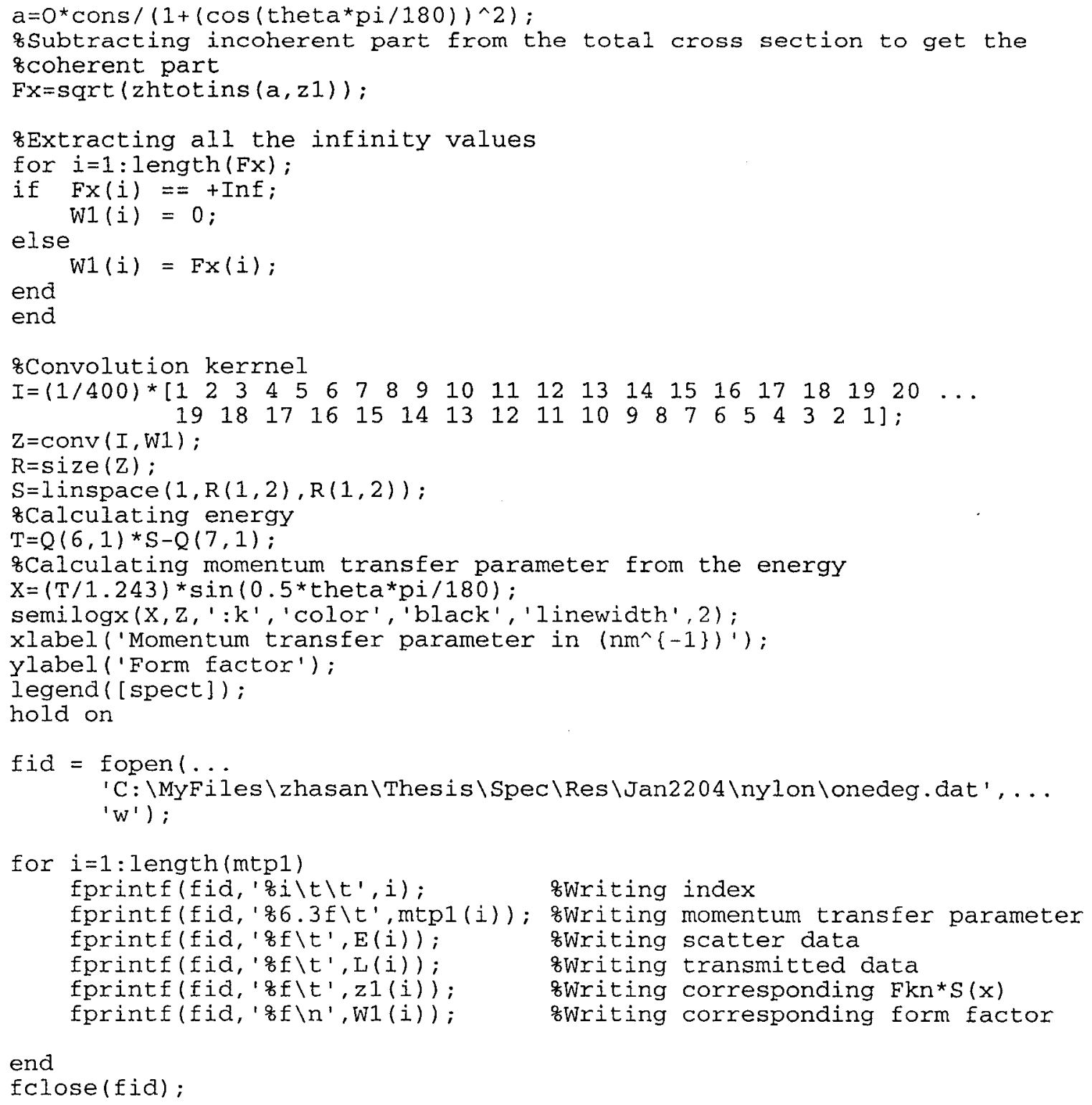




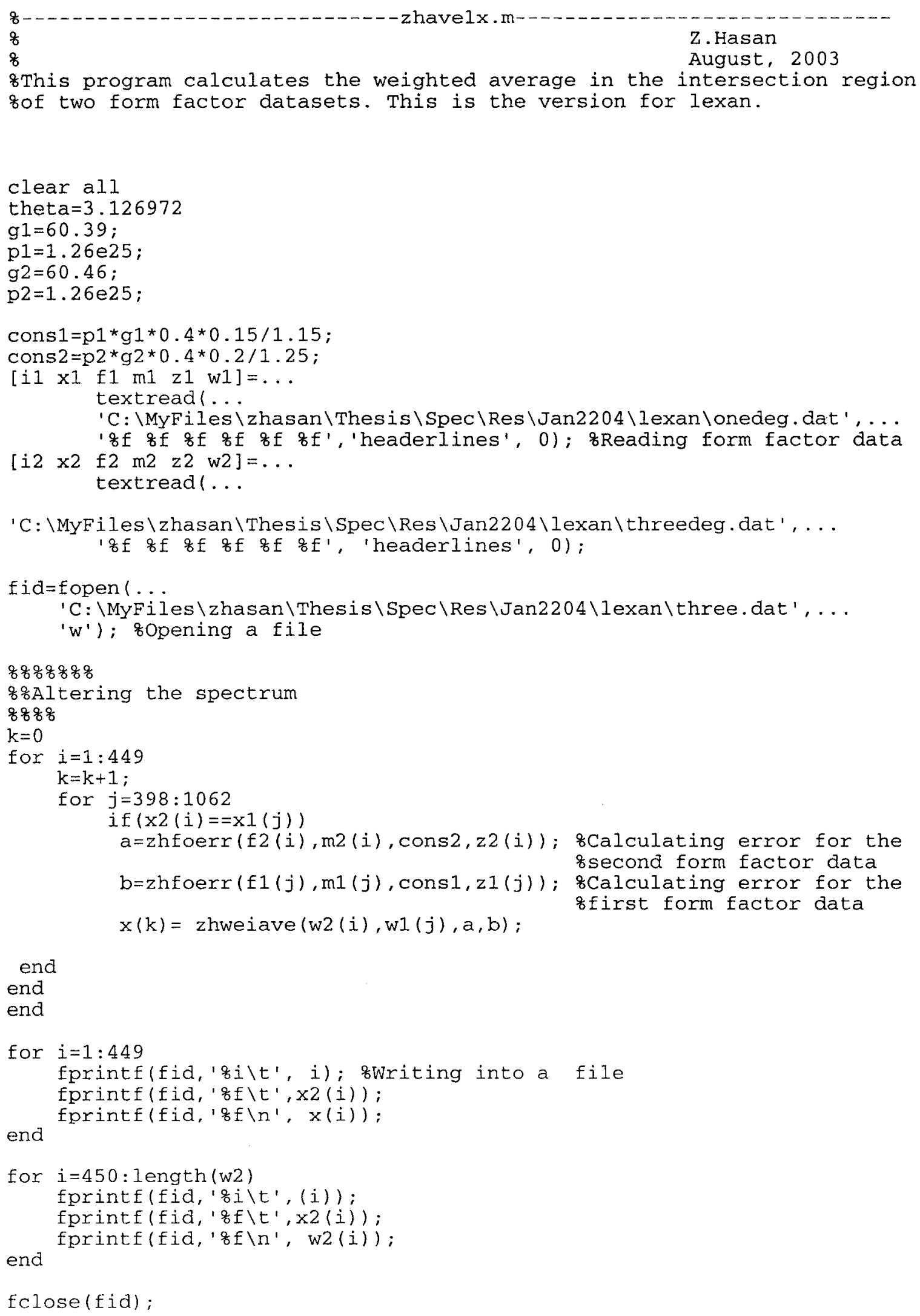

fclose (fid) ; 
$\left[\begin{array}{lll}a & b & c\end{array}\right]=$ textread $\ldots$

'C: \MyFiles $\backslash$ zhasan $\backslash$ Thesis $\backslash$ Spec $\backslash$ Res $\backslash J a n 2204 \backslash$ lexan $\backslash$ three . dat ', ...

' $8 \mathrm{f}$ of $8 \mathrm{f}$ ', 'headerlines',0);

kernel $=(1 / 400) *\left[\begin{array}{llllllllllllllllllll}1 & 2 & 3 & 4 & 5 & 6 & 7 & 8 & 9 & 10 & 11 & 12 & 13 & 14 & 15 & 16 & 17 & 18 & 19 & 20, \ldots\end{array}\right.$

$\mathrm{d}=\operatorname{conv}($ kernel, $\mathrm{c})$;

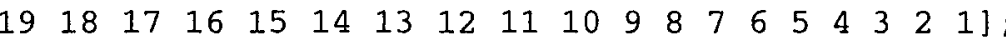

$[Q]=$ textread('C: $\backslash$ MYFiles $\backslash z$ hasan $\backslash$ Thesis $\backslash$ Spec $\backslash$ Nov1003 $\backslash 24121$ wtt.DE1',... ' $8 \mathrm{f}, 8)$

$\mathrm{R}=\operatorname{size}(\mathrm{d})$;

$S=1$ inspace $(1, R(1,1), R(1,1))$;

\&Calculating energy

$\mathrm{T}=\mathrm{Q}(6,1) * \mathrm{~S}-\mathrm{Q}(7,1)$;

$m t p 2=(T / 1.243) * \sin (0.5 *$ theta*pi/180);

fid $=$ fopen $(\ldots$

'C: \MyFiles $\backslash z$ hasan $\backslash$ Thesis $\backslash$ Spec $\backslash$ Res $\backslash J a n 2204 \backslash$ lexan $\backslash$ three1.dat ' , . .

' $W$ ') :

for $i=1:$ length $(d)$

fprintf(fid, ' $8 i \backslash t$ ', i) :

fprintf(fid, 'zf\t', mtp2(i));

end

fprint $f\left(f i d, ' g f \backslash n^{\prime}, d(i)\right)$;

fclose (fid);

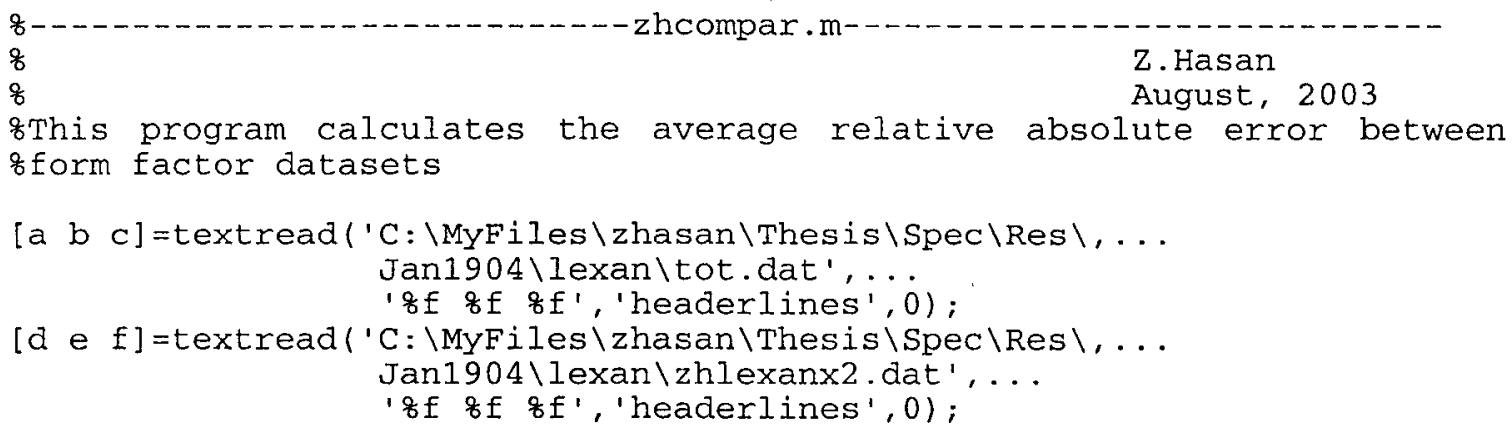

$\mathrm{ad}=0$

$\mathrm{k}=0$;

for $i=3: 108$

for $j=392: 1353$

if $(e(i)==b(j))$ $a d=a d+a b s(c(j)-f(i)) / f(i)$;

end

end

end $\mathrm{k}=\mathrm{k}+1$;

$\operatorname{arpd}=\mathrm{ad} / \mathrm{k}$ 


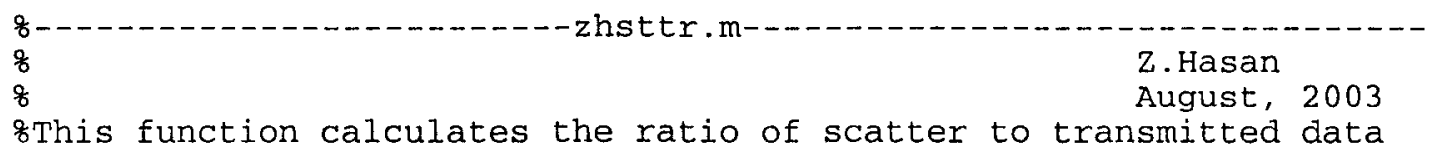

function st $=$ zhstpr $(S, P)$

for $i=1$ : length $(S)$

if $S(i) / P(i) '<=+$ Inf;

else st $(i)=S(i) / P(i) '$;

end st $(i)=0$;

end

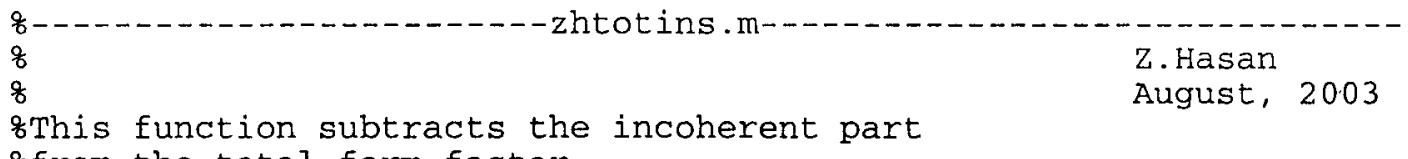

ifrom the total form factor

function $f=z h t o t i n s(T, I)$

for $i=1:$ length $(T)$

if $(T(i)-I(i))<0$

$f(i)=0$;

else $f(i)=T(i)-I(i)$;

end

end

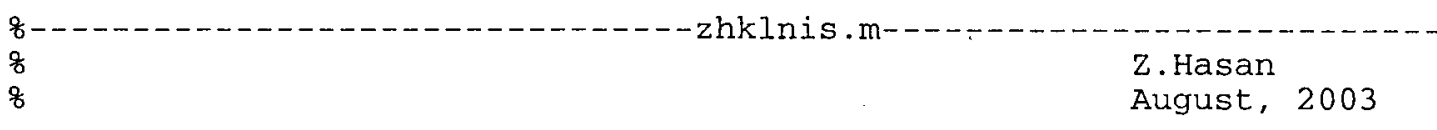

\%This function calculates Klein Nishina coefficient for a given energy sand theta

function $\mathrm{Fkn}=$ zhklnis $(\mathrm{T}$, theta)

for $i=1:$ length $(T)$; alpha $(1, i)=T(1, i) / 511$; Energies in $\mathrm{keV}$ $y=\left(1 . /(1+a l p h a(1, i) *(1-\cos (\right.$ theta*pi/180) $))) \cdot \wedge^{\wedge}$; $z=1+\left(\operatorname{alpha}(1, i) \wedge 2 *\left(1-\cos (\text { theta*pi/180) })^{\wedge} 2\right) /((1+a l p h a(1, i), \ldots\right.$ * $(1-\cos ($ theta*pi/180) $)) *(1+(\cos ($ theta*pi/180) $) \wedge 2))$;

end $F \operatorname{kn}(1, i)=y^{*} z$; 


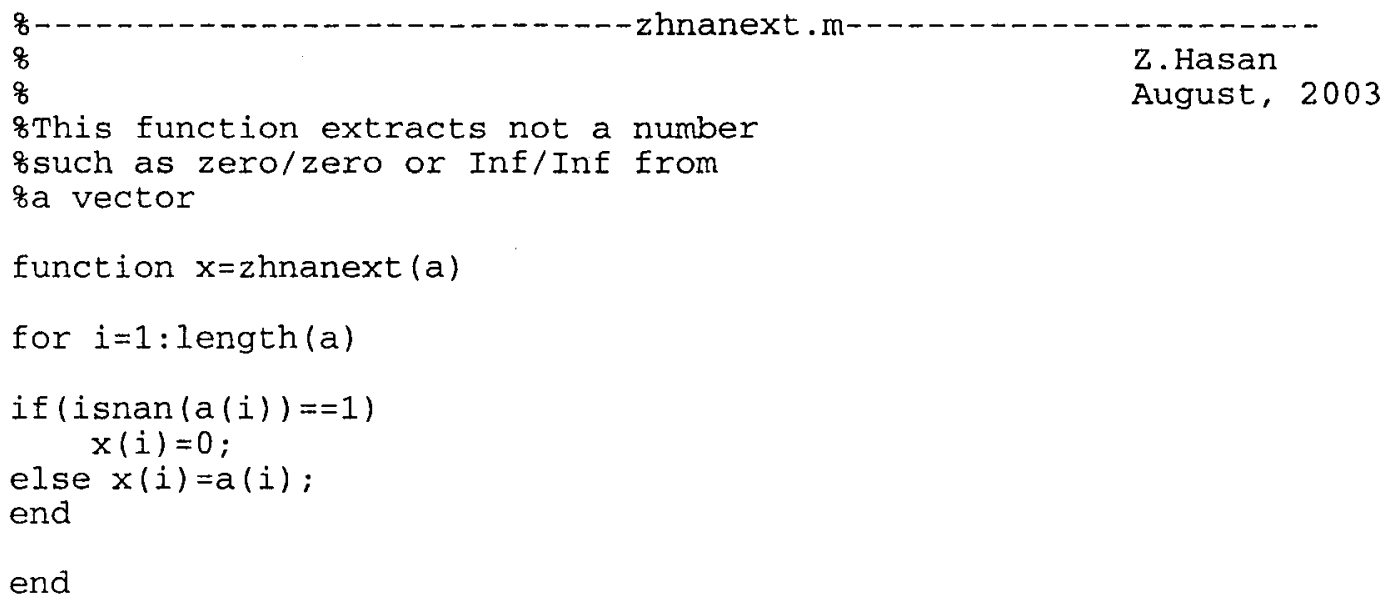

end 